The Cost of

Wetland Creation and Restoration

Final Report
By
D. King and
C. Bohlen

August 1995

Work Performed Under Contract No. DE-AC22-92MT92006

Prepared for

U.S. Department of Energy

Assistant Secretary for Fossil Energy

\author{
Brent Smith, Project Manager \\ Metairie Site Office \\ 900 Commerce Road, East \\ New Orleans, LA 70123
}

Prepared by

The University of Maryland

P.O. Box 38

Solomons, MD 20688-0038

DISTRIBUTION OF THIS DOCUMENT IS UNLIMITED 



\section{DISCLAIMER}

This report was prepared as an account of work sponsored by an agency of the United States Government. Neither the United States Government nor any agency thereof, nor any of their employees, make any warranty, express or implied, or assumes any legal liability or responsibility for the accuracy, completeness, or usefulness of any information, apparatus, product, or process disclosed, or represents that its use would not infringe privately owned rights. Reference herein to any specific commercial product, process, or service by trade name, trademark, manufacturer, or otherwise does not necessarily constitute or imply its endorsement, recommendation, or favoring by the United States Government or any agency thereof. The views and opinions of authors expressed herein do not necessarily state or reflect those of the United States Government or any agency thereof. 


\section{DISCLAIMER}

Portions of this document may be illegible in electronic image products. Images are produced from the best available original document. 


\section{TABLE OF CONTENTS}

List of Tables.................................................................................................................. v

List of Figures................................................................................................... vi

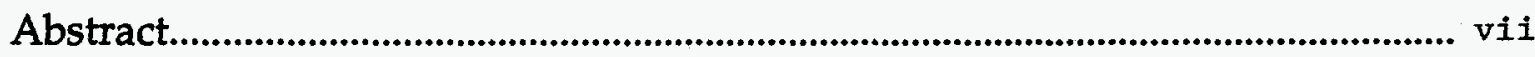

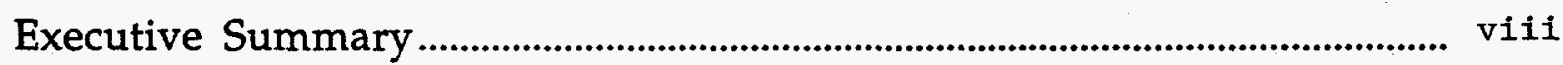

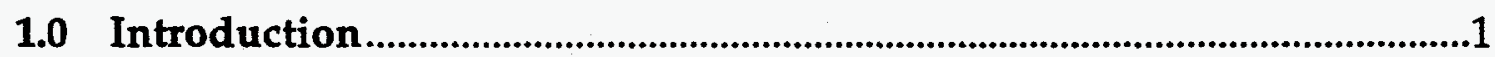

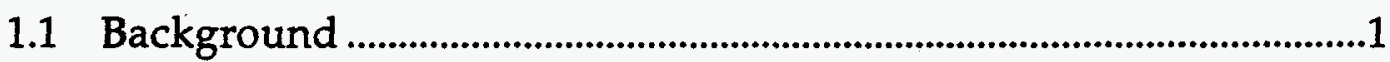

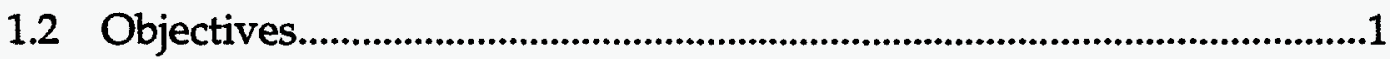

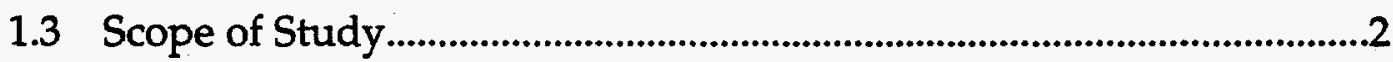

1.4 Methods and Approach .........................................................................

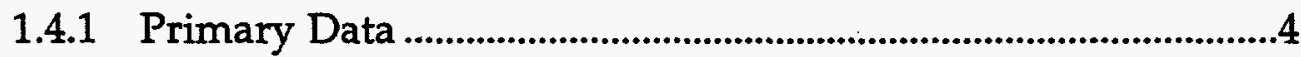

1.4.2 Secondary Data ................................................................................

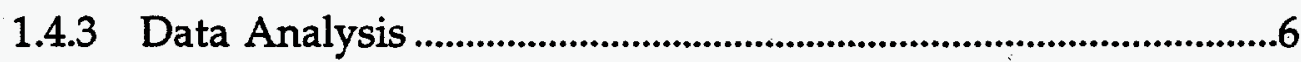

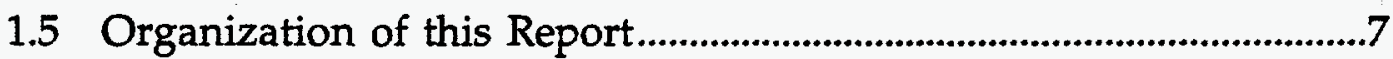

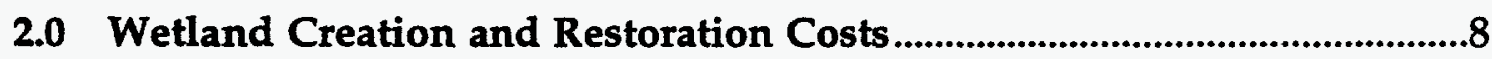

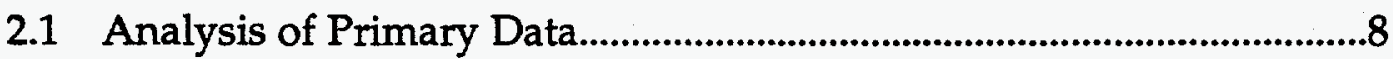

2.1.1 Wetland Types..............................................................................8

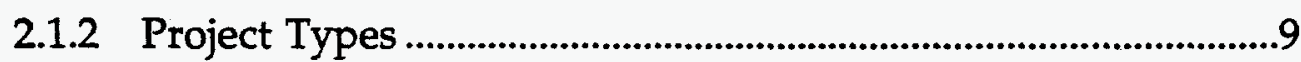

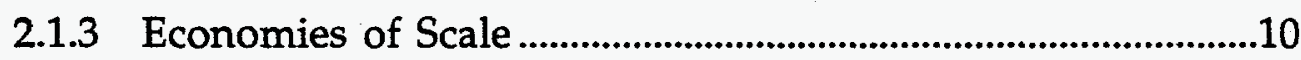

2.2 Secondary Data .........................................................................................11

2.2.1 Limitations of the Secondary Database ....................................11

2.2.2 Agricultural Conversions vs. Other Projects...........................13

2.2.3 Projects Other Than Agricultural Conversions.......................14

2.3 Comparisons Between Primary and Secondary Data...........................16

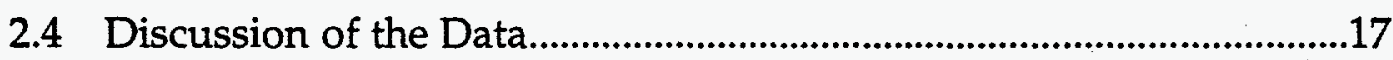

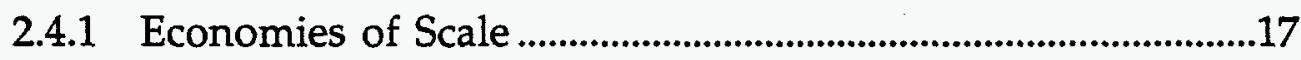

2.4.2 Creation, Restoration, Enhancement.....................................18

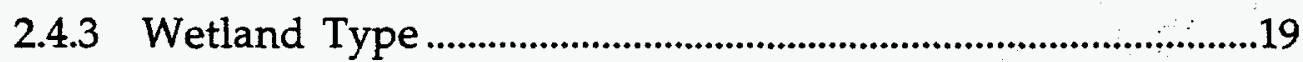

2.4.4 Differences Between Primary and Secondary Data.................20

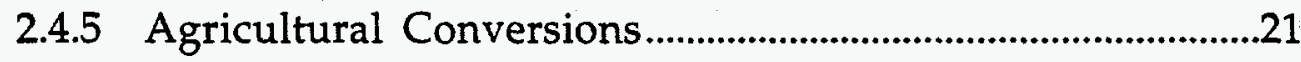

2.4.6 High Cost Projects...................................................................22

2.4.7 Cost Implications of Regulatory Involvement .......................22

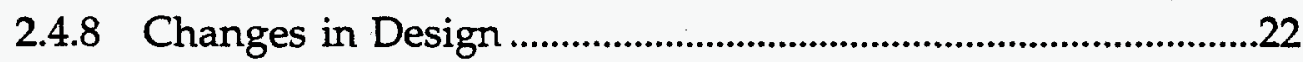

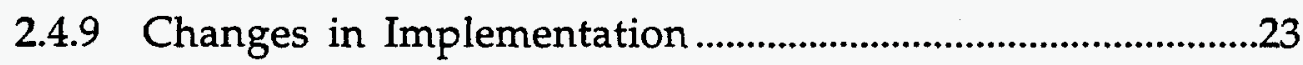

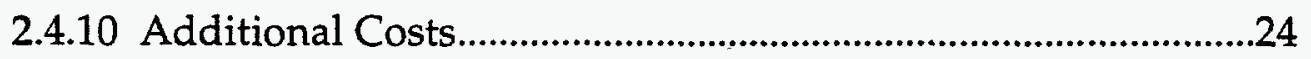


2.5 Regional Differences in Project Costs................................................24

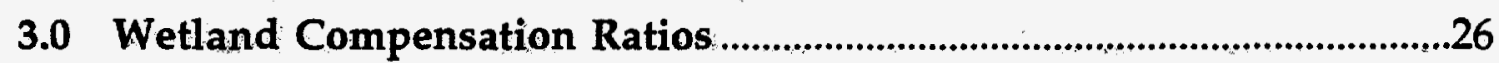

4.0 Economics of Wetland Restoration and Mitigation ...................................31

4.1 The Market for Wetland Restoration......................................................31

4.2 Underlying Incentives........................................................................31

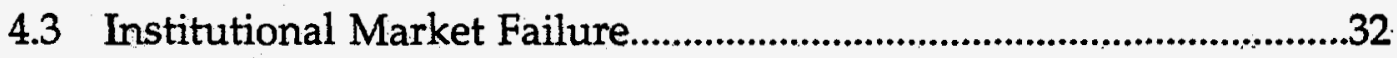

4.4 Conclusions About the Economics of Wetland Resoration.............32

5.0 Special Regional Profiles...........................................................................34

5.1 Special Regional Analysis-The Southwest......................................34

5.1.1 Regional Climate, Ecology, and Wetlands ................................34

5.1.2 Wetland Losses.......................................................................35

5.1.3 Regional Economic Conditions...............................................37

5.1.4 Wetland Projects of the Region..................................................38

5.1.5 Analysis of Region-Specific Data................................................40

5.2 Special Regional Analysis-The Southeast.......................................42

5.2.1 Regional Climate, Ecology, and Wetlands .............................42

5.2.2 Wetland Losses............................................................................43

5.2.3 Regional Economic Conditions.............................................44

5.2.4 Wetland Projects of the Region...................................................45

5.2.5 Analysis of Region-Specific Data ...............................................47

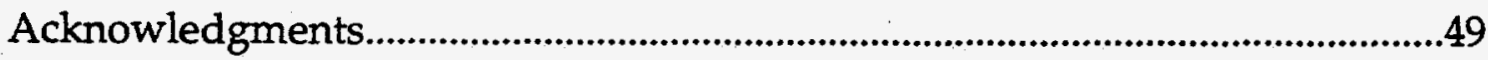

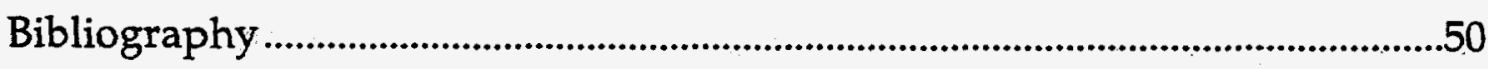

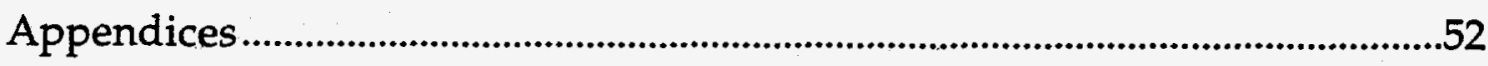

Appendix A: Analysis of Covariance Tables..................................................53

Appendix B: Understanding Wetland Restoration Costs...................................58

Appendix C: Compensation Ratios..................................................................73

Appendix D: Cost Estimation Spreadsheet.........................................................91

Appendix E: Compensation Ratios for Wetlands Mitigation...........................93 


\section{LIST OF TABLES}

Table 2.1 Cost Estimates and Cost Allocation by Task and by Input

Category,

Table 3.1 Some Calculated Compensation Ratios for a Variety of Hypothetical Compensation Scenarios.

Table A.1 Analysis of Covariance for Primary Data

Table A.2 Analysis of Covariance Comparing Agricultural Conversions and other Projects

Table A.3 Analysis of Covariance on the Secondary Data, Omitting Agricultural Conversions.

Table A.4 Analysis of Covariance on the Secondary Data, Omitting Agricultural Conversions (reduced model)

Table A.5 Comparison of Cost Estimates from the Primary and Secondary Data.

Table A.6 Analysis of Covariance for Comparison of Southwestern Wetland Projects and Projects from Other Regions of the Country.

Table A.7 Analysis of Covariance for Comparison of Southwestern Wetland Projects and Projects from Other Regions of the Country.

Table A.8 Analysis of Covariance for Comparison of Southeastern Wetland Projects and Projects from Other Regions of the Country.

Table A.9 Analysis of Covariance for Comparison of Southeastern Wetland Projects and Projects from Other Regions of the Country. 


\section{LIST OF FIGURES}

Figure 2.1 Point estimates and range of project costs from the Primary database for specific wetland types.

Figure 2.2 Comparisons of predicted costs of creation, enhancement, and restoration projects from the Primary database.

Figure 2.3 Cost per acre of creation, restoration and enhancement projects from the Primary data.

Figure 2.4 Cost per acre of agricultural conversion and non-agricultural projects from our Secondary data.

Figure 2.5 Cost per acre of wetland projects estimated from the Secondary data.

Figure 3.1 A simple wetlands compensation model.......................................28

Figure 5.1 Primary data-Southwest.......................................................................41

Figure 5.2 Secondary data-Southwest....................................................42

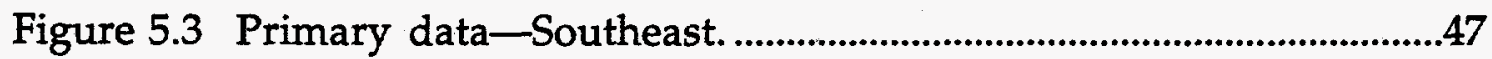

Figure 5.4 Secondary data-Southeast. ..................................................................48 


\section{ABSTRACT}

This report examines the economics of wetland creation, restoration, and enhancement projects, especially as they are used within the context of mitigation for unavoidable wetland losses. Complete engineering-costaccounting profiles of over 90 wetland projects were developed in collaboration with leading wetland restoration and creation practitioners around the country to develop a primary source database. Data on the costs of over 1,000 wetland projects were gathered from published sources and other available databases to develop a secondary source database. Cases in both databases were carefully analyzed and a set of baseline cost per acre estimates were developed for wetland creation, restoration, and enhancement.

Observations of costs varied widely, ranging from $\$ 5$ per acre to $\$ 1.5$ million per acre. Differences in cost were related to the target wetland type, and to site-specific and project-specific factors that affected the preconstruction, construction, and post-construction tasks necessary to carry out each particular project. Project-specific and site-specific factors had a much larger effect on project costs than wetland type for non-agricultural projects. Costs of wetland creation and restoration were also shown to differ by region, but not by as much as expected, and in response to the regulatory context.

The costs of wetland creation, restoration, and enhancement were also analyzed in a broader economic context through examination of the market for wetland mitigation services, and through the development of a framework for estimating compensation ratios-the number of acres of created, restored, or enhanced wetland required to compensate for an acre of lost natural wetland. The combination of per acre creation, restoration, and enhancement costs and the compensation ratio determine the overall mitigation costs associated with alternative mitigation strategies. 


\section{EXECUTIVE SUMMARY}

\section{Introduction}

Federal and state laws generally require anyone who proposes activities that could adversely impact wetlands to obtain a permit. In what has become known as "sequencing," permit seekers must show that they have avoided wetland impacts to the maximum extent "practicable," that they have minimized any unavoidable wetland impacts, and that they have or will compensate for any remaining wetland impacts through wetland creation, restoration, or enhancement projects. This study examined the economics of wetland creation, restoration, and enhancement, with special focus on the use of such activities in the final stage of "sequencing" - as wetland mitigation.

Historically, the level of mitigation required for wetland permit approval was determined on an ad hoc basis through negotiation between permit seekers and regulators. Mitigation requirements typically were set below replacement levels, and mitigation suppliers often failed to achieve the levels of mitigation that were set. In 1990, a Memorandum of Agreement between the Army Corps of Engineers and the Environmental Protection Agency, spelled out wetland sequencing and compensation procedures, and established the federal government's "no-net-loss" goal for wetlands. The goal called for a halt in the net loss of wetland resources, not only by restricting activities that harm wetlands, but also by expanding activities that increase wetlands and wetland functions. This has greatly increased both the prominence and importance of wetland creation, restoration, and enhancement as a component of federal and state wetlands policy.

\section{Cost of Wetland Mitigation}

The work reported here focused on the cost of wetland creation and restoration efforts within the continental United States. We examined cost estimates for approximately 1,000 historical wetland creation, restoration, and enhancement projects carried out in 44 states over the past 25 years. These historical cost estimates were collected from secondary sources such as published reviews of wetland mitigation and existing databases of wetland creation and restoration projects. In most cases detailed site selection and project design characteristics for these secondary projects were unknown. We therefore supplemented our database by developing detailed engineering and cost profiles for 90 wetland creation and restoration projects in 10 states. The siting and project design characteristics for these 90 projects-the primary database-were known in detail. Because some specialized data was available from other research, regional factors that could affect costs were also examined for two specific areas: the southeastern United States, and the desert and pacific Southwest. 
The results of our review and analysis of wetland creation, restoration, and enhancement costs can be summarized as follows:

- Costs of wetland creation and restoration projects varied widely, from $\$ 5$ per acre to $\$ 1.5$ million. For projects other than those that involved converted agricultural land, average project costs from the more reliable primary database (excluding land costs) ranged from just under $\$ 20,000$ to over $\$ 75,000$ per acre.

- Conversions of agricultural land to wetland for non-regulatory purposes, as often carried out by the Fish and Wildlife Service, the Department of Agriculture and Ducks Unlimited in cooperation with farmers, proved substantially less costly than mitigation projects, usually less than $\$ 1,000$ per acre.

- $\quad$ Per acre costs of wetland mitigation decline with project size. However, small projects and large projects are typically different in design and execution, so small and large projects were not comparable for purposes of estimating economies of scale for wetland mitigation.

- Small projects (under $1 / 2$ acre) accounted for a disproportionate share of very high-cost mitigation projects. This is due to the relatively high fixed costs associated with these projects and the standardizing of costs at the level of one acre (e.g., a 1/4 acre project costing $\$ 15,000$ implies costs of $\$ 60,000$ per acre).

- $\quad$ Per acre project costs were only weakly related to the type of wetland being constructed. Site specific and project specific factors had a much larger effect on per acre project costs.

- Construction costs, as opposed to pre-construction or post-construction costs, usually were the largest component of overall project costs. However, monitoring and follow-up costs were highly variable, and led to unusually high project costs in some cases.

- Despite wide ranges within project categories, reliable estimates of project costs can be derived if a few key facts about each project and site are known. Key factors include overall project size, the amount of excavation needed to establish appropriate hydrologic conditions, whether off-site disposal of fill material will be required, and whether the site has any unusual conditions that may affect project costs (presence of an endangered species, limitations on site access, etc.).

- Projects in the southwestern United States (especially California) were typically more expensive, and projects in the southeast somewhat less costly than the national average. These differences reflect regional differences in ecological and economic conditions. A summary of cost 
estimates and the allocation of costs by task and by input category is provided on page 55 .

\section{Other Economic Issues}

An analysis of cost data was placed into a broader economic context through development of a framework for estimating compensation ratios necessary to prevent loss of wetland values via mitigation and through examination of markets for wetland creation and restoration services. Overall mitigation costs depend on both the cost per acre of providing mitigation and the compensation ratio, which determines the number of mitigation acres required. Conditions in mitigation market determine the levels of commitment to low cost vs. high quality.

\section{Compensation Ratios}

To the regulators responsible for implementing wetland permitting programs, determining what constitutes appropriate mitigation for wetland losses is a central challenge. Federal policy requires, at least in principle, that compensation requirements be established on the basis of a comparison of the wetland functions and values expected from compensation wetland and those lost with destruction of the original wetland. This idea has proven difficult to apply in practice, because all wetlands are not equally valuable in ecological or economic terms, and criteria for making comparisons are not well developed. Moreover, the value of each wetland depends on the level and characteristics of many different biological and geophysical functions it provides, its proximity to other features of the watershed, and it's accessibility to animal and human populations.

The value of a wetland mitigation project-its ability to compensate for what was lost-is determined by several project performance characteristics. The long-term increase in wetland value at the mitigation site, the speed with which those values are produced, and the risk that the project will fail are especially important. In Chapter 3.0, these parameters are combined in an analytical framework that produces an estimate of the compensation ratio needed to exactly balance the loss of wetland function due to destruction of an existing wetland. The framework provides a useful way of thinking about mitigation. Determining the values of the parameters required to use the framework can take place through scientific investigation or expert negotiation. Tables providing estimates of compensation ratios for a typical range of parameter values are provided as an Attachment.

\section{The Mitigation Market}

The market for wetland creation and restoration services is driven primarily by regulatory requirements in the sense that most wetland projects 
are undertaken as a condition to get a wetland permit from federal or state authorities. Expenditures on mitigation are viewed by most permittees as an unwelcome cost of doing business. Permitees tend to be highly cost conscious, and tend to be concerned about the quality of wetland mitigation only to the extent that regulators force them to be. These unusual market conditions and relatively lax enforcement of mitigation requirements by regulators have resulted in incentives for mitigation suppliers to provide wetland creation, restoration, and enhancement that emphasizes low cost, rather than high quality. These "perverse incentives" in the historical mitigation market contributed to the record of poor mitigation performance, which continues to enflame wetland policy debates. They are also resulted in a record of historical mitigation costs that underrepresent the cost of providing successful mitigation. This is why our work to provide reliable cost estimates involved developing and analyzing primary source cost data in addition to reviewing the historical record of reported mitigation costs. 


\subsection{INTRODUCTION}

\subsection{Background}

Most activities that impact wetlands are regulated by federal law under section 404 of the Clean Water Act. State wetland protection laws are also in effect in many states. These laws require anyone who proposes activities that could adversely impact wetlands to obtain a permit. In what has become known as "sequencing," permit seekers must show that they have avoided wetland impacts to the maximum extent practicable, that they have minimized any unavoidable wetland impacts, and that they have or will mitigate any remaining wetland impacts through wetland creation, restoration, or enhancement projects. The research described in this report deals with the last step of this wetland permitting process. In particular, it focuses on the cost of providing compensatory mitigation for wetland impacts that are permitted under the Section 404 program and comparable state programs.

Historically, the level of mitigation required for permit approval was determined on an ad hoc basis through negotiation between permit seekers and regulators. Mitigation requirements typically were far below replacement levels. In 1988, a broadly based and influential wetland policy forum that was convened to explore wetland policy alternatives recommended a "no-netloss" goal for federal wetland policy (Conservation Foundation 1988). The goal called for a halt in the net loss of wetland resources, not only by restricting activities that harm wetlands, but also by expanding activities that increase wetlands and wetland functions. The federal government officially espoused this goal in 1990, in a Memorandum of Agreement between the Army Corps of Engineers and the Environmental Protection Agency, which spelled out wetland sequencing and compensation procedures. The no-netloss goal and the Memorandum of Agreement increased both the significance and attention given to wetland mitigation within the federal wetland regulatory scheme. This new focus on wetland mitigation as a means of achieving the "no net loss" goal has changed the context within which the cost and performance of wetland creation, restoration, and enhancement projects are evaluated.

\subsection{Objectives}

Because achievement of the no-net-loss goal for wetlands depends, in part, on the success of wetland mitigation, much recent research has focused on criteria for evaluating the performance of mitigation projects, the development of design standards and engineering techniques for mitigation projects, and exploration of methods to maximize the likelihood that mitigation projects will succeed. The research summarized in this report complements this ongoing research by evaluating the factors that contribute to the cost of 
designing and implementing successful wetland creation and restoration projects. Our research also illustrates the range of costs for historical wetland mitigation projects and provides estimates of the costs associated with pre-construction, construction, and post-construction tasks related to modern wetland restoration projects.

\subsection{Scope of Study}

Our project focused on wetland creation and restoration efforts within the continental United States. We examined cost estimates for approximately 1,000 historical wetland creation, restoration, and enhancement projects carried out in 44 states over the past 25 years. These historical cost estimates, which were collected primarily from secondary sources, were supplemented by detailed engineering and cost profiles that we developed for 90 current wetland creation and restoration projects in 10 states. In most cases the site selection and project design characteristics for the 1,000 historical projects-the secondary database-were unknown. The siting and project design characteristics for the 90 projects that we collected and analyzed ourselves-the primary database-were known. Because specialized data was available from other research: Regional factors that could affect costs were examined for two specific areas: the desert and pacific southwest, including California, Nevada and Arizona; and the southeastern United States, including the states of Alabama, Florida, Georgia, Kentucky, Mississippi, North Carolina, South Carolina, and Tennessee.

Although our research focused on the cost of wetland restoration and creation efforts, we have placed these costs in a broad $z:-$ ntext. In particular, we evaluated how changes in the regulatory environment have affected the incentive structure in historical and current markets for mitigation services and, consequently, the cost and performance of wetland creation and restoration projects. An understanding of the relationships between project costs and project success is also essential for a complete picture of the economics of wetland restoration projects. Although detailed analyses of these relationships was beyond the scope of this project, this report includes the results of some preliminary investigations in this area. The report also includes as appendices, two documents developed as part of this DOE project. Appendix A is our interim project report of January, 1994, entitled "Making Sense of Wetland Restoration Costs." This is a stand-alone paper that summarizes the results of our cost study in non-technical language and after review by DOE, it will be published in an appropriate journal. Appendix B is our interim project report of July, 1993, entitled "Watershed Management and Wetland Mitigation: A Framework for Estimating Compensation Ratios," This paper describes a framework for evaluating and comparing the performance of wetland creation and restoration projects and for determining "compensation ratios"- the number of created or restored acres that should be required to re- 
place each acre of lost natural wetland. It will also be published in a suitable journal after DOE approval.

\subsection{Methods and Approach}

Wetland creation and restoration costs vary tremendously. Our survey of existing sources of information on costs found projects with costs ranging from a low of $\$ 5$ per acre to a high of $\$ 1.5$ million per acre. This wide range of costs reflects the equally wide range of wetland types, site characteristics, project goals, and project design and construction standards that characterized these projects. Typical projects ranged from the simple reflooding of drained agricultural land to complex projects involving careful engineering of surface and groundwater flows, extensive excavation and grading, hand planting and seeding, and long-term site monitoring and maintenance.

Given this wide range of projects, it would be misleading to simply provide an average cost estimate for wetland restoration. It is no more useful to think about the average cost of restoring an acre of wetland than to consider the average cost of restoring a damaged automobile. In both cases what is being restored is important-a Rolls Royce vs. a VW, a prairie pothole vs. a mangrove swamp. Our results, however, show that costs also depend on what features are damaged and how badly; and how fast, perfect, and permanent the repairs need to be. Accordingly, our approach to data collection and analysis was based on the understanding that aggregating cost data compiled for very different projects could mask important differences and produce misleading results. Wherever possible we avoided aggregating dissimilar projects and emphasized, rather than ignored, important wetland-specific, sitespecific, and project-specific differences.

Unfortunately, our ability to classify projects in our large secondary database on the basis of wetland, site, or project characteristics proved to be limited. Cost estimates derived from published sources in the trade and technical press, as well as from public and nonprofit agencies were often accompanied only by brief project descriptions (e.g., "PFO1A," "salt marsh," or "drain tile"). Few sources provided detailed project descriptions, and they tended to be sources that included data on few projects. After phone, mail, and in-person contacts with the staff of agencies and organizations responsible for the bulk of the cost estimates, we found that many of the source agencies no longer had, or had never had, access to detailed project descriptions. Most of these agencies collected data about wetland creation and restoration projects for which they did not have day-to-day management authority. Our impression is that record keeping about historical mitigation projects, in general, has been weak and that, as a result, developing better profiles for projects in our secondary database would be prohibitively expensive. 
Because of the high variability in project cost and lack of detailed project descriptions in our secondary database, we felt that we could develop only a limited understanding of costs on the basis of the secondary-source cost record alone. In many cases, we also had reason to believe that published cost estimates and those available from state and federal agencies excluded some significant cost components or were associated with projects that would not meet modern design or construction standards. Therefore, we took a more time consuming approach and worked directly with wetland restoration experts to develop primary-source cost data using standard cost-accounting procedures applied to detailed engineering descriptions of known wetland creation and restoration projects.

All cost estimates in both the primary and secondary databases were standardized in 1993 dollars prior to analysis. Whenever the data were sufficiently detailed, projects were classified on the basis of location, site characteristics, wetland type, and project objectives.

\subsubsection{Primary Data}

We developed our primary cost data for approximately 90 different wetland restoration and creation projects. Working with subcontracted wetland restoration specialists with experience in various parts of the United States, we characterized each project in terms of specific preconstruction, construction, and postconstruction tasks. Typical preconstruction tasks included hydrologic monitoring, site surveys, and preparation of project plans; typical construction tasks included excavation, grading, and planting; typical postconstruction tasks included site monitoring and maintenance.

Each project task was then characterized in terms of input requirements (e.g., labor, material equipment) to complete each essential task. Pertask and overall project costs were calculated by applying unit costs (e.g., wages, rents, prices) with appropriate adjustments to cover overhead expenses. Most project profiles were based on actual wetland creation or restoration projects that were designed or constructed by our collaborating wetland restoration specialists. However, some were based on projects that they bid or planned, but never built; or projects with which they were familiar for other reasons. In some cases, hypothetical variations in site characteristics were used to develop project profiles and cost ranges that reflected differences in site conditions (e.g., steep slopes, poor site access, difficult hydrology, or the presence of an endangered species). Although developed in more detail, the worksheets we used were very similar to those used routinely by engineering and construction firms to estimate costs and prepare bids for restoration and other work. The spreadsheet program we developed that lists restoration tasks and associated input requirements and computes various components of project costs, input requirements, and unit costs is presented in Appendix C. The actual spreadsheet programs are available from the authors. 
We classified wetland creation and restoration projects into eight project categories that we used to sort data. These categories were based on wetland characteristics that affected the tasks required to achieve restoration success rather than by conventional wetland classification criteria. Thus wetlands dominated by shrubs were treated as part of the forested wetland categories, because tree and shrub planting require similar equipment and have broadly similar inputs even though they may have dissimilar functions and values. Our classification turned out to be similar to the standard Cowardin et al. (1978) wetland classification system. With a few adjustments, such as the grouping of wetlands with trees or shrubs, it may be thought of as a simplified version of Cowardin et al. The eight categories selected on the basis of required restoration tasks tend to reflect differences in hydrology and vegetation structure. They are influenced very little by the complexity of resulting wetland functions. The eight categories include:

(1) Aquatic Beds consisting of tidal or nontidal communities of permanently or nearly permanently submerged plants;

(2) Complex Projects incorporating three or more wetland types in a single project;

(3) Freshwater Mixed Projects, consisting of nontidal projects in which both forested and emergent vegetation is produced;

(4) Freshwater Forested Projects, establishing woody vegetation (forest or shrub) in nontidal wetlands;

(5) Freshwater Emergent Projects establishing emergent wetlands in nontidal wetlands;

(6) Tidal Freshwater Wetlands Projects, often consisting of mixed emergent and woody vegetation;

(7) Saltmarsh Projects and other marine or estuarine projects, establishing wetlands dominated by emergent vegetation,

(8) Mangrove Projects, establishing mangrove communities.

\subsubsection{Secondary Data}

Our secondary database contains over 900 records of costs for individual wetland creation, restoration, and enhancement projects and was developed from published and unpublished project reports, the general trade literature, and databases collected from county, state, and federal agencies in the contiguous 48 states. This database includes examples of wetland creation, restoration, and enhancement used as mitigation, as well as wetlands constructed for water quality improvement, waterfowl habitat, and for other pur- 
poses. Approximately half the records in the secondary database involve the restoration or creation of wetlands on agricultural lands undertaken outside of a mitigation context. Of the remaining cases, over $95 \%$ were mitigation projects, and three-quarters were associated with mitigating road or highway impacts to wetlands; the rest were non-agricultural projects undertaken outside a mitigation context (e.g., wetlands for stormwater management or nutrient removal from sewage effluent). Records vary widely with respect to the degree of detail about site and project characteristics, but all included the general location of the project, project size, and overall project cost. Our interim project report, included as Appendix A, describes this Secondary database in detail.

\subsubsection{Data Analysis}

After developing means, medians, and ranges of project costs for projects in each category, we prepared the non-technical cost summary presented as Appendix A. We then explored both data sets more fully to look for more subtle patterns. Within both the Primary and Secondary databases, there was an extremely uneven distribution of cases within and among project categories. Freshwater emergent wetland creation projects were abundant in our sample, for example, while projects to restore beds of submerged aquatic plants were rare. We cannot at this time assess how much this reflects the abundance of restoration projects across the United States and how much it reflects the limitations of our data collection efforts.

Different categories of wetlard projects tended to have different average sizes. Creation projects, for example, are typically smaller than restoration projects; freshwater emergent wetland projects tend to be smaller than projects producing forested wetlands; and agricultural conversion projects tend to be larger than other projects. Costs per acre also decreased substantially with increasing project size. We expect that similar (but not necessarily equal) economies of scale exist within each category of wetland project. However, under these circumstances, a direct comparison of average cost per acre for different categories of wetland projects may be misleading. In an attempt to sort out those differences, we used a standard statistical technique called an analysis of covariance (ANCOVA) to produce estimates by project categories of per acre project cost adjusted for typical project size, as well as to develop equations that indicate how project costs change as project size changes.

Costs per acre data for projects in both the primary and secondary databases were highly skewed, so more elaborate statistical analyses, including the analysis of covariance, required transformation of the data. All parametric analyses were carried out on $\log _{10}$ transformed data. Reported results, except where otherwise noted, are based on hypothesis tests with $p<0.05$. Nonsignificant $(p>0.10)$ and nonestimable interaction terms were dropped sequentially from all analyses. The results shown here reflect the most com- 
plete analyses possible with the existing databases. Full analysis of covariance tables are included in Appendix A.

\subsection{Organization of this Report}

Results are summarized here in three chapters. Chapter 2.0 summarizes our analysis of wetland creation and restoration costs and provides baseline cost estimates and preliminary estimates of economies of scale; Chapter 3.0 describes the framework that we developed to facilitate the analysis of project cost-performance relationships through consideration of appropriate compensation ratios for wetland mitigation; Chapter 4.0 puts the empirical part of the project-measures of cost and performance-in context by describing how the regulatory environment and conditions in mitigation markets affect the characteristics of wetland creation and restoration projects. Additional information on each of these topics is provided in Appendices A and B. Chapter 5 includes the regional summaries for the southeast and southwest United States. 


\subsection{WETLAND CREATION AND RESTORATION COSTS}

\subsection{Analysis of Primary Data}

\subsubsection{Wetland Types}

Analyses of the Primary Data by Analysis of Covariance and by Kruskal-Wallis tests show that differences in the costs of restoring different types of wetlands are not large relative to the differences in costs within any one wetland category. This reflects the enormous differences in the site and project design characteristics within project categories and the fact that the tasks and costs associated with restoring wetlands in different categories can be quite similar. Median, mean, minimum, and maximum per acre creation and restoration costs for eight categories of wetland projects are shown in Figure 2.1.

Cost Per Acre

(In 1993 \$; excludes land costs)

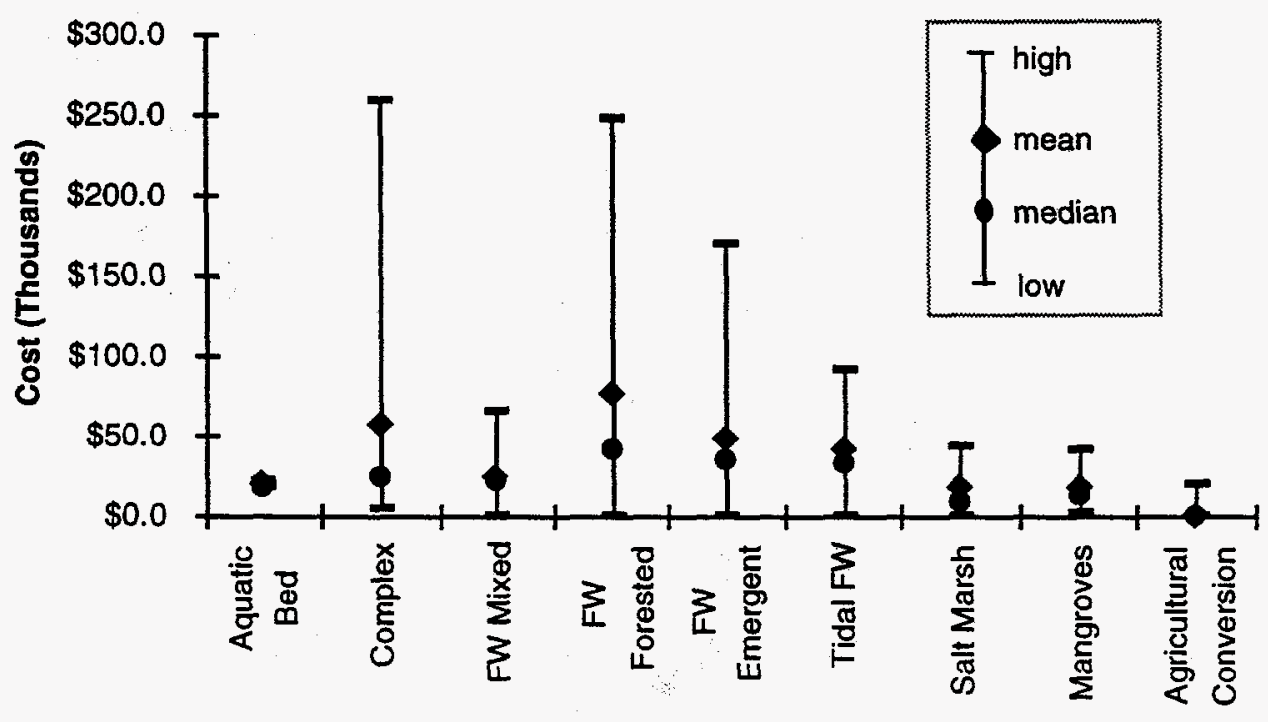

Wetland Type

Figure 2.1 Point estimates and ranges of project costs from the Primary database for specific wetland types.

Table 2.1 displays the summary cost statistics for each wetland category and includes a percentage breakdown of estimated costs by project stage (preconstruction, construction, and post construction) and by input category (labor, equipment, materials, other). In general, construction costs constitute between two thirds and three quarters of total project costs, although they are somewhat higher for freshwater tidal wetlands. Labor costs tend to account 
for the largest overall share of project costs, ranging from about one-third of overall project costs to about three-quarters.

Table 2.1 Cost Estimates and Cost Allocation by Task and by Input Category (excludes land cost)

\begin{tabular}{|c|c|c|c|c|c|c|c|c|c|}
\hline \multicolumn{10}{|c|}{ Project Type } \\
\hline & Aquatic Bed & Complex & $\begin{array}{l}\text { FW } \\
\text { Mixed } \\
\end{array}$ & $\begin{array}{l}\text { FW } \\
\text { Forest* }\end{array}$ & $\begin{array}{l}\text { FW } \\
\text { Emerg. }\end{array}$ & $\begin{array}{l}\text { Tidal } \\
\text { FW }\end{array}$ & $\begin{array}{l}\text { Salt } \\
\text { Marsh }\end{array}$ & $\begin{array}{l}\text { Man- } \\
\text { grove }\end{array}$ & $\begin{array}{l}\text { Agric. } \\
\text { Conv** }\end{array}$ \\
\hline \multicolumn{10}{|c|}{ Project Costs (Thousands) } \\
\hline Average & $\$ 19.5$ & $\$ 56.7$ & $\$ 25.3$ & $\$ 77.9$ & $\$ 48.7$ & $\$ 42.0$ & $\$ 18.1$ & $\$ 18.0$ & $\$ 1.0$ \\
\hline Minimum & 18.3 & 4.3 & 1.4 & 0.9 & 1.7 & 0.6 & 1.0 & 2.1 & 0.005 \\
\hline Maximum & 21.7 & 258.8 & 65.8 & 248.4 & 170.6 & 92.6 & 43.6 & 42.8 & 20.8 \\
\hline Median & 18.6 & 24.8 & 23.4 & 42.7 & 35.2 & 32.9 & 10.2 & 13.6 & 0.5 \\
\hline Sample Size & 3 & 8 & 10 & 19 & 28 & 3 & 9 & 4 & 494 \\
\hline \multicolumn{10}{|l|}{ Breakdown by Tasks: } \\
\hline Preconstruction & $17 \%$ & $10 \%$ & $5 \%$ & $9 \%$ & $13 \%$ & $9 \%$ & $16 \%$ & $13 \%$ & $0 \%$ \\
\hline Construction & 63 & 74 & 78 & 74 & 58 & 87 & 73 & 66 & 100 \\
\hline Postconstruction & 20 & 16 & 17 & 18 & 28 & 4 & 11 & 21 & 0 \\
\hline \multicolumn{10}{|c|}{ Breakdown by Input Category: } \\
\hline Labor & $58 \%$ & $50 \%$ & $74 \%$ & $51 \%$ & $63 \%$ & $31 \%$ & $52 \%$ & $51 \%$ & $45 \%$ \\
\hline Materials & 8 & 23 & 10 & 30 & 26 & 54 & 27 & 21 & 0 \\
\hline Equipment & 34 & 14 & 16 & 18 & 9 & 14 & 20 & 28 & 55 \\
\hline Other & 0 & 14 & 0 & 2 & 1 & 1 & 2 & 0 & 0 \\
\hline
\end{tabular}

* High end of range involves researching and restoring hydrology and planting; low end involves restoring hydrology only.

* Cost breakdowns for agricultural conversions are based on a project consisting of hydrologic modification without planting or formal plan development.

\subsubsection{Project Types}

Although our data do not show strong differences between the costs of restoring different wetland types, they do show significant differences in per acre costs between creation, restoration, and enhancement projects (see Figure 2.2). Enhancement projects are less expensive than creation or restoration projects by approximately a factor of three. For complex wetland projects (those incorporating several wetland types or both estuarine and freshwater components), the enhancement projects in our databases were similar in cost to creation and restoration projects. There are also weak indications in the data that wetland enhancement costs, on a per acre basis, may not decline as rapidly with increasing project size as wetland creation and restoration projects (see Figure 2.3).

We found no significant difference between wetland creation and restoration costs for many types of wetlands (this pattern was repeated in the secondary data as well). This runs counter to the conventional wisdom that restoration projects are less expensive than creation projects because of the 
ease with which wetland hydrology can be established in areas that once were wetland.

\section{Least Square Mean Costs of Creation, Enhancement, and Restoration}

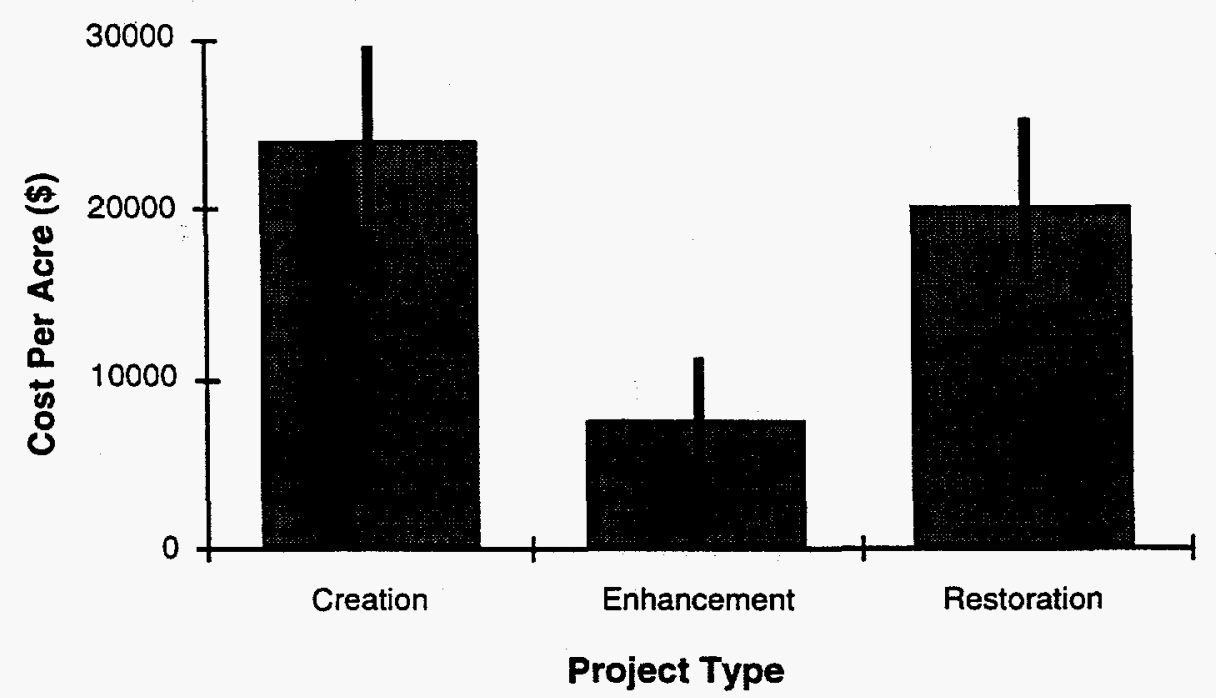

Figure 2.2. Comparisons of predicted costs of creation, enhancement, and restoration projects from the primary database.

\subsubsection{Economies of Scale}

As expected, the analysis of covariance revealed that (1) project size has a strong effect on per acre project costs, and (2) project type (creation, restoration, enhancement) also significantly affects project costs. The analysis of covariance confirmed, however, that any effects of wetland type on project costs are hidden by the wide variability in project costs among projects within each wetland type. It is possible, but by no means certain, that with more cost data on underrepresented project types, effects of wetland type on project costs could be revealed.

Figure 2.3 illustrates the inverse relationship between cost per acre and project size for wetland mitigation projects in the primary database. The prediction lines in the figure, (produced by the analysis of covariance), are given by the following prediction equations.

(6) Cost $=49742 *$ Size $e^{-0.3833}$ for wetland creation projects.

(7) Cost $=3712 *$ Size $e^{0.2086}$ for wetland enhancement projects.

(8) Cost $=43946 *$ Size $e^{-0.4684}$ for wetland Restoration Projects. 
Because of the small sample of enhancement projects, the exponent in equation (7) is not significantly different from zero, and the differences in exponents among the three project types are marginally statistically significant (size by project type interaction, $\mathrm{P}=0.531$ ). A simpler and more robust prediction relationship pools all three project types to give:

$$
\text { Cost }=30706 * \text { Size } e^{-0.3596}
$$

For each $10 \%$ increase in project size, this relationship predicts that costs per acre will decline by $3.4 \%$. A doubling in project size results in a $22 \%$ decrease in per acre costs.

Cost Per Acre: Primary Data

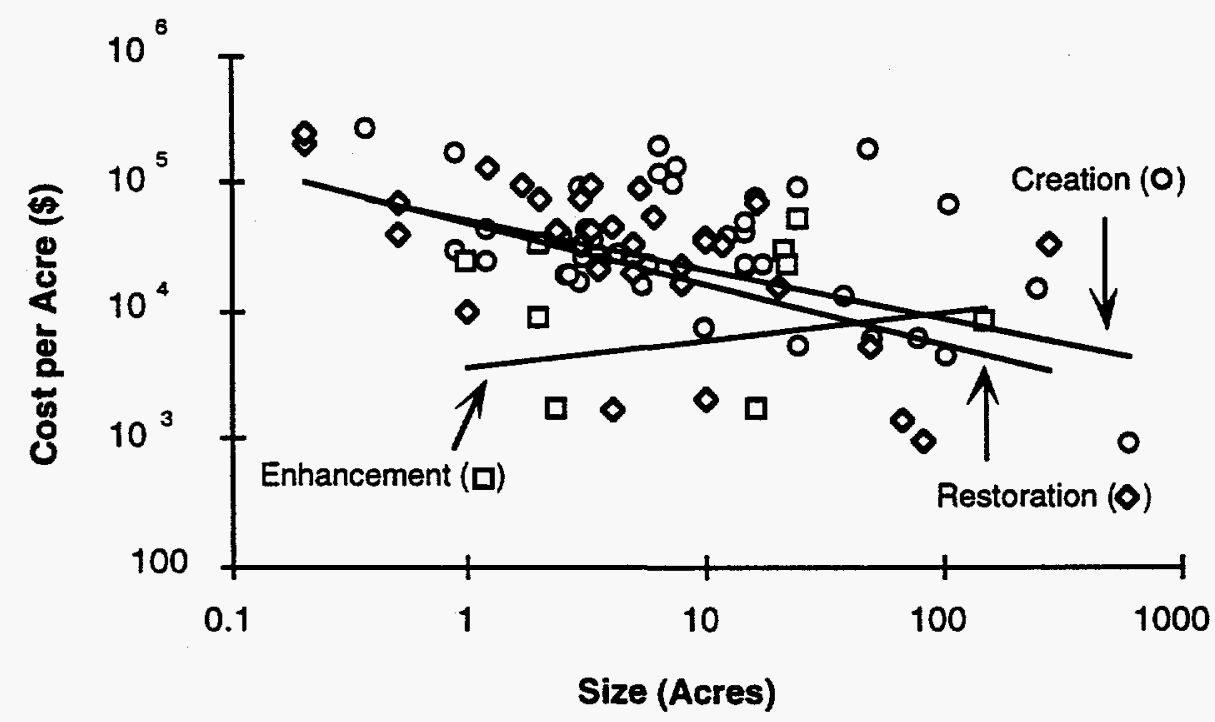

Figure 2.3 Cost per acre of creation, restoration and enhancement projects from the primary data.

\subsection{Secondary Data}

\subsubsection{Limitations of the Secondary Database}

Developing reliable statistical results from the secondary database, despite the large number of observations, proved to be difficult. Without details about each creation or restoration project, including site conditions before the project was undertaken, budget constraints, project goals, and so forth, one can draw only limited conclusions about project costs. Inconsistencies in how costs were defined, measured, and reported for various projects complicated interpretation of the data still further. These inconsistencies reflect the wide range of purposes for which the data were originally collected by many individuals within private and governmental organizations. 
Another difficulty arose because cost data proved much more abundant for certain types of projects than for others. We found many published and readily available cost estimates for the conversion of agricultural land to wetland for wildlife and waterfowl benefits, and a similarly large amount of data related to wetland mitigation projects that involved the creation of small to medium size, freshwater, emergent wetlands. Reported costs for most other kinds of wetland projects were relatively rare.

In our efforts to find additional background information for the projects included in our Secondary database, we uncovered several other sources of potential problems. These problems were revealed to members of our research team during phone interviews with individuals who had provided us with cost estimates or had published cost estimates that we included in our database. The four main problem areas were:

(1) Joint Costs-Mitigation and Development. The providers of cost data for some projects were unable to distinguish between restoration costs and the costs of earth moving and landscaping associated with the construction project that resulted in the need for mitigation; this was especially true for highway expansion projects. To the extent that this results in allocation of construction project costs to mitigation, it will result in an overstatement of mitigation costs. If mitigation costs are erroneously allocated to the original project (less common, we believe), mitigation costs will be underestimated.

(2) Joint Costs-Mitigation and Permitting. In other cases, it was impossible for providers of cost data to distinguish between restoration costs and the costs of engaging in the wetland permitting process itself; this was especially true for large complex projects and mitigation banks. To the extent that project costs are inflated by permitting costs, this would overstate true project costs.

(3) Differing Design/Precision Standards. The secondary database includes wetland construction projects designed to improve water quality (e.g., treat sewage, storm water, farm runoff, and acid mine drainage). Since these projects involve substantial engineering effort, and all siting, design, and construction decisions for them are directed exclusively at waste treatment, they might be expected to be especially expensive, as wetland creation projects go. Actual costs of constructed wetlands designed to improve water quality, however, were not statistically different from costs of wetlands created or restored for mitigation, and all such projects were retained.

(4) Non-priced Project Inputs. The database also includes projects carried out with participation of volunteers or with voluntary contributions of land, expertise, or equipment. These projects were generally designed to create or restore specific wetland functions (e.g., duck habitat), usu- 
ally, but not always, through the conversion of agricultural land to wetland conditions. The cost estimates for projects that use volunteers often exclude the opportunity cost of contributed labor and other "in kind" contributions, and thus may under report true project costs.

The combination of very different sample sizes for various categories of wetland projects, inconsistencies in the descriptive information available to us on each project, and differences among sources of data regarding how costs were reported make detailed interpretation of data from historical sources of information (like those on which we based our secondary database) of limited value. Further attempts to improve this database through additional contacts with individuals who provided or published the data we used as the basis for our database were unsuccessful. We believe that additional attempts to improve the secondary data would be marginally successful and would not be as cost effective or as useful as adding to the primary database.

\subsubsection{Agricultural Conversions vs. Other Projects}

The secondary data consisted of almost equal parts agricultural conversions to wetland carried out for wildlife enhancement purposes and projects carried out for other reasons, mostly mitigation. The two groups of data were very different. In general, agricultural projects (1) were significantly less expensive than the other projects, and (2) the cost per acre of agricultural conversions was less sensitive to project size than was the cost per acre of mitigation projects (Figure 2.4).

The relationships between project cost to project size found in the analysis of covariance correspond to a decrease in per acre costs of about $4.3 \%$ and $22 \%$ respectively for agricultural and other projects in response to a doubling of project size. The prediction equations for cost per acre that correspond to these parameters are as follows.

$$
\begin{aligned}
& \text { Cost }=536.4 * \text { Size } e^{-0.06279} \text { for agricultural conversions and, } \\
& \text { Cost }=30850 * \text { Size } e^{-0.35798} \text { for non-agricultural projects. }
\end{aligned}
$$




\section{Cost Per Acre Of Agricultural Conversions and Nonagricultural Wetland Projects}

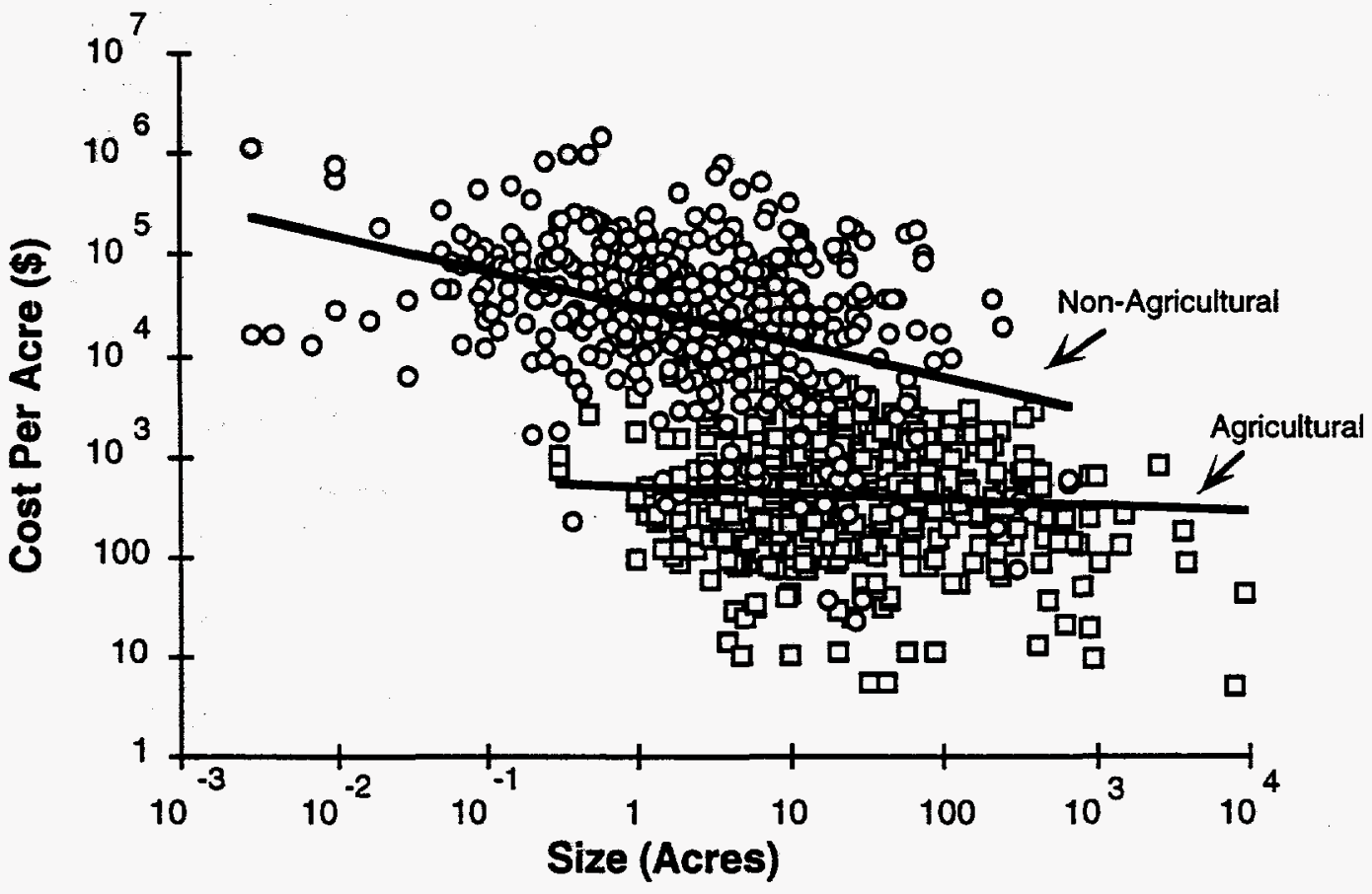

Figure 2.4. Cost per acre of agricultural conversion and non-agricultural projects from our secondary data.

Thus a one acre agricultural conversion project typically costs just over $\$ 500$, while a one acre project that is not an agricultural conversion typically cost about $\$ 30,000$. Exact reasons for this difference in cost could not be determined as part of this study; however, the effect does not appear to be entirely due to geography. Even when attention is restricted to those states (CA, KS, MN, MT, OR, TX) in which data was available for both agricultural conversions and other projects, the cost per acre of agricultural conversion projects remain significantly lower, and less sensitive to project size than are other projects (by analysis of covariance, $\mathrm{p}<0.0001$ for both comparisons).

Unfortunately, the databases from which we drew information on agricultural conversion projects for this report were inconsistent with respect to the descriptive information they included, and thus further analyses of agricultural conversion projects were impossible.

\subsubsection{Projects Other Than Agricultural Conversions}

Sufficient descriptive information was included with 160 non-agricultural projects to allow exploration of factors that may affect the per acre costs of wetland creation, restoration, and enhancement. Analyses followed the analysis of covariance approach already described $\left(\log _{10}\right.$ transformed data, co- 
variate given by a $\log _{10}$ transformed project size data). Factors for which sufficient information were available included vegetation type (open water, emergent, woody, mixed), a rough hydrologic classification (estuarine or marine, palustrine or lacustrine, riparian), and project type (creation, restoration, enhancement, mixed). The highly unbalanced statistical design forced on us by the secordary data we were able to collect, again, makes the results difficult to interpret. Our conclusions, therefore, should be seen as preliminary.

As in the primary data, project size had a strong influence on per acre project costs (Figure 2.5). Vegetation type, however, was not an important determinate of project costs, contrary to our initial expectation that the increased difficulty of planting woody vegetation should increase costs. Because vegetation type never proved statistically important, we dropped it from the analysis. The hydrologic classification had a weak effect on project costs, which proved statistically significant under certain analyses, but unimportant in others. Riparian restoration projects were typically more expensive, on a per acre basis, than other projects. Estuarine/Marine and Lacustrine/Palustrine projects, however, were similar in cost. Project type affected per acre project costs as well. In general, costs of wetland creation projects and mixed projects decreased less with size than did costs of enhancement and restoration projects (see ANCOVA table in Appendix A for details).

In part, the results of this analysis of covariance may reflect the poor quality of the secondary data. Descriptive information was unavailable for a majority of projects in the database, and, by chance, for almost all wetland enhancement projects. To double check the legitimacy of the results of the full analysis of covariance, we fit a simpler model, in which we separated projects only by project kind. This allowed us to increase our total sample size to 367 projects, (309 creation projects, 28 enhancement projects, 16 restoration projects, and 14 mixed projects). The results of this analysis of variance were generally similar to those shown above, and are shown in Figure 2.5. At larger project sizes (greater than one acre), mixed projects and creation projects tended to be more expensive, and less sensitive to project size than restoration and enhancement projects. At smaller sizes, we had little data for anything other than wetland creation projects, and thus comparisons of the different project types are inappropriate.

The prediction equations corresponding to the different project types (averaged across all hydrologic classes) produced by this analysis of covariance are given by the following equations

$$
\begin{array}{ll}
\text { Cost }=33164 * \text { Size } e^{-0.2421} & \text { for creation projects } \\
\text { Cost }=13198 * \text { Size } e^{-0.6495} & \text { for enhancement projects } \\
\text { Cost }=20212 * \text { Size } e^{-0.7016} & \text { for restoration projects }
\end{array}
$$




$$
\text { Cost }=39354 * \text { Size } e^{-0.3814} \quad \text { for mixed projects }
$$

\section{Cost Per Acre of Creation, Enhancement, and Restoration Projects}

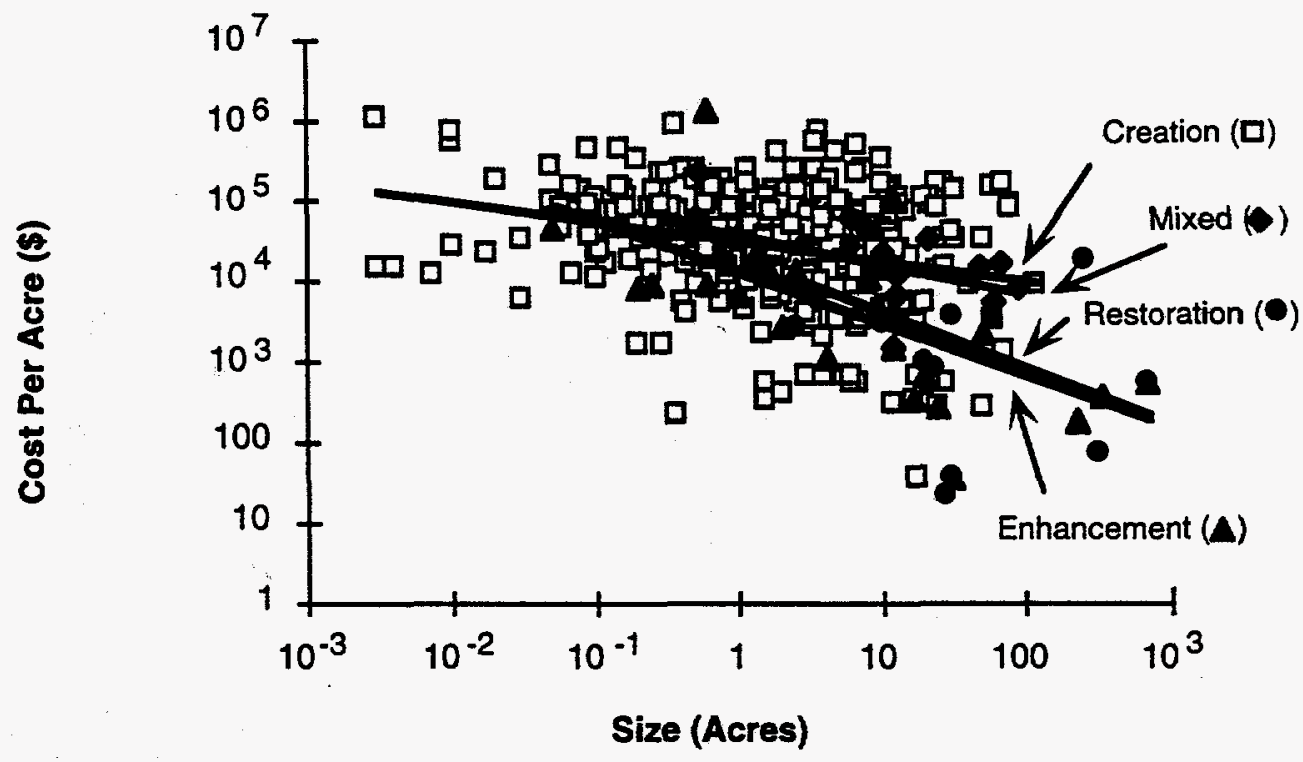

Figure 2.5 Cost per acre of wetland projects estimated from the secondary data.

At one acre in size, enhancement projects are somewhat less expensive on a per acre basis than other projects, and the relative cost advantage over creation projects increases as projects get bigger. At larger sizes, however, enhancement and restoration projects have similar predicted costs per acre.

\subsection{Comparisons Between the Primary and Secondary Data}

An analysis of covariance comparing the primary with the non-agricultural portion of the secondary database showed that (1) the overall slope relating project size to per acre project costs are not different for the two databases, and (2) projects in the primary database are more expensive than projects in the secondary database. Projects from the secondary database have costs that are typically only $56.3 \%$ of the costs of similar sized projects in the primary data. Put another way, the projects from our primary database cost about $78 \%$ more than the projects in our secondary data. As discussed previously, we expect that this is due to the relatively low quality standards represented in the secondary database and the fact that our primary database was developed using modern project design and construction standards. 


\subsection{Discussion of the Data}

\subsubsection{Economies of Scale}

In both the primary and secondary databases, per acre project costs were observed to decline with project size. The analysis we have presented here provides a glimpse into scale issues and probably offers the most reliable available estimates of scale factors applied to wetland creation and restoration costs. We have not, however, measured true economies of scale because we could not isolate project size from other project-related characteristics that tend to change with project size.

Economies of scale, by definition, measure changes in unit cost as the scale of production-number of units-changes. Economies of scale can reflect changes in how production takes place at different scales of production (e.g., more mechanical production or more labor specialization). They can not, however, be estimated reliably when there are significant changes in what is being produced at different scales of production. Unfortunately, the unevenly sized samples of different types and sizes of wetland projects, made it impossible to fully isolate project size as the only cause of differences among project costs. Small scale projects tend to include careful (and expensive) grading and planting, while larger projects are usually carried out with less precision and use less intensive planting methods. Furthermore, certain types of projects (e.g., erosion control plantings) are likely to produce small wetlands, while others (e.g., removing or building water control structures) are likely to produce larger wetland areas. Thus small and large wetland projects almost always differ by more than just size. Accurate determination of true economies of scale would require examination of the effects on per acre project cost of project size alone, independent of confounding influences.

We were able to show that scale effects on per acre project costs differ among categories of wetland projects. Agricultural conversion projects, in particular, decreased in cost much less rapidly with increasing project size than did mitigation projects. We are uncertain why that should be so. It may reflect differences in the economies of scale for component restoration tasks (like monitoring, or planting of trees and shrubs) that seldom are incorporated into agricultural projects. It may also reflect the wide range of approaches used to provide mitigation, as compared with limited techniques commonly used to restore agricultural land to wetland. It may simply reflect the role of volunteer and in-kind contributions in agricultural conversions that are less commonly part of mitigation projects. Or the difference may reflect the dynamics of negotiations between wetland regulators and permit seekers, which played no role in the agricultural projects.

Although different scale effects on project costs were observed for creation, restoration, and enhancement projects in the Secondary data, those dif- 
ferences were statistically unstable, changing with apparently small changes in how the data was analyzed. Since no similar patterns were found in the Primary data, it would be premature to hypothesize what produced the differences. There are significant fixed costs associated with all but the most simple kinds of restoration projects, so economies of scale most certainly exist for most types of wetland creation and restoration projects. Further research on the scale issue should probably wait until there are specific questions raised that require information about economies of scale and justify the expense of measuring and explaining them precisely.

\subsubsection{Creation, Restoration, Enhancement}

Conventional wisdom suggests that wetland enhancement should be less costly on a per acre basis, than wetland restoration, which in turn should be less costly than wetland creation. The primary and secondary data both support the hypothesis that wetland enhancement projects are less costly than creation and restoration projects. However, we saw no evidence in the primary data that restoration is less costly than creation, and we found only weak evidence of this pattern (it holds for large projects only) in the secondary data.

It has frequently been suggested that restoration projects should be less expensive than creation projects primarily because of the relative ease with which appropriate hydrology can be reproduced in an area that previously was wetland. Creation and restoration projects in our primary database generally required similar tasks and subtasks to reach completion. Many restoration projects, however, required substantial expenditures for excavation and site preparation that were similar to those required for wetland creation. In fact, we could detect no systematic differences between creation and restoration projects in their allocation of costs between background research, project planning and design, site preparation, planting, monitoring, or maintenance. The surprisingly high costs of restoration projects relative to creation projects may reflect the costs of working in or near existing wetlands, including increased regulatory costs, and the added costs of working "in the wet" (creation projects presumably can be worked dry). In addition, both creation and restoration projects in historical mitigation markets were often built under strong pressure to minimize costs, with only secondary regard for quality. Because purchasers of mitigation services have been price sensitive, the costs of the two mitigation alternatives may simply have begun to converge because they serve the same market (see Chapter 4.0 and Appendix C).

Differences in per acre costs for creation, restoration, and enhancement projects provide only a partial view of the actual costs of providing wetland mitigation through each of these strategies. The appropriate mitigation ratio and the risk of project failure need to be taken into account in the final cost comparison. Ordinarily, a larger area of wetland would have to be enhanced 
to provide adequate compensation for an acre of lost natural wetland than would have to be created or restored. The overall cost of mitigation using enhancement, therefore, may not be lower than the cost using creation or restoration. Furthermore, conventional wisdom suggests that restoration projects have a much higher success rate than wetland creation projects. To the extent that regulators actually hold permit seekers responsible for mitigation failures (e.g., through bonds or other financial assurances), or require higher mitigation ratios to account for risk of failure, restoration will often prove to be a substantially less costly way to mitigate for wetland losses than creation (see Chapter 3.0 and Appendix B).

\subsubsection{Wetland Type}

In both the primary and secondary databases, the per acre costs of wetland creation and restoration projects were relatively insensitive to the type of wetland being created or restored, whereas ranges of per acre project costs tended to be relatively wide within most wetland categories. It is unlikely that wetland type plays an insignificant role in determining per acre project costs. Site-specific and project differences, however, are apparently so important in determining project costs that they mask whatever role wetland type alone is playing.

Wetland creation or restoration projects can differ in cost either because the inputs required to carry out the projects differ, or because the permit cost of those inputs differ. Costs of inputs, especially of labor, can vary substantially by region. Within the United States, however, regional differences in the costs of inputs alone are unlikely to lead to variation in per acre project cost by even as much as a factor of two. Much greater differences in per acre costs arise because the inputs required to complete two projects may be very different. Inputs may differ because the wetlands being produced are of substantially different types. Many projects producing dissimilar wetlands, however, have similar inputs, and many differences in inputs reflect differences in the projects that are less obvious than target wetland type. Such differences may arise for many reasons, including:

(1) Regional differences in the types of projects typically carried out (e.g., Florida has numerous mangrove restoration projects; in Southern California, wetland specialists have difficulty finding sufficient water for wetland construction);

(2) Differences in project design (e.g., planting densities, choice of water control structures, size and pattern of variation in pool depth, use of enhancement techniques like artificial snags or nest boxes); or

(3) Site-specific factors (amount of excavation required, difficulty of access, hydrologic conditions, etc.); and 
(4) Differences in project implementation (thoroughness of site-specific research, use of hydrologic modeling, degree of post-construction monitoring, etc.).

Of these four reasons that inputs for wetland projects may differ, twonumbers (1) and (2), above-reflect differences in the physical product being produced, the target wetland. The other two reflect variation in how the wetland is produced, or in what is needed to produce the wetland.

In both the primary and secondary databases, the type of project being carried out (creation, restoration, enhancement) has a stronger and more consistent influence on overall project costs than does the type of wetland being constructed. Costs apparently depend not so much on what you are producing, as on what you are doing to produce it. A wide range of dissimilar projects were lumped together in each wetland category. Required inputs for those projects vary widely depending on project goals, pre-existing site condition, landscape context, regional environmental patterns, and local regulatory standards, and as a result, the costs of those projects also vary widely.

It would require considerable additional effort to collect and verify enough additional cost data to fully sort through the effect of wetland type on average project costs. In our view, this effort would be of limited value unless specific questions are identified that can only be addressed in this way. This study has demonstrated that the per acre costs of apparently similar projects can differ significantly, easily by a factor of five or ten, but that costs for individual wetland projects can be forecast with acceptable precision if only a few basic facts about the project and the restoration or creation site are known. Our analysis suggests that cost adjustment factors based on simple indicators of site conditions (volume of soil to be moved, amount to be disposed of offsite, site access requirements, whether the site can be prepared and planted dry, etc.) can reduce cost-estimating error to within acceptable bounds.

Appendix $D$ is a copy of a spreadsheet that we developed to help estimate costs of wetland creation, restoration, and enhancement projects when project and site-specific information is available. It is based on site-specific, project-specific, and wetland-specific information. When a specific project is being evaluated, that spreadsheet or a similar engineering cost-accounting framework, is a far more reliable way to provide accurate cost estimates than relying on baseline cost estimates, and it is relatively inexpensive.

\subsubsection{Differences Between Primary and Secondary Data}

Costs of wetland projects in our primary database were almost double what they were for projects in the secondary data. The primary data represent projects designed with a reasonable commitment to both cost and quality, whereas the secondary data, collected from a wide range of historic sources, 
reflects projects developed in a mitigation context where low cost projects have been allowed often with little regard for quality (see Chapter 4.0). In this sense, the difference in project costs between primary and secondary data provides a rough estimate of the costs of increased quality. We believe that the secondary data may faithfully represent patterns of project cost that have held in the recent past. Relatively low cost projects, however, contributed significantly to the poor success rates of historical mitigation efforts, which have in turn resulted in new standards. We do not believe that the lower cost estimates drawn from our secondary data reflect the costs of wetland creation, restoration, and enhancement projects that will meet the standards of the future.

\subsubsection{Agricultural Conversions}

Federal agencies involved in programs to restore converted agricultural lands back to wetland (e.g., USDA Water Bank Program, Department of the Interior Small Wetlands Acquisition Program, Department of Agriculture's Wetland Reserve Program) have previously reported estimates of the cost of wetland creation and restoration. We used some of their reported data in developing the analysis of costs of agricultural projects. Although the agricultural conversion projects carried out under the auspices of these federal programs represent a significant portion of nationwide wetland creation and restoration efforts, the costs of such projects are quite different from costs of projects carried out for mitigation. We believe there are several reasons for this.

(1) Agricultural conversion projects usually involve restoring altered hydrology (e.g., breaking drainage tiles or filling ditches), which is inexpensive and often successful. Such projects are simpler than projects aimed at restoring structurally and biologically more complex wetlands that occur with greater frequency outside the farm belt.

(2) Agricultural conversions usually do not face the complications of restoration and creation of wetlands in urban and suburban landscapes, precisely where wetland losses and the associated needs for mitigation are often the greatest.

(3) Many agricultural conversion projects are carried out with the help of agency personnel and volunteers. The opportunity costs of labor and other contributions by these "unpaid" participants are sometimes incompletely reported.

(4) Agricultural conversion projects, as we have used the term, include only those projects carried out outside of a mitigation context. Costs of complying with regulatory requirements (e.g., plant species composi- 
tion or vegetative cover requirements) and costs of participating in regulatory processes are therefore minimized.

\subsubsection{High Cost Projects}

Our secondary database contained a few records of exceptionally high costs, including one case of restoration costs near $\$ 1.5$ million per acre. However, limited investigation revealed that unusually high costs were usually pushed up by extremely small project size (under one-half acre) or by extraordinary conditions at the restoration site (e.g., the need to blast through granite to attain an acceptable elevation). In many cases the selection of extraordinary sites appears to be the result of regulatory decisions, in particular, the regulatory preference for on-site rather than off-site mitigation. There are many reasons why on-site mitigation might be preferred to off-site mitigation, and we did not compare on-site and off-site alternatives to determine if there were significant cost differences. However, there were clearly cases where exceptionally large amounts of money spent on restoration may have been better invested if siting decisions were based on a search for more favorable locations from the perspective of improving wetland or watershed functions rather than strictly adhering to the regulatory preference for on-site mitigation.

\subsubsection{Cost Implications of Regulatory Involvement}

Our findings on the relative costs of (nonregulatory) agricultural conversions and mitigation projects suggest that regulatory involvement itself may increase the costs of wetland creation and restoration. Similarly, our limited evaluation of the few very high cost wetland projects in our database suggest that, even within the mitigation context, regulatory policies and decisions may affect project costs. These findings, however, must be interpreted with some care, as regulatory involvement affects not only the cost of creation, restoration, and enhancement, but also the character of the services (design construction and monitoring) provided and, ultimately, of the product (the wetland) produced.

\subsubsection{Changes in Design}

Agricultural conversion projects carried out outside of a mitigation context usually involve little more than restoration of pre-disturbance hydrologic conditions by destruction of the ditches and drain tile used to artificially drain land. Such an approach to wetland restoration, is considerably less rigorous than would prove acceptable to most regulatory agencies.

Most regulatory agencies are concerned about ensuring re-establishment of wetland conditions as rapidly as possible, working to see specific biotic communities become established on site, and trying to minimize risks of 
project failure. Accordingly, many agencies require more intensive management of mitigation sites than they would require of a non-mitigation restoration effort. In particular, mitigation projects must often meet specific performance conditions (e.g., plant survival or vegetative cover) by a certain time after construction. No such requirements are imposed on most wildlife enhancement projects.

Regulatory preferences for on-site mitigation may also increase the need for site preparation. To the extent that wetland creation or restoration at a specific location requires grading or hydrologic modification, costs will be increased. Many mitigation projects incorporate site grading, hydrologic modification and extensive planting. For many of the projects in our primary database, these three activities represented a majority of project costs. These tasks also require considerable design and planning effort, with its associated costs.

\subsubsection{Changes in Implementation}

Even if regulatory involvement did not change the design and implementation of a wetland restoration, regulatory involvement may be expected to increase project costs by imposing planning, documentation, and monitoring requirements that alter how a specific project is designed and carried out. Regulatory requirements for increased care and better documentation of plans, construction, and other activities bear additional cost, and, one hopes, carry some benefits in terms of reduced risks of failure and higher probability of producing desired wetland functions.

Many agricultural conversion projects have essentially no design costs. Existing structures (drain tile and ditches) are simply eliminated, and the area that floods becomes wetland. In contrast, the area of many mitigation projects is often calculated precisely (often in square feet, not acres). Design details are worked out in detail long before any earth is moved or seedlings planted. Blueprints are rare for agricultural conversions, while several iterations of blueprints are routinely produced for mitigation projects before construction begins.

After construction, mitigation projects are more likely than agricultural conversions to incorporate monitoring and follow-up practices such as annual vegetation surveys, photographs recording site conditions, and asbuilt project plans. Long-term maintenance activities and remedial actions to correct undesirable developments are also more likely with mitigation projects. 


\subsubsection{Additional Costs}

Undoubtedly, participation in the regulatory process has certain costs that neither alter the final wetland project, nor affect how the project is implemented. Many mitigation projects are the result of extensive negotiations among the builder, his or her client, regulators, and other interested parties. The transaction costs associated with these negotiations and with regulatory compliance in general can be substantial. Meetings with regulators, construction delays produced by permitting problems, and so forth, are costs of regulatory decision making itself that are unlikely to bear direct environmental benefits.

\subsection{Regional Differences in Project Costs}

Substantial variation in per acre costs of typical wetland creation and restoration projects among different regions of the country are almost inevitable. These regional cost differences are likely to arise as a result of several contributing factors, including:

(1) Regional ecological and meteorological conditions. Climate and topographic differences between regions lead to development of different natural wetland types, and thus different types of problems building and designing wetland projects. For example, different suites of undesirable exotic species invade wetlands in different regions, requiring different monitoring and control measures.

(2) Patterns of development and human use of the landscape. The landscape context of wetland projects typically differs from region to region. These differences also pose contrasting problems for designers and builders of wetland projects in different regions. Urban, suburban, and rural development have significant hydrological and chemical consequences for adjacent wetland and waterways that must be taken into account when creating or restoring wetlands. Different types of rural development (forestry vs. agriculture, mining vs. recreation) and even different kinds of agriculture (row crops vs. dairy) may also pose different problems and thus affect project costs.

(3) Regional patterns of wetland loss. Historic patterns of wetland loss and typical present-day losses vary from region to region. Thus different regions of the country have distinct mitigation needs, as well as different opportunities for wetland restoration.

(4) Local differences in regulatory policies. Although the most important wetland regulatory program nationwide has developed under Section 404 of the Clean Water Act, a federal law, significant differences in implementation of the act are found from district to district within the U.S. Army Corps of Engineers, which implements the law. State and 
local laws may also affect both development of wetlands, mitigation of wetland losses, and applicable standards for both. These legal differences may significantly alter project design.

(5) Regional differences in labor, equipment, and material costs. The costs of specific engineering inputs differ from region to region, directly affecting both total project costs and the allocation of those costs among inputs and tasks. The availability of certain inputs may affect both project cost and performance.

In order to get a better understanding of these and other regional phenomena, we carried out two regional case studies, one for the southeastern United States (including the states of Alabama, Florida, Georgia, Kentucky, Mississippi, North Carolina, South Carolina, and Tennessee), and a second focusing on the southwestern United States (California, Nevada, and Arizona). To develop the regional case studies, we combined four analytic steps. First, we collected appropriate information on regional climate, wetlands, land use, and economic conditions. Second, we re-analyzed our primary and secondary data to determine whether regional projects were typically more or less expensive than projects elsewhere in the country. Third, we examined in detail projects in the primary database from each region to determine whether regional projects shared any common themes. Finally, we contacted wetland restoration and creation experts around the country to determine whether they were aware of important regional differences in project design or implementation that might influence per acre project costs. The results of this regional analysis is provided in Chapter 5.0. 


\subsection{WETLAND COMPENSATION RATIOS}

To regulators responsible for managing wetland resources, determining what constitutes appropriate mitigation for wetland losses is a central challenge. If compensation requirements are set too low, agencies will fail, to protect scarce wetland resources and the important functions and values they provide. If compensation requirements are set too high, the social and economic costs of mitigation may be so high that there will be legal and legislative challenges, poor compliance, and an undermining of public support for wetland regulation.

Some regulatory programs address the problem of determining what constitutes appropriate compensation by using standard compensation ratios, which give the number of acres of created or restored wetlands required to make up for each acre of wetland originally damaged. Maine, Florida, and Maryland are among the jurisdictions that have taken this approach (Want 1993). The federal program under $\$ 404$ of the Clean Water Act, however, does not rely on standard ratios. Instead, an Army Corps of Engineers-EPA Memorandum of Agreement (MOA) provides guidance for determining what may constitute appropriate compensation on the basis of a comparison of wetland functions and values. The MOA specifies that wetland mitigation should "strive to achieve a goal of no overall net loss of wetland values and functions." Moreover, the MOA specifically requires that the assessment of what constitutes appropriate mitigation of wetland impacts should be based "solely on the values and functions of the aquatic resources impacted" and not on economic or other considerations. In principle, therefore, compensation requirements under the federal program require a comparative analyses of the wetland functions and values expected from the proposed mitigation and those lost with the destruction of the original wetland.

The relatively simple idea of comparing wetland functions and values is relatively complex in practice. Wetlands, as a form of natural capital, are valuable in ecological and economic terms because of the streams of functions, products, and services that they provide over time. Thus the value of any given wetland depends on the level and characteristics of the many functions it provides, it's proximity to other features of the watershed and it's accessibility to human populations. Assessing the adequacy of compensatory mitigation involves comparing streams of wetland functions and associated values that would occur if the original wetland were not disturbed with the stream of functions and values provided by the proposed mitigation. This comparison depends on three critical factors:

(1) The relative level of sustained wetland function provided by the lost and the compensation wetland, which depends in part on the relative sizes of the two wetlands (the compensation ratio); 
(2) The speed with which the created or restored wetland reaches a sustained level of function;

(3) The risk of compensation failure, or more generally, the uncertainty about the level of wetland function the compensation project will provide.

By combining these factors into a single analytical framework, we have produced a method of quantitatively assessing whether the trade off between wetland quality and wetland area under a proposed mitigation plan results in no overall loss of wetland value. The version of the model presented here does not take into account multiple wetland values and therefore, it is most appropriate when a single wetland value is of overriding management interest. An expanded version of the framework requires a procedure for weighting the importance of various wetland functions on the basis of socio-economic values, ecological significance, watershed goals or some other criteria. The version we present here is intended to illustrate the ideas underlying the model (see Appendix $\mathrm{C}$ for a more complete description of this model).

The conceptual basis for the analytical framework is depicted in Figure 3.1. Destruction of its original wetland leads to a loss of $100 \%$ of the wetland functions and values. At some time $\mathrm{T}_{0}$, a compensatory wetland is created or restored. The per acre environmental functions provided by the compensatory wetland is at level $\mathrm{A}$, the level of value provided at the mitigation site in the absence of any mitigation and climbs gradually over a period of $C$ years to a maximum level at B. A and B are both measured as a percent of the per acre value of the original wetland and reflect the level of function at the mitigation site before and after the mitigation project.

The cross hatched rectangle below the line at $A$ in Figure 3.1 represents wetland value that would have existed at the compensatory wetland site even in the absence of mitigation activity. Thus the dotted area above line $\mathrm{A}$ and below the recovery curve represents the net increase in wetland value at the compensation site due to mitigation. The area of that area, a polygon, reflects the total increase in relative value caused by construction of one acre of the compensatory wetland. To estimate an appropriate compensation ratio, one needs to compare that area with the entire area below the line at $100 \%$, which reflects the decline in value of the original wetland. The ratio of these two areas, the value provided by the mitigation divided by the value lost with the original wetland, reflects the loss of wetland value with acre-for-acre mitigation. The inverse of that ratio, therefore, reflects the compensation ratio that would result in no net loss in wetland value.

A more refined estimate can be developed by (1) taking into account time discounting (the reduction in the perceived importance of values that will not be received for many years), (2) the risk that a wetland creation or restoration project will not perform as well as expected, and (3) the possibility 
that mitigation may be carried out either before or after the loss of the original wetland. Incorporating these refinements into the model produces an equation that estimates the compensation ratio in such a way that the lower quality of the compensatory wetland is balanced by its increased area.

\section{Compensation Model}

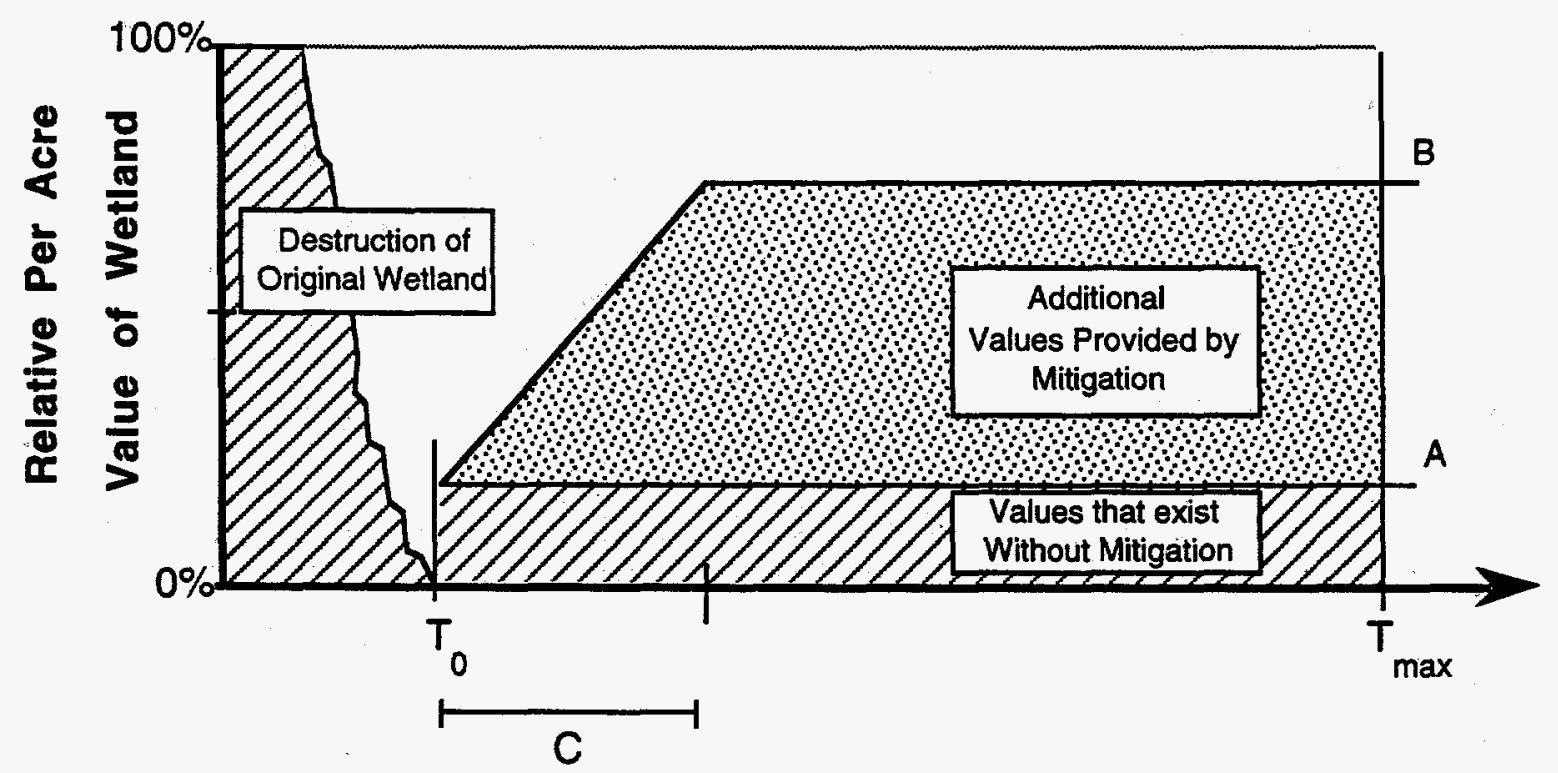

Time

Figure 3.1. A Simple Wetlands Compensation Model.

For discrete time, the appropriate compensation ratio can be calculated using the following formula:

$$
R=\frac{C \sum_{t=0}^{T_{\text {max }}}(1+r)^{-t}}{(B-A)\left[\sum_{t=-D}^{C-D}\left[(t+D)(1+r)^{-t}\right]+C \sum_{(C-D)+1}^{T_{\text {max }}}(1+r)^{-t}\right]}
$$

where the symbols have the following meanings:

$\mathrm{R}$ : The smallest compensation ratio that assures no loss of (time discounted) wetland values;

A: The level of per acre wetland function at the compensation site prior to the compensation project, expressed as a proportion of the value of the original wetland; 
B: The maximum acre-by-acre level of wetland function the compensation project will reach, expressed as a proportion of the per acre value of the original wetland;

C: $\quad$ The year after construction of the compensation project that it achieves maximum function;

D: The number of years before destruction of the original wetland (at time $t=0$ ) that construction of the compensation project occurs (negative values represent delayed compensation);

E: The estimated chance that the mitigation project will fail and provide substantially fewer environmental benefits than anticipated;

$r=\quad$ The discount rate (the $7 \%$ recommended by OMB or other value); and

$\mathrm{T}_{\max }$ : The time horizon used for planning purposes. (At $\mathrm{r}=7 \%$, present value is negligible beyond $t=70$ years).

The equivalent continuous time model is analytically more tractable, although it is arguably less realistic, since real wetlands typically are strongly seasonal. The formula for the compensation ratio that balances gains and losses of wetland function is

$$
R=\frac{r C\left(1-e^{-r T_{\max }}\right)}{(1-E)(B-A)\left[e^{r D}\left(1-e^{-r C}\right)-r C e^{-r T_{\max }}\right]}
$$

where parameters are defined as above, and $\mathrm{e}$ is the base of the natural logarithms. As shown in the following equations, the compensation ratio, $\mathrm{R}$ behaves appropriately in the limits as $r$, the discount rate approaches zero, and as $\mathrm{T}_{\max }$ the time horizon, increases without bound.

$$
\lim _{r \rightarrow 0} R=\frac{T_{\max }}{(1-E)(B-A)\left[2 T_{\max }-\frac{C}{2}+D\right]}
$$

$$
\lim _{T_{\max \rightarrow \infty}} R=\frac{r C}{(1-E)(B-A) e^{r D}\left(1-e^{-r C}\right)} \quad r \neq 0
$$

$$
\lim _{T_{\max } \rightarrow \infty, r \rightarrow 0} R=\frac{1}{(1-E)(B-A)}
$$

Table 3.1 shows some calculated compensation ratios based on the discrete time version of the model. The first three examples show the effect on compensation ratios of delaying or advancing the compensatory wetland 
project. The next group indicate how pre-existing wetland values or compensation for loss of a degraded wetland would affect the compensation ratio. The final group of examples shows the effect of a significant risk of failure on compensation ratios.

The last of these examples is especially significant. It shows the substantial reduction in compensation ratios that may result from advanced compensation when risks of failure are significant. Since a substantial portion of mitigation failures can (1) be detected, and (2) be corrected within a year or so of initial construction, advanced compensation allows the permittee to manage those risks, and present regulators with a compensation project with a substantially lower risk of long term failure. That reduction in risk, when coupled to the additional reduction caused by the timing of availability of wetland values, results in a substantial reduction in compensation requirements. Under these circumstances, advanced mitigation-lower mitigation requirements-could outweigh the economic costs of tying up investment capital. This could bed important, for example, in evaluating the economics of wetland mitigation banking.

Table 3.1 Some Calculated Compensation Ratios for a Variety of Hypothetical Compensation Scenarios, (based on the discrete time model described above)

\begin{tabular}{|c|c|c|c|c|c|c|c|c|c|}
\hline & & & & & & \multirow{2}{*}{\multicolumn{4}{|c|}{$\begin{array}{c}\text { COMPENSATION } \\
\text { RATIOS } \\
\text { Discount Rate }\end{array}$}} \\
\hline & \multicolumn{5}{|c|}{ Parameters } & & & & \\
\hline & $\mathrm{A}$ & $\overline{\mathrm{B}}$ & $\mathrm{C}$ & $\mathrm{D}$ & $\bar{E}$ & 0 & 0.05 & 0.1 & 0.2 \\
\hline Concurrent Creation & $\overline{0}$ & $\overline{0.7}$ & 10 & $\overline{0}$ & 0 & 1.43 & $\overline{1.82}$ & 2.26 & $\overline{3.3}$ \\
\hline Advanced Creation & 0 & 0.7 & 10 & 5 & 0 & 1.43 & 1.41 & 1.37 & 1.22 \\
\hline Delayed Creation & 0 & 0.7 & 10 & -5 & 0 & 1.43 & 2.33 & 3.73 & 8.98 \\
\hline Concurrent Restoration & 0.1 & 0.7 & 10 & 0 & 0 & 1.67 & 2.12 & 2.64 & 3.86 \\
\hline Original Wetland Degraded & 0 & 1.4 & 10 & 0 & 0 & 0.71 & 0.91 & 1.13 & 1.65 \\
\hline Concurrent Enhancement & 0.5 & 0.7 & 10 & 0 & 0.2 & 6.25 & 7.94 & 9.89 & 14.5 \\
\hline Difficult Creation & 0 & 0.7 & 10 & 0 & 0.5 & 2.86 & 3.63 & 4.52 & 6.61 \\
\hline Very Difficult Creation & 0 & 0.7 & 10 & 0 & 0.75 & 5.71 & 7.26 & 9.04 & 13.2 \\
\hline $\begin{array}{l}\text { Same, Advanced and Risk } \\
\text { Adjusted }\end{array}$ & 0 & 0.7 & 10 & 5 & 0.2 & 1.79 & 1.77 & 1.71 & 1.52 \\
\hline
\end{tabular}




\subsection{ECONOMICS OF WETLAND RESTORATION AND MITIGATION}

This report focuses primarily on the costs of wetland creation and restoration. Cost information, however, is of little value unless it can be discussed in a broader economic and environmental context. In this section, we summarize some of the broader issues related to the economics of wetland creation and restoration.

\subsection{The Market for Wetland Restoration}

Recent surveys confirm that restoration projects undertaken to meet mitigation requirements under Section 404 of the Clean Water Act had extraordinarily high failure rates, over $50 \%$ in Florida, California, and the mid Atlantic states. (See Want 1993) These high failure rates are often used as evidence that restoration science is failing. What is rarely reported with the evidence of mitigation failure; however, is the fact that in most cases, the causes of these failures are known-bad plans, poor execution, lack of followup, and so on. In fact, in both Florida and the Mid-Atlantic region, many historical mitigation "failures" occurred because planned projects were never undertaken. Analyzing the records of some projects that were undertaken reveals a similar lack of commitment. For example, at some sites once one excluded the cost of land and the cost of engaging in the 404 permitting process itself, the amount of money devoted to actual restoration activities (e.g., hydrological testing, earth moving, planting) was as low as a few hundred dollars per acre. In general, the records of low costs and high failure rates, are two sides of the same coin and reveal less about the state of restoration science than the motivation of those providing restoration.

\subsection{Underlying Incentives}

Wetland restoration is an applied science; but the historical record of wetland restoration projects has been influenced to a significant extent by the fact that providing wetland restoration is also a business. With few exceptions those who design and implement wetland restoration projects earn their livelihoods satisfying the needs of permit seekers involved in the Section 404 wetland permitting program. This mitigation market is driven primarily by demand for low cost permits, not the production of high quality wetlands. There are certain scientific limitations, but high failure rates for these projects, in general, were the result of underfunded, badly planned, and poorly executed restoration efforts which were themselves the result of the perverse incentive structure that evolved in the mitigation market that served the needs of Section 404 permit seekers. The problems had to do with institutional and market limitations, not scientific limitations. 


\subsection{Institutional or Market Failure}

It would be easy to blame poor incentives and mitigation failure on the wetland mitigation market itself. However, the mitigation market, like most markets, was, in fact, extremely effective at providing what was in demandlow cost mitigation. What was extraordinary about this market was that buyers (permit seekers) and sellers (mitigation suppliers) had strong incentives to be price conscious but hardly any reason to be quality conscious. The regulators should have been responsible for imposing quality control but apparently did not exercise enough authority to link permit approval with mitigation results. Without such a link, those demanding and supplying mitigation had little incentive to spend what was necessary to provide high quality restoration; thus low costs and high failure rates. This basic problem was exacerbated by (1) the fact that until recently permit approval sometimes depended only on a promise, often unsecured, to construct mitigation, and (2) the fact that enforcement actions to ensure that permitees complied with mitigation agreements were rare.

For purposes of cost analysis the important point is that the cost records of past mitigation projects generally reflect the cost of low quality, low cost projects and therefore offer a biased perspective on the cost of high-quality wetland restoration. However, as more attention is given to the use of incentive-based and market-based strategies for achieving wetland and other environmental goals, there may be more important lessons to be learned from this example of how and why environmental trading systems can fail to achieve hoped-for results. ${ }^{1}$

\subsection{Conclusions About the Economics of Wetland Restoration}

On the basis of our analysis of cost data for wetland creation and restoration projects and a review of what is known about the success of these projects and the economic and regulatory conditions under which they were undertaken, we reached the following general conclusions:

- Restoration success depends on the level of spending on restoration and the motivation of the restoration provider, as well the state of restoration science and site-specific conditions.

1. The hope that mitigation banking will improve the success of wetland mitigation is an important example. The role of regulations in establishing the trading rules and incentives for trade in wetland mitigation banks, and the resulting effects on mitigation decisions are described in Shabman, L., P. Scodari, and D. King. 1994. Expanding Opportunities for Successful Wetland Mitigation: The Private Credit Market Altemative. Report prepared for the U.S. Army Corps of Engineers Water Resources Institute, Fort Belvoir, VA. 
- Historically low restoration costs and historically low success rates for non-agricultural restoration projects reflect as much the failure of regulators to demand results as the failure of restoration science to provide results.

- Because conditions in mitigation markets-the rules of exchange and units of exchange-are determined by regulators, they can control the incentives that determine how mitigation suppliers make cost-quality tradeoffs.

- The development of wetland restoration as an applied science and as a policy tool will depend on how well regulators manage the incentives in mitigation markets.

- $\quad$ Site-specific differences can cause the cost of apparently similar projects to differ significantly, sometimes by a factor of five or ten. However, predictability and reliability increases substantially if only a few basic facts are known about the restoration site. So far our analysis suggests that cost adjustment factors based on simple indicators of site conditions can reduce cost estimating error to within acceptable bounds.

- The physical characteristics and geographic scale of agricultural conversion projects and projects undertaken as mitigation for wetland losses differ significantly. Even reliable information about the costs of agricultural conversions is of limited value when assessing the potential of restoration within the context of regulatory policy.

- Wetland restoration is an emerging field of applied science with very few engineering or performance standards, and the range of skills and experience among restoration specialists is enormous. This is reflected in a wide range of costs and success rates for most types of restoration projects. 


\subsection{SPECIAL REGIONAL PROFILES}

\subsection{Special Regional Analysis-The Southwest}

\subsubsection{Regional Climate, Ecology, and Wetlands}

The southwestern United States, including the states of California, Nevada, and Arizona is characterized by great geographic, climatologic, and ecological diversity. Climate varies from the cool Mediterranean climates of northern California and the montane climate of the Sierras to the cool desert of Nevada's Great Basin, and the warm desert climates of the Mojave and Sonoron deserts. This climatological diversity is reflected in wide ecological variation across the region, as well as in a diversity of wetland types.

Precipitation throughout the region is either rare and episodic or strongly seasonal. Rainfall is most abundant (and most predictable) in the northwest, with both quantity and predictability decreasing toward the southeast. Mediterranean climates throughout much of California (with cool, wet winters and warm, dry summers) ensure that the soil moisture and surface water on which wetlands depend are also strongly seasonal, except in northwestern forests where coastal fogs and orographic precipitation maintain relatively high soil moisture levels throughout much of the year.

In the Great Basin to the East, precipitation is generally lower (Reno, Nevada averages 7.64 inches of rain a year, but precipitation on mountain ridges may be several times that), and somewhat unpredictable, although typically concentrated in the winter snowfall and to a lesser extent in torrential summer rains. Surface waters in the Great Basin do not flow to the sea, but instead drain locally to desert lakes, playas, and sinks. Year-to-year variation in precipitation is large, causing substantial interannual variation in water depth in many of the lakes, rivers, and wetlands within the basin.

In the warm deserts to the south and east, rainfall is concentrated in late summer thunderstorms, although a secondary rainfall peak sometimes occurs during the winter. When rainfall comes, it often is brief and intense, producing flash floods, which in turn produce geomorphically distinct desert streams with their diagnostic riparian vegetation.

Because of low and highly seasonal rainfall throughout much of the region, riparian wetlands (sensu lato) are especially important. River and stream systems collect water from large areas, import water from places with higher precipitation, or transport it from areas of large snow accumulation. They are islands of moisture in arid or seasonally arid landscapes and thus are associated with most of the regions perennial water and wetlands. Small, isolated wetlands are uncommon, except on the western slopes of mountain 
ranges, where orographic precipitation is significant. Elsewhere, isolated wetlands tend to be ephemeral, appearing after rain events only to quickly evaporate, sometimes for years at a time (e.g., vernal pools, playas, and saline lakes).

The other major group of perennial wetlands in the region are the coastal wetlands of California. Because of the regions' active geology and associated uplifting, much of the California coast is steep and rocky, with few shallow areas in which coastal wetlands could develop. Historically, therefore, coastal wetlands were concentrated in estuaries and embayment, especially San Francisco Bay.

Endangered species are significant components of wetland ecosystems throughout the region, for a variety of reasons.

- Because of many thousands of years of evolution in isolated aquatic habitats, a relatively large number of endemic species are found in wetlands and other aquatic habitats in desert regions of the Southwest. As human activity has altered the hydrology of desert springs and major river systems, the endemic species that depend on them have declined, in many cases becoming endangered or threatened.

- In Nevada's Great Basin, extensive Pleistocene lakes were replaced by much smaller water bodies as evapotranspiration began to outstrip precipitation. Once interconnected populations of aquatic organisms have become fragmented as the lakes shrank. Aquatic refugia within the basin are often saline and hot, presenting an especially harsh environment for small aquatic organisms. Strong selection, isolation, and thousands of years have produced several groups of relatively young endemic species, sometimes adapted to very specific harsh environmental conditions.

- High degrees of endemism are also found throughout much of California, apparently the result of biogeographic isolation provided by surrounding mountains and deserts. Here too, as human activity as destroyed most of the state's wetlands, and as the region's appetite for water has grown, species dependent on wetlands and other aquatic ecosystems have been hit especially hard.

\subsubsection{Wetland Losses}

Estuaries and river basins have been favored areas for human settlements since before the development of writing. The availability of water for transportation, drinking, irrigation, and removal of wastes makes riparian areas and coastal estuaries especially attractive areas for human settlement. These areas are especially attractive in arid landscapes, in which water is rare or seasonally unavailable. Thus human settlement in arid regions tends to focus around water courses, wetlands, and coastal embayments. Indeed, the 
impacts of humans on the wetlands of the Southwest have been substantial. Significant wetland losses occurred very early in the European settlement of the region.

By the mid 1980s, wetland losses throughout the region were substantial. California had lost $91 \%$ of its original wetland inheritance (more than any other state) Arizona had lost 36\%, and Nevada, 52\% (Dahl 1990). While the losses in the desert states are at or below the national average, the losses are notable for two reasons. First, population densities over most of these states are very low (the majority of the population lives in a few urban areas). Thus, relatively small rural populations have caused significant wetland losses. Second, these states originally had relatively low percentages of their surface area as wetland $(1.3 \%$ for Arizona, $0.7 \%$ for Nevada, $4.9 \%$ for California), thus wetlands were never widespread, and continued losses have made them even less so.

Agriculture, irrigation, and massive water projects have taken their toll on wetlands throughout the region, not only by directly eliminating wetlands, but also by degrading those that are left. Large water projects have flooded extensive riparian areas, removed large quantities of fresh water from river flows throughout the region, thus drying out many riparian wetlands, altering the timing and severity of peak stream flows, and otherwise changing hydrologic and sediment transport characteristics of the region's rivers and streams on which remaining wetlands depend. Development of riparian areas for agriculture has been extensive throughout the region; these areas were relatively flat, close to water, and easily irrigated. Irrigation return flows have significantly altered the ecology of rivers and other surface waters by increasing concentrations of dissolved solids in river water. These arid-land impacts to wetlands and surface water are in addition to the more widespread problems of nutrient enrichment, sediment loading, and toxic discharges associated with human activities throughout North America and the world.

Major wetland losses in California have occurred in the Central San Joaquin and Sacramento river valleys (Herbold and Moyle 1989) and in the San Francisco Bay region (Josselyn 1983). In the San Joachin-Sacramento river delta, many of the natural freshwater wetlands have been levied and drained for agriculture. The first such levees were constructed as early as 1852 , and the 60 largest delta islands had all been converted to agricultural use before the turn of the century. Small but widespread vernal pools once found throughout California's central valley were often leveled or plowed, leading to the endangerment of many typical vernal pool inhabitants.

Early losses of coastal wetlands in the San Francisco Bay region were to agriculture, but losses to urban and industrial uses also began early. Many former wetlands and mud flats of northern San Francisco, San Pablo, and Suisun Bays were diked before the turn of the century for agricultural pur- 
poses, especially grazing. Many still provide fodder for local dairies. Land speculation and inaccurate surveys helped drive the filling of wetlands in port and urban areas. Whole communities along the coast of San Francisco Bay are built on wetland fill. The tidal marshes of the southern San Francisco Bay area are naturally more saline than those in the north, and less suitable for agriculture. However, many of the marshes and mud flats there were diked for salt evaporation ponds. The first local salt production occurred in the $1850 \mathrm{~s}$. By the middle of this century, few natural marshes were left in the southern bay.

Major wetlands losses in the desert states have been more widely distributed, in part because wetlands were more widely distributed. Wetland losses have been the result of agricultural development, diversions of surface water, and pumping of groundwater (Minshal et al. 1989). Direct wetland losses to urban development are predominately a recent phenomenon.

\subsubsection{Regional Economic Conditions}

California's economy is large and diverse. Recent downturns in the defense and areospace industries, however, and a series of natural disasters have hit California hard, and the state remains mired in recession despite the national economic upswing. Southern California, long a center for aerospace and military contracting, has been especially hard hit. The Los Angeles area accounted for approximately half of the jobs lost in the state during the height of the recession. Property values, extremely high five years ago, have declined by as much as $50 \%$ over the last few years, most significantly in southern California. California housing and construction industries are still in a slump, reducing short-term pressure on the State's wetlands .

Paradoxically, the recent Los Angeles earthquake may help pull California out of its recent economic malaise by forcing households and businesses to invest in rebuilding rather than making other investments out-ofstate. The housing and construction industries, in particular, are expected to get a boost as earthquake victims rebuild. The influx of federal assistance to the region, along with the multiplier effect of the increase in construction activity may trigger an economic resurgence and development throughout the region. The effect of these investments on the region's wetland resources, however, remain unclear. Much will depend on the extent to which new construction on previously undeveloped land replaces or is spurred along by the redevelopment of areas damaged by the quake.

The economic recovery was not as slow in coming to Arizona and Nevada. Arizona and Nevada have grown rapidly over the last decade or so. The two states have taken part in sunbelt growth made possible by the development inexpensive air conditioning and large water projects. While retirement, tourism, and recreational development have been important to growth 
in both states in the recent past, both states are making an effort to attract manufacturing industries as well. Most recent growth has occurred in and around major urban areas, a trend that is likely to continue, and has been associated with large-scale land development rather than high density development. This has put increasing pressure on wetlands and other features of the environmental landscape.

\subsubsection{Characteristic Wetland Projects of the Region}

Characteristic wetland creation and restoration projects in the southwest United States are determined, in part by the meteorological and ecological conditions in the region, and in part by the limited opportunities that exist for restoration and the high demand for mitigation sites. The need for wetland mitigation, by definition, is tied to the level of development activities that harm wetlands. The politics of water projects have changed dramatically, and it appears that the future will bring few massive, federally subsidized water projects, which will limit wetland impacts from water projects. The swampbuster provisions of the 1985 and 1990 Farm Bills, the wetlands reserve program, and changing priorities in agricultural programs generally are likely to continue a nationwide trend away from destruction of wetlands for agriculture. Urban development and associated highway and utility construction, however, in general keeps pace with development, and is likely to accelerate as the current economic recovery expands throughout the Southwest.

All three states have very low percentages of their land area in wetlands $(0.4 \%$ in California, $0.8 \%$ in Arizona, $0.3 \%$ in Nevada), which in principle should make avoidance of wetland impacts easier than in states with a higher percentage of the land in wetland. However, many of the region's metropolitan areas are near rivers and the sea, so much wetland development will continue to be in areas with higher than average concentrations of wetland. Many wetland impacts will come from linear projects like road and utility construction which must cross waterways in order to fulfill their basic purpose. Demand for mitigation may also be increased by endangered species impacts, some of which will be mitigated through creation or restoration of wetland.

Restoration outside of the context of mitigation is likely to remain less common in the southwest than elsewhere in the country. Regional demand for water withdrawn from rivers and stream systems for human uses has grown explosively over the last several decades. Reserving water from human distribution for environmental purposes will prove expensive, legally difficult, and politically unpopular. However, without available water, restoration of many former wetland areas will be difficult or impossible, and those restoration projects that are possible will be relatively complex and expensive. The Southwest has relatively few opportunities to pursue the kind of inexpensive agricultural conversions that have proven so successful in the 
Midwest. In northern California, and along the coast, where restoration is not hindered by a lack of water, property values are high, and many degraded or converted wetlands are in profitable use for agriculture or salt evaporation. Acquiring permission to restore wetlands on these lands, or outright acquisition of restoration sites in these areas are likely to be expensive. Restoration and enhancement projects outside the context of mitigation is likely to continue to focus on lands held by local, state, or federal governments, and on riparian restorations that can be carried out without removing large areas of land from existing profitable uses.

Regional climate conditions and the history of human use of the land combine to make typical wetland creation and restoration projects throughout the Southwest unusually complex, and therefore expensive. The regional context for wetland restoration in the Southwest can be summarized as follows:

(1) Wetland creation and restoration projects in the region face unusual technical challenges because of a lack of available surface water. Careful planning, engineering, and construction are often necessary to ensure simultaneous compliance with storm water management requirements and provision of adequate water supplies for the wetland itself.

(2) Many wetland creation and restoration projects are undertaken, in part to satisfy requirements for mitigation of losses of endangered species habitat (e.g., the San Diego Mesa Mint, Light Footed Clapper Rail, and Least Bell's Verio). Endangered species compliance increases project complexity, as well as monitoring and follow-up costs and greatly increases project costs.

(3) The concentration of wetland impacts in and around urban areas also increases project complexity. Creation or restoration of natural or seminatural wetlands in or near urban centers is especially challenging. While this is especially true of freshwater wetlands, for which provision of appropriate hydrologic conditions may be impossible in an urbanized watershed, an urban context also increases the difficulty of tidal restorations and limits the ability to restore populations of plant pollinators, predators, and other key ecosystem links.

(4) Project complexity may also be increased by the preponderance of riparian wetlands in the desert parts of the region. Riparian restorations can be expensive because of the complex engineering sometimes required to ensure stable channels in flowing water systems. Restoration of lowflow wetland systems seldom requires as much engineering expertise flood-prone riparian systems. Unfortunately, it is difficult to compare the costs of riparian restorations and typical wetland restoration, since the size of riparian restorations is more appropriately measured by linear stream length and stream discharge, rather than area. 
(5) Where restoration of coastal wetlands is undertaken, simple plantings are seldom sufficient. Restoration efforts often must take into consideration extensive hydrologic modifications that have occurred in the Southwest over nearly 150 years of development activity in the region's wetlands. A majority of the restoration and enhancement projects from the region in our Primary database included substantial hydrologic modification, such as installation of culverts, re-establishment of tidal guts, and so on.

(6) Project costs throughout much of the region are also be inflated because labor and equipment costs tend to be higher than those found in the rest of the country. Construction costs in 12 California cities, as well as in Reno and Las Vegas, Nevada, are slightly above the average for cities nationwide (Means Landscape Cost Data 1991). The construction cost differential in California varied from $7 \%$ above average in Vallejo to $25 \%$ above average in San Francisco. In Las Vegas and Reno, construction typically costs $3 \%$ and $4 \%$ higher than the national average, respectively. Construction costs in Arizona are 8\% (Tucson) or 9\% (Phoenix) below national averages.

\subsubsection{Analysis of Region-Specific Data}

\subsubsection{Primary Data}

Our Primary database contains 32 projects from the southwestern region, all from California. Approximately half of these projects are from southern California and half from northern California. Projects from the south were primarily intended to produce wooded wetland habitat for the Least Bell's Verio, but we also have data for a vernal pool creation project and a few other emergent wetland projects. Northern California projects were more diverse, including riparian restorations, and complex wetland enhancement projects in estuarine-palustrine wetland complexes along the San Francisco Estuary.

An analysis of covariance was used to determine whether wetland creation and restoration projects in our Primary Data from California were different in cost from similar projects elsewhere in the country. They were. Wetland projects in California were approximately double the cost of similar projects elsewhere in the country (the ANCOVA Table is presented in Appendix A). A more complete analysis, adjusting for wetland project type (creation, restoration, enhancement), shows a slightly larger cost difference. California projects are about 2.3 times as expensive as projects elsewhere in the country (ANCOVA table not shown). 
Primary Data: Southwest vs. Other Regions

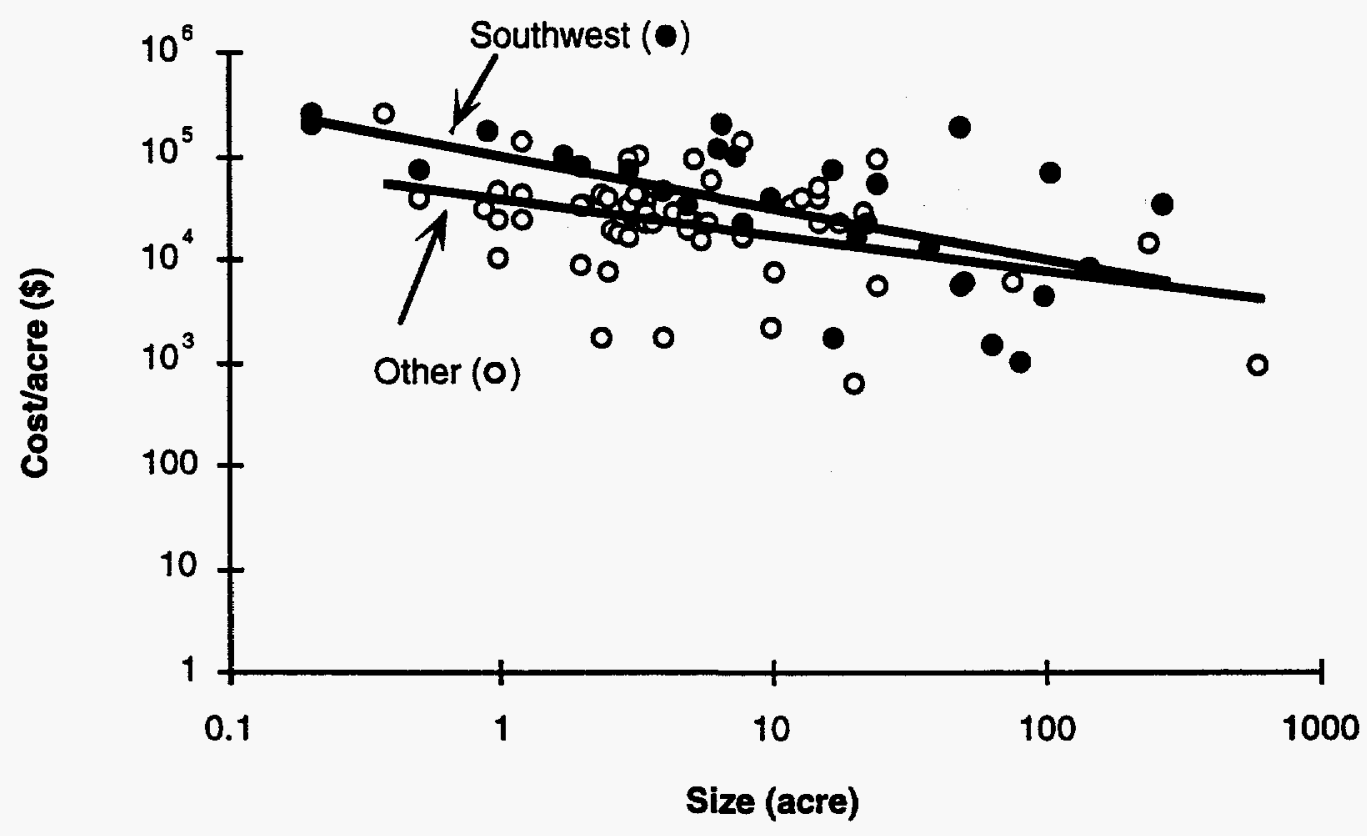

Figure 5.1. Primary data-Southwest.

\subsubsection{Secondary Data}

Of our sample of 397 projects (excluding agricultural conversion projects), forty-six were located in the Southwest region. All but two were from California. Of the 46 projects, 20 were wetland creation projects, while 5 were restoration, 5 enhancement, and 2 mixed projects. We could not determine project type for the remaining 14 projects. The frequency of wetland creation projects in this sample is lower than in the rest of the database (by chi-squared test, $X^{2}=15.647, p=0.0013$ ). Projects in the southwest were substantially larger than projects elsewhere in the country (t-test on log-transformed project sizes, $t=4.034 p=0.0001$ ). The analysis of covariance showed no significant differences in per acre project costs between projects in the southwest and those elsewhere. 
Secondary Data: Southwest vs. Other Regions

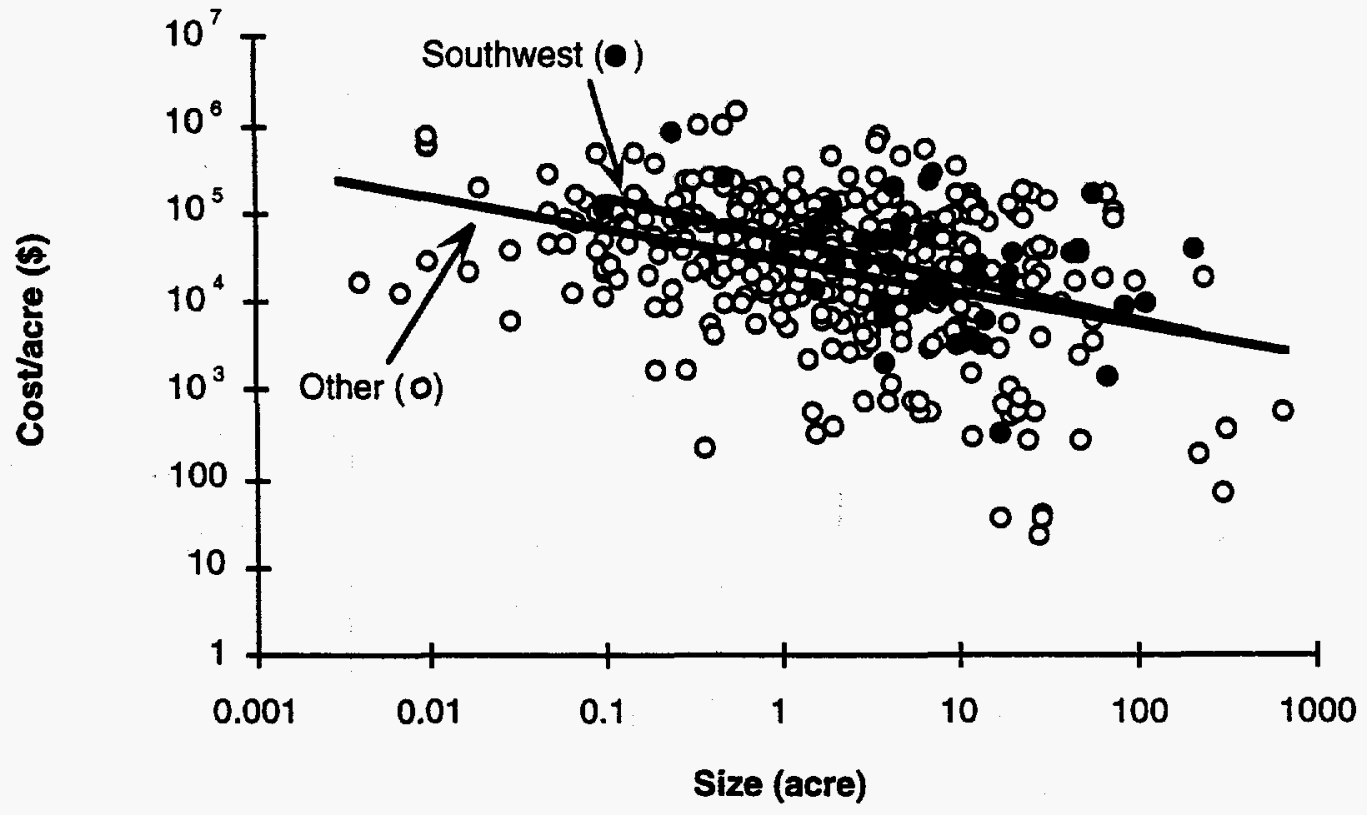

Figure 5.2. Secondary data-Southwest.

\subsection{Special Regional Analysis-The Southeast}

\subsubsection{Regional Climate, Ecology, and Wetlands}

The southeastern United States, including the states of Alabama, Florida, Georgia, Kentucky, Mississippi, North Carolina, South Carolina, and Tennessee, includes some of the states with the highest natural abundance of wetlands in the nation. Florida, with the extensive wetlands of the Everglades ecosystem, as well as hydric hammocks, coastal mangroves, salt marshes, and riverine cypress-tupelo swamps, is estimated to have been $54 \%$ wetlands at the time of European settlement. Adjacent Georgia and Alabama were about 18 and $23 \%$ wetlands respectively.

The region receives abundant rainfall distributed throughout the year. Some seasonality of precipitation is found throughout the region, with winter storms and summer thunderstorms providing somewhat increased rainfall. In Florida, however, precipitation is heavily concentrated in the summer months. Temperatures vary according to elevation and proximity to the ocean from cold-temperate in the northwestern mountains to subtropical in south Florida. Seasonal temperature fluctuations are greatest in the north, decreasing to the south and east. A general excess of annual precipitation over evapotranspiration ensures that isolated wetlands are common wherever geologic or pedogenic processes have produced local topographic lows or where 
ground water reaches the surface, as at the bases of slopes and adjacent to streams.

The geography of the region is dominated by low mountains inland, with extensive sedimentary and marine deposits toward the coasts. The low, flat coastal plain sediments provide ideal areas for the development of extensive wetlands, both tidal and non-tidal. A general lack of topographic relief means that there is little hydraulic gradient, and water takes a long time to run off the land. Low gradient coastal streams and rivers have extensive floodplains that support two of the most widespread and recognizable wetland types in the region, the cypress-tupelo and bottomland hardwood forests. Low coastal relief also facilitates the extension of tidal influences many miles inland, increasing wetland development many miles from the coast. Tidal wetland development has also been facilitated by widespread barrier islands along the coast. The sheltered lagoons inland of the islands provide excellent conditions for tidal wetland development.

The southeastern region, except for Florida, supports fewer endangered and threatened taxa than California and the Southwest. Florida, however, contains more than its expected share of endemic and rare species. The subtropical climate of southern Florida makes it the northernmost outpost of many tropical taxa, while the biogeographic isolation provided by the state's peninsular shape encouraged evolution of endemic taxa to accommodate local conditions. The survival of many of these taxa into the twentieth century undoubtedly owes much to the state's extensive wetlands, which increased the states inaccessibility in the days before air conditioners, mosquito control, and highways. Other states in the region are not unusually endowed with endemics or rare species, although the region includes the headwaters of several important river systems, and may represent a center of endemism for several freshwater taxa.

\subsubsection{Wetland Losses}

Historic wetland losses throughout much of the region have been near $50 \%$, about typical for the nation as a whole (Alabama $50 \%$, Florida, $46 \%$, Mississippi 50\%, North Carolina 49\%, Tennessee 59\%). In Tennessee, wetland losses have been somewhat greater. Eighty one percent of the wetlands of the state had been lost by the mid 1980s (Dahl 1990). Losses in Georgia and South Carolina have been somewhat smaller than elsewhere, with losses in South Carolina of $27 \%$ and in Georgia of $23 \%$.

Wetland losses of the region have occurred as a result of a complex mix of agricultural development, coastal dredging, urban and suburban development, and industrial use. Disruption of coastal wetlands began in colonial times, especially around urban centers where direct conversion of wetlands to urban land and indirect destruction of wetlands via sedimentation and hy- 
drologic alterations were common. Emergent marshes near urban centers were undoubtedly among the first to be used for grazing and other agricultural purposes. Extensive areas of eastern saltmarsh were diked by slave labor in the nineteenth century for rice agriculture; however, the end of the civil war and the decline of the plantation culture and slave economy lead to abandonment of much of the rice land, and reversion of many of these areas to wildlands similar to the original tidal marshes (Wiegert and Freeman 1990; Odum et al. 1984). Many wetland forests that harbored populations of valuable timber trees like the Atlantic White Cedar were cut over early in the region's history, significantly altering species composition, but conversion of wetland to non-wetland because of forestry practices was uncommon.

Wetland losses in Florida follow a similar pattern to losses elsewhere in the region, except that a higher proportion of the state's wetland losses track Florida's twentieth century emergence as a retirement haven and vacation spot. During the nineteenth century, much of the state was inaccessible, too wet even for most agricultural uses, and difficult to drain. Large scale hydrologic modifications in south Florida began late in the nineteenth century. Broader, government-sponsored reclamation efforts in south Florida when Governor Broward pushed for expanded state efforts to convert wetland for agriculture beginning in 1905. Federal involvement in flood control efforts expanded in 1930, and again in 1948, and continued until the early 1980s, when concern for the environmental consequences of the extensive hydrologic changes began to affect management of the Everglades ecosystem. In addition to the direct wetland losses caused by these large-scale hydrologic modifications, each modification also triggered rapid development as previously unsuitable lands became drier, less prone to floods, or easier to drain. With rapid development of the Florida landscape came equally rapid destruction of the wetlands. Between the mid-1970s and 1980s (well after many of South Florida's water management structures were completed), approximately $1.5 \%$ of Florida's remaining wetlands were lost, primarily to agriculture and urban expansion (Frayer and Hefner 1991).

\subsubsection{Regional Economic Conditions}

Economic growth in the Southeast has been uneven. Some regions, notably the Atlanta region and much of Florida have enjoyed rapid growth and robust economies (Forrestal 1993). Elsewhere, and by some measures for the region as a whole, economic performance has been poor. Poverty is relatively widespread, and disposable incomes relatively low in much of the region. On the other hand, the region was relatively quick to respond to the current nationwide economic expansion, with job growth faster than that found in the nation as a whole in the later parts of 1992. That performance is expected to continue. While locally important, defense is not a mainstay of the regional economy, and thus long-term repercussions of defense cutbacks in the region should be mild. Regional strength in timber, furniture, and ap- 
pliance manufacturing should help the regional economy grow in response to robust housing markets nationwide triggered by low mortgage interest rates.

This economic growth can be expected to lead to on wetland impacts. Birth rates in the region are below national averages, but population growth through the 1980s was above national average in the Atlantic states (NC, SC, GA, FL) and at or below the national average for the gulf and inland states (KY, TN, AL, MS) (Statistical Abstract of the United States 1992). This suggests that the Atlantic coastal states have been attracting immigrants from other parts of the country and around the world. New residents need housing, public services, additional roads, and shopping facilities. In the process of providing the growing population with these needs, wetlands will be affected.

\subsubsection{Wetland Projects in the Region}

For at least the past twenty years, the southeastern United States has been the national center for innovation in the field of wetland creation and restoration. Projects to create, modify, and restore many different types of wetland have been carried out in the region. Thus it is difficult to identify one or a few "typical" wetland projects. The wide variety of restoration and creation projects, include projects to produce or restore cypress-tupelo swamps, bottomland hardwood forests, freshwater tidal wetlands, saltmarshes, and mangroves. As the technology of wetland management continues to improve, the range of wetland types being created and restored in the region is likely to continue to increase. Indeed, some of the most ambitious wetland creation and restoration projects ever attempted anywhere in the world are now getting underway in the Kissimmee-Okechobee-Everglades ecosystem.

Most of the states in the southeast have substantial percentages of their land area in wetland (AL: $11.5 \%$, FL: $29.5 \%$, GA, $14.1 \%$, MS: $13.3 \%$, NC: $16.9 \%$, SC: 23.4\%). The two landlocked states, however, do not (TN: $2.9 \%$, KY: 1.2\%). Thus on an a priori basis, one might expect that, with continued population growth and economic development, impacts to wetland will be most significant in the coastal states where economic growth is expected to be strongest, and where remaining wetlands are most widespread; thus demand for wetland mitigation will continue to be highest in the coastal states.

If the region follows the pattern seen in most of the eastern United States, mitigation needs will be greatest for forested wetlands, especially those supporting flood-tolerant hardwoods. Demand for mitigation of riparian wetlands, including cypress-tupelo swamps and mangroves will probably also be substantial, as construction of roads, utility lines, and other linear projects result in additional losses to riparian communities. Continued development of 
coastal areas will also drive ongoing needs for mitigation of tidal wetlands, especially saltmarshes.

Reconversion of agricultural lands to wetland has been less common in the Southeast than in the upper Midwest, where interest in providing breeding habitat for waterfowl has focused national attention. Nonetheless, opportunities for agricultural conversions exist, and have been exploited in the past. Whether such projects become more common in the future is likely to depend on development of appropriate incentives for landowner involvement. Opportunities for enhancement of forested wetlands may also exist if appropriate enhancement techniques and landowner incentives can be developed to induce appropriate investments by forest products industries.

Opportunities for inexpensive wetland projects should be greatest in states with a long history of agriculture and forestry where most current population growth is concentrated in a few major metropolitan areas. Historic wetland losses in Kentucky of over $80 \%$, with a relatively high proportion $(45.5 \%)$ of the state's land in active agriculture and relatively little $(4.7 \%)$ of it developed (Statistical Abstract of the United States 1992), suggest that restoration opportunities should be available there. While the coastal states have had somewhat lower wetland losses on a percentage basis, the total area of converted wetlands is substantial, and restoration opportunities are likely to be relatively widespread, especially on the coastal plain.

General construction costs throughout the southeast are typically below the national average because of relatively low regional labor costs. Even in the most rapidly growing areas of the southeast (Atlanta and northern Florida), labor costs for typical construction projects are $15 \%$ or more below the national average. In some southeastern cities, labor costs are less than two-thirds of the national average. Wetland creation and restoration efforts are typically labor-intensive processes, with labor accounting for approximately $60 \%$ of typical project costs. Thus, if labor rates are $20 \%-30 \%$ below national averages, overall project costs in the Southeast, all other things equal, may be $10 \%-20 \%$ below the national average.

Despite low labor costs, restoration and creation costs across the southeast vary above and below the national average, depending on the details of specific projects. On one extreme, restoration of freshwater nontidal wetland previously impacted by forestry or agriculture may be very inexpensive if little soil needs to be moved, and planting of trees and shrubs is limited. On the other hand, a mitigation project designed to compensate for destruction of a cypress-tupelo forest near an urban area may require extensive planting, complex hydrologic modeling, management for endangered species, and long-term monitoring and maintenance. One should expect more heterogeneity in wetland projects and costs in the southeast; because of the varied soils, hydrology, vegetation, and wildlife found in the region. 


\subsubsection{Analysis of Region-Specific Data}

\subsubsection{Primary Data}

Our primary database contains 26 projects from the southeastern United States. These projects were disproportionately from Florida (19), with a few projects in South Carolina and Georgia ( 2 and 5 projects, respectively). Projects represent a wide range of different project types, including tidal and nontidal wetlands, forested and emergent systems, aquatic beds, even mangrove restorations.

An analysis of covariance was used to determine whether wetland creation and restoration projects in our Primary Data from the Southeast differed significantly in cost from similar projects elsewhere in the country. They did. Overall wetland projects in the southeast are three times less expensive than projects from the remainder of the country (excluding agricultural conversions)

Primary Data: Southeast vs. Other Regions

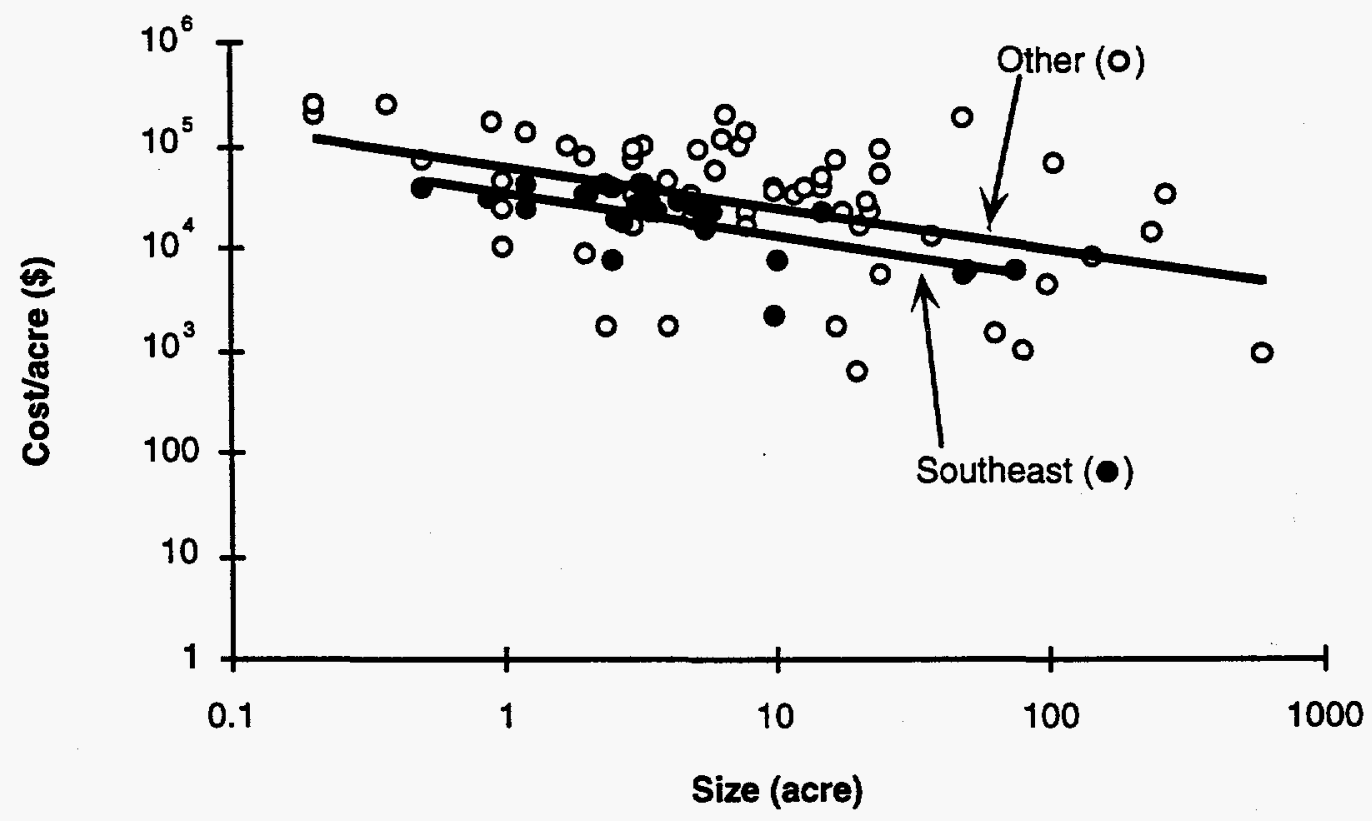

Figure 5.3. Primary data-Southeast.

\subsubsection{Secondary Data}

Fifty-one of the 397 projects in our Secondary database (excluding agricultural conversions) were from the Southeast. Most were from Mississippi, Georgia, or Florida $(17,14$, and 12 projects respectively, with the remainder from Alabama, (6 projects), North Carolina (1 project), and Tennessee ( 1 pro- 
ject). Of those, most (33) were creation projects, while 3 were enhancement projects, 3 were complex mixed projects, and 1 was a restoration project. We could not determine project type for 11 of the projects from this region. Projects from the southeast typically are slightly larger than projects from other regions of the country (Kruskal-Wallis test, $Z=2.10201, p=0.0356$ ).

We carried out an analysis of covariance to determine whether projects from the southeast were more or less expensive than projects from elsewhere in the country (ANCOVA table in Appendix A). Projects from the Southeast are typically less expensive than projects elsewhere in the country by approximately a factor of three (3.26). That is, wetland projects from the Southeast in our Secondary database are (on average) less than one-third as expensive as projects from other parts of the country. This conclusion is remarkably similar to the conclusions we drew from our Primary data, where regional projects were slightly less than a third as expensive as nationally.

\section{Secondary Data: Southeast vs. Other Regions}

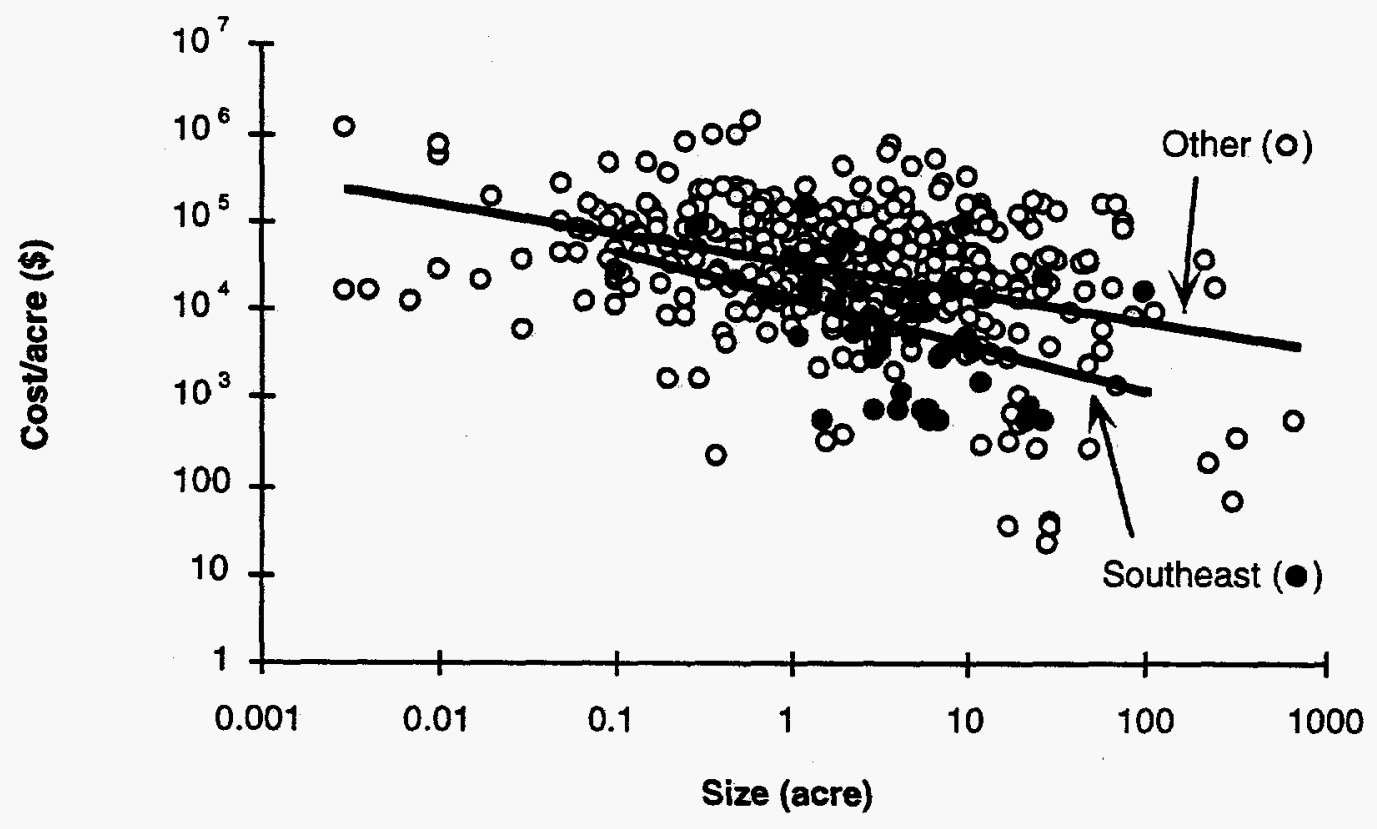

Figure 5.4. Secondary data-Southeast. 


\section{ACKNOWLEDGMENTS}

The research on which this report is based was carried out jointly with related research funded by the U.S. EPA, Office of Policy Analysis, and the U.S. Department of Transportation, Department of Environmental Quality. A number of wetland restoration experts were subcontracted to assist with this research by providing data and guidance and helping interpret statistical results . Significant contributions were made by subcontractors Edgar Garbisch and Mark Krause of Environmental Concern, Inc. (Maryland), Robin Lewis of Lewis Environmental Services, Inc. (Florida), John Reiger of Reiger and Associates (Southern California), Michael Josslyn of Wetland Research, Inc. (California), Bart Baca of Coastal Sciences, Inc. (Georgia), and Donald Hey of Wetland Research, Inc. (Illinois). Preliminary data collection and analysis were provided by University of Maryland research assistants, Patrick Hagan, Jennifer Stevens, and Barbara Wesley. Cooperation and data were provided by Washington and regional offices of federal agencies involved with wetlands and by state highway, environment and natural resource agencies in 44 states. Private organizations, especially Ducks Unlimited and the Nature Conservancy also data and insights about project characteristics. The principal authors of this report, Dennis M. King and Curtis C. Bohlen, take responsibility for all errors and omissions. 


\section{BIBLIOGRAPHY}

Bernstein, G., and R. L. Zepp, Jr. 1990. Evaluation of selected Wetland Creation Projects Authorized Through the Corps of Engineers Section 404 Program. U.S. Fish and Wildlife Service, Annapolis Field Office, Amnapolis, MD.

Conservation Foundation. 1988. Protecting America's Wetlands: An Action Agenda. The Final Report of the National Wetlands Policy Forum. The Conservation Foundation. Washington DC.

Cowardin, Lewis M., V. Carter , F, C. Golet, and E. T. LaRoe. 1979. Classification of Wetlands and Deepwater Habitats of the United States. FWS/OBS-79/31 Office of Biological Services, Fish and Wildlife Service. U.S. Government Printing Office.,Washington DC.

Crewz, D. W., and R. R. Lewis III. 1991. An Evaluation of Historical Attempts to Establish Emergent Vegetation in Marine Wetlands in Florida. Florida Sea Grant Technical Paper TP-60. Florida Sea Grant College, Univ. of Florida, Gainesville, FL.

Dahl, T. E. 1990. Wetland Losses in the United States 1780's to 1980's. U.S. Department of the Interior, Fish and Wildlife Service, Washington, DC, $21 \mathrm{pp}$.

Environmental Protection Agency and the Department of the Army. 1990. Memorandum. of Agreement Between the Environmental Protection Agency and the Department of the Army Concerning the Determination of Mitigation Under the Clean Water Act $\S$ 404(b)(1) Guidelines. June 6, 1990.

Erwin, K. L. 1991. An Evaluation of Wetland Mitigation within the South Florida Water Management District. South Florida Water Management District, West Palm Beach, FL.

Florida Department of Environmental Regulation. 1991. Report on the Effectiveness of Permitted Mitigation. Department of Environmental Regulation, Tallahassee, FL.

Forrestal, R. P. 1993. Statement by Robert P. Forrestal, President and Chief Executive Officer, Federal Reserve Bank of Atlanta before the Committee on Banking, Housing and Urban Affairs, U.S. Senate, March 10, 1993. As published in Federal Reserve Bulletin, May 1993.

Harvey, H. T., and M. N. Josselyn. 1986. Wetlands restoration and mitigation policies: comment. Environmental Management 10(5): 567-9.

Herbold, B., and P. B. Moyle. 1989. The Ecology of the Sacramento-San Joaquin Delta: A Community Profile. U.S. Fish and Wildlife Service Biological Report 85 (7.22). xi + 106 pp.

Josselyn, M. 1983. The Ecology of San Fransisco Bay Tidal Marshes: A Community Profile. U.S. Fish and Wildlife Service, Division of Biological Services, Washington DC. FWS/OBS-83/23. 102 pp. 
Kusler, J. A., and M. E. Kentula. 1989. Wetland Creation and Restoration: The Status of the Science.. U.S. Environmental Protection Agency. Washington, DC.

Minshal, G. W., S. E. Jensen, and W. S. Platts. 1989. The Ecology of Stream and Riparian Habitats of the Great Basin Region: A Community Profile. U.S. Fish and Wildlife Service Biological Report 85(7.24). 142 pp.

National Research Council. 1992. Restoration of Aquatic Ecosystems: Science, Technology, and Public Policy. National Academy Press. Washington, DC.

Odum, W. E., T. J. Smith, III, J. K. Hoover, C. C. McIvor. 1984. The Ecology of Tidal Freshwater Marshes of the United States East Coast: A Community Profile. U.S. Fish and Wildlife FWS/OBS83/17. 177 pp.

Race, M. S. 1985. Critique of present wetlands mitigation policies in the United States based on an analysis of past restoration projects in San Francisco Bay. Environmental Management 9(1): 71-82.

Smit, K., and P Waier, eds. 1991. Means Landscape Cost Data. Kingston, MA: R. S. Means Co.

Turner, R. E. 1992. Coastal Wetlands and penaeid shrimp habitat. In Stemming the Tido of Coastal Fish HAbitat Loss, ed. Richard H. Stroud. Marine Recreational Fisheries 14. National Coalition for Marine Conservation, Inc. Savannah, GA.

U.S. Department of Commerce. 1992. Statistical Abstract of the United States 1992. Bernan Press, Lanham, MD.

Want, W. L. 1993. Law of Wetlands Regulation. Release \#4. Clark Boardman Callaghan. Deerfield IL.

Wiegert and Freeman. 1990. Tidal Saltmarshes of the Southeast Atlantic Coast: A Community Profile. U.S. Fish and Wildlife Service Biological Report 85(7.29). 


\section{APPENDICES}




\section{Appendix A: Analysis of Covariance Tables}

The following analysis of covariance tables provide statistical details for the conclusions presented in Chapter 2.0 of the main text. All analyses were performed on $\log _{10}$-transformed data. The tables show partial sums of square and $\mathrm{F}$ ratios, testing the hypothesis that the particular source of variation is associated with more of the variability in cost among projects than can be accounted for by chance.

Table A.1. Analysis of Covariance for Primary Data

\begin{tabular}{|c|c|c|c|c|c|}
\hline \multicolumn{6}{|l|}{ ANCOVA Table } \\
\hline Source & DF & $\begin{array}{l}\text { Sum of } \\
\text { Squares }\end{array}$ & $\begin{array}{l}\text { Mean } \\
\text { Square }\end{array}$ & F Ratio & Prob $>F$ \\
\hline $\log (\operatorname{Size})$ & 1 & 0.9383 & 0.9383 & 4.4075 & 0.0393 \\
\hline Wetland Type & 7 & 3.1219 & 0.4460 & 2.0951 & 0.0551 \\
\hline Project Type & 2 & 2.6330 & 1.3165 & 6.1843 & 0.0033 \\
\hline Cre./Rest. vs Enhnc. & 1 & 2.6318 & 2.6318 & 12.3631 & 0.0008 \\
\hline Create vs Restore & 1 & 0.0042 & 0.0042 & 0.0198 & 0.8885 \\
\hline Log(Size)*Project Type & 2 & 1.3026 & 0.6513 & 3.0595 & 0.0531 \\
\hline Model & 12 & 12.0979 & 1.0081 & 4.7359 & 0.0000 \\
\hline Error & 71 & 15.1146 & 0.2129 & & \\
\hline Total & $83^{*}$ & 27.2123 & & & \\
\hline \multicolumn{6}{|l|}{ Parameter Estimates } \\
\hline & & Std Error & $\begin{array}{l}\text { Least Sq. } \\
\text { Mean }\end{array}$ & Std Error & $\mathbf{N}$ \\
\hline Creation & & 0.10721 & 4.3742 & 0.08744 & \\
\hline Enhancement & & 0.24937 & 3.7452 & 0.17701 & \\
\hline Restoration & & 0.12848 & 4.2788 & 0.09211 & \\
\hline
\end{tabular}


Table A.2. Analysis of Covariance on the Secondary Data, Comparing Agricultural Conversions with all Other Projects

\begin{tabular}{|c|c|c|c|c|c|}
\hline \multicolumn{6}{|l|}{ ANCOVA Table } \\
\hline Source & $\mathrm{DF}$ & $\begin{array}{l}\text { Sum of } \\
\text { Squares }\end{array}$ & $\begin{array}{l}\text { Mean } \\
\text { Square }\end{array}$ & F Ratio & Prob $>F$ \\
\hline $\log _{10}$ (acres) & 1 & 23.051 & 23.051 & 52.061 & 0.0000 \\
\hline Ag. Status & 1 & 239.244 & 239.244 & 540.339 & 0.0000 \\
\hline Ag. Status ${ }^{*} \log ($ acres $)$ & 1 & 11.345 & 11.345 & 25.624 & 0.0000 \\
\hline Model & 3 & 688.041 & 229.347 & 517.984 & 0.0000 \\
\hline Error & 878 & 388.750 & 0.443 & & \\
\hline C Total & 881 & 1076.792 & & & \\
\hline \multicolumn{6}{|l|}{ Parameter Estimates } \\
\hline & Slope & Std Error & $\begin{array}{l}\text { Least Sq. } \\
\text { Mean }\end{array}$ & Std Error & $N$ \\
\hline $\begin{array}{l}\text { Ag Conversion } \\
\text { Other }\end{array}$ & $\begin{array}{l}-0.06279 \\
-0.35798\end{array}$ & $\begin{array}{l}0.04471 \\
0.03744\end{array}$ & $\begin{array}{l}2.67410 \\
4.17241\end{array}$ & $\begin{array}{l}0.03619 \\
0.03912\end{array}$ & $\begin{array}{l}485 \\
387\end{array}$ \\
\hline
\end{tabular}

Table A.3. Analysis of Covariance on the Secondary Data, Omitting Agricultural Conversions

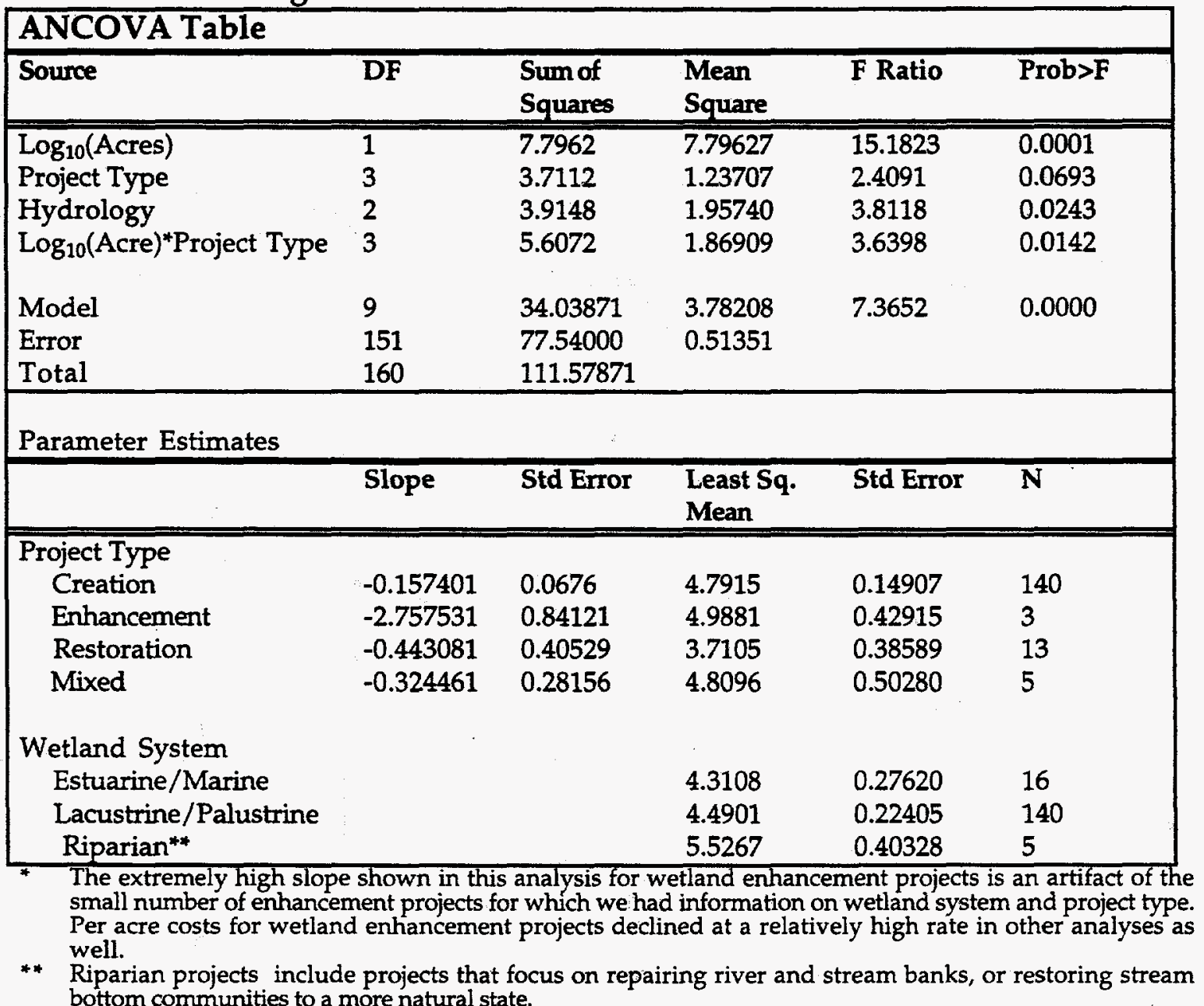


Table A.4. Analysis of Covariance for the Secondary Data (Omitting Agricultural Conversions), Reduced Model

\begin{tabular}{|c|c|c|c|c|c|}
\hline \multicolumn{6}{|c|}{ ANCOVA Table } \\
\hline Source & DF & $\begin{array}{l}\text { Sum of } \\
\text { Squares }\end{array}$ & $\begin{array}{l}\text { Mean } \\
\text { Square }\end{array}$ & F Ratio & Prob $>F$ \\
\hline $\log$ (Acres) & 1 & 13.8270 & 13.8270 & 27.2307 & 0.0000 \\
\hline Project 2 & 3 & 2.8677 & 0.9559 & 1.8826 & 0.1321 \\
\hline Project ${ }^{*} \log$ (Acre & 3 & 5.2751 & 1.7583 & 3.4629 & 0.0165 \\
\hline Model & 7 & 63.5650 & 9.0807 & 17.8834 & 0.0000 \\
\hline Error & 359 & 182.2906 & 0.5077 & & \\
\hline \multirow[t]{2}{*}{ C Total } & 366 & 245.8557 & & & \\
\hline & Slope & Std Error & $\begin{array}{l}\text { Least Sq. } \\
\text { Mean }\end{array}$ & Std Error & $\mathbf{N}$ \\
\hline \multicolumn{6}{|l|}{ Project Type } \\
\hline Creation & -0.242127 & 0.04784 & 4.446027711 & $\begin{array}{l}0.040940308 \\
5\end{array}$ & \\
\hline Enhancement & -0.649531 & 0.14003 & 3.920265920 & $\begin{array}{l}0.147056387 \\
7\end{array}$ & \\
\hline Mixed & -0.381426 & 0.24257 & 4.477403264 & $\begin{array}{l}0.242684024 \\
0\end{array}$ & \\
\hline Restoration & -0.701555 & 0.24991 & 4.089342538 & $\begin{array}{l}0.313474831 \\
5\end{array}$ & \\
\hline
\end{tabular}

Table A.5. Analysis of Covariance Comparing Costs from the Primary and Secondary Data

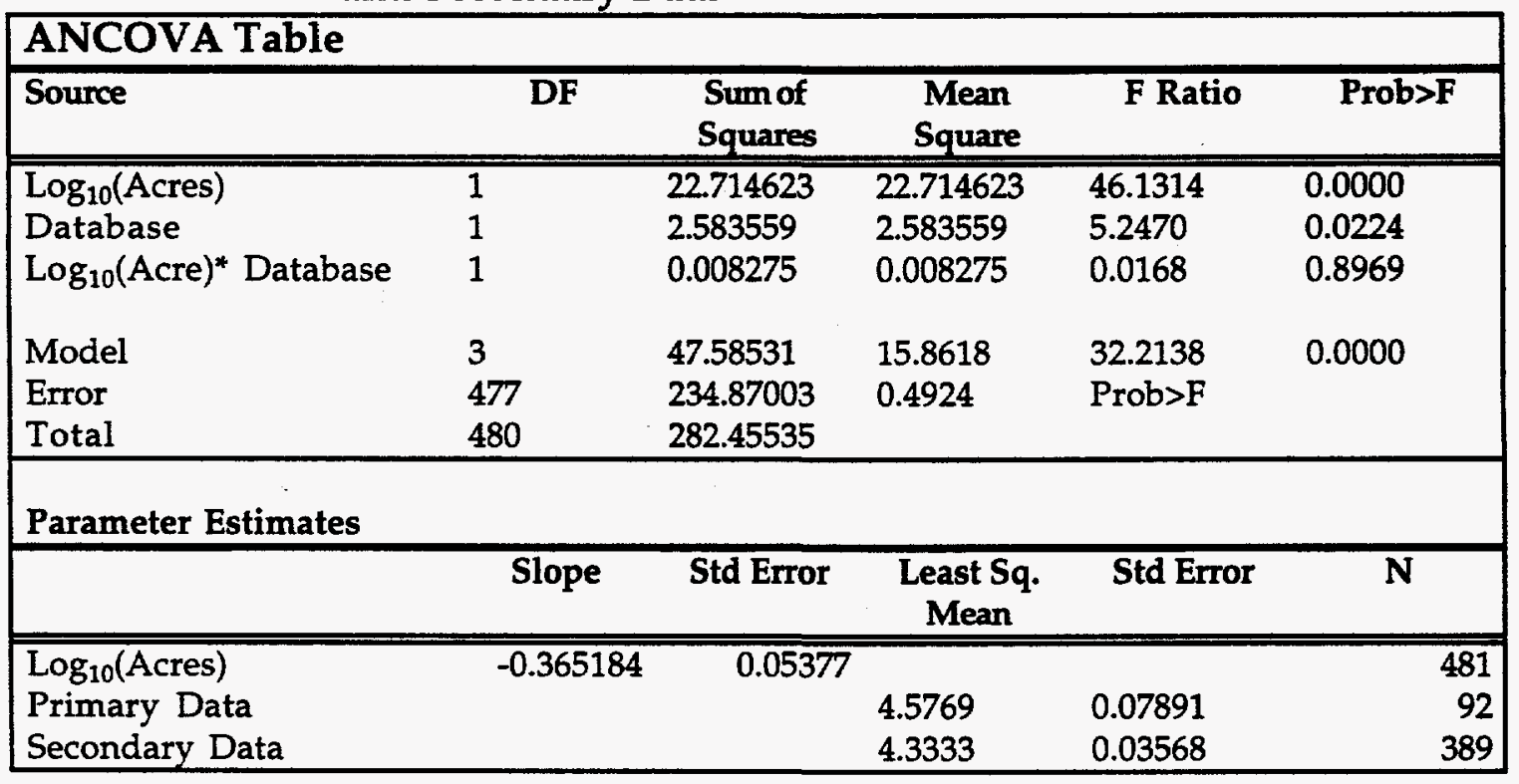


Table A.6. Analysis of Covariance for Comparison on the Primary Data Comparing Southwestern Wetland Projects and Projects from other Regions of the Country

\begin{tabular}{|c|c|c|c|c|c|}
\hline \multicolumn{6}{|l|}{ ANCOVA Table } \\
\hline Source & DF & $\begin{array}{l}\text { Sum of } \\
\text { Squares }\end{array}$ & $\begin{array}{l}\text { Mean } \\
\text { Square }\end{array}$ & F Ratio & Prob $>F$ \\
\hline $\log _{10}$ (Acres) & 1 & 7.0745352 & 7.0745352 & 29.4279 & 0.0000 \\
\hline Region & 1 & 1.4014807 & 1.4014807 & 5.8297 & 0.0179 \\
\hline Log10(Acre)* Region & 1 & 0.2140059 & 0.2140059 & 0.8902 & 0.3481 \\
\hline Model & 3 & 7.807924 & 2.60264 & 10.8262 & 0.0000 \\
\hline Error & 84 & 20.193814 & 0.24040 & & \\
\hline Total & 87 & 28.001738 & & & \\
\hline \multicolumn{6}{|l|}{ Parameter Estimates } \\
\hline & Slope & Std Error & $\begin{array}{l}\text { Least Sq. } \\
\text { Mean }\end{array}$ & Std Error & $\mathbf{N}$ \\
\hline $\begin{array}{l}\text { Log10(Acres) } \\
\text { Southwestern } \\
\text { Other }\end{array}$ & & & $\begin{array}{l}4.6174 \\
4.3074\end{array}$ & $\begin{array}{l}0.09386 \\
0.06475\end{array}$ & \\
\hline
\end{tabular}

Table A.7. Analysis of Covariance for the Secondary Data Comparing Southwestern Wetland Projects and Projects from other Regions of the Country

\begin{tabular}{|c|c|c|c|c|c|}
\hline \multicolumn{6}{|l|}{ ANCOVA Table } \\
\hline Source & DF & $\begin{array}{l}\text { Sum of } \\
\text { Squares }\end{array}$ & $\begin{array}{l}\text { Mean } \\
\text { Square }\end{array}$ & F Ratio & Prob $>F$ \\
\hline $\log _{10}$ (Acres) & 1 & 12.280460 & 12.280460 & 22.5736 & 0.0000 \\
\hline Region & 1 & 1.062403 & 1.062403 & 1.9529 & 0.1631 \\
\hline $\log _{10}(\text { Acre })^{*}$ Region & 1 & 0.155829 & 0.155829 & 0.2864 & 0.5928 \\
\hline Model & 3 & 41.88826 & 13.9628 & 25.6659 & 0.0000 \\
\hline Error & 393 & 213.79980 & 0.5440 & & \\
\hline Total & 396 & 255.68806 & & & \\
\hline \multicolumn{6}{|l|}{ Parameter Estimates } \\
\hline & Slope & Std Error & $\begin{array}{l}\text { Least Sq. } \\
\text { Mean }\end{array}$ & Std Error & $\mathbf{N}$ \\
\hline $\begin{array}{l}\log _{10} \text { (Acres) } \\
\text { Southwestern } \\
\text { Other }\end{array}$ & & & $\begin{array}{l}4.5686 \\
4.3468 \\
\end{array}$ & $\begin{array}{l}0.13624 \\
0.03946\end{array}$ & \\
\hline
\end{tabular}


Table A.8. Analysis of Covariance Based on the Primary Data Comparing Southeastern Wetland Projects and Projects from other Regions of the Country

\begin{tabular}{|c|c|c|c|c|c|}
\hline \multicolumn{6}{|c|}{ ANCOVA Table } \\
\hline Source & DF & $\begin{array}{l}\text { Sum of } \\
\text { Squares }\end{array}$ & $\begin{array}{l}\text { Mean } \\
\text { Square }\end{array}$ & F Ratio & Prob $>$ F \\
\hline$\overline{\log (\text { Size })}$ & $\overline{1}$ & 7.5576 & 7.5576 & 37.0243 & 0.0000 \\
\hline Project 2 & 2 & 3.8196 & 1.9098 & 9.3560 & 0.0002 \\
\hline Region 4 Flag & 1 & 2.8030 & 2.8030 & 13.7319 & 0.0004 \\
\hline Model & 4 & 10.9833 & 2.7458 & 13.4516 & 0.0000 \\
\hline Error & 82 & 16.7383 & 0.2041 & & \\
\hline C Total & 86 & 27.7216 & & & \\
\hline \multicolumn{6}{|c|}{ Parameter Estimates } \\
\hline & Slope & Std Error & $\begin{array}{l}\text { Least Sq. } \\
\text { Mean }\end{array}$ & Std Error & $\mathbf{N}$ \\
\hline $\log _{10}$ (Acres) & -0.45207 & 0.0743 & & & \\
\hline SouthEastern & & & 3.9485 & 0.11214 & \\
\hline Other & & & 4.3951 & 0.06398 & \\
\hline Creation & & & 4.5006 & 0.06929 & \\
\hline Enhanced & & & 3.7914 & 0.15439 & \\
\hline Restored & & & 4.2233 & 0.09070 & \\
\hline
\end{tabular}

Note: no estimable interaction terms were statistically significant, so they were omitted from the analysis.

Table A.9. Analysis of Covariance Based on the Secondary Data for Comparison of Southeastern Wetland Projects and Projects from other Regions of the Country

\begin{tabular}{|c|c|c|c|c|c|}
\hline \multicolumn{6}{|c|}{ ANCOVA Table } \\
\hline Source & DF & $\begin{array}{l}\text { Sum of } \\
\text { Squares }\end{array}$ & $\begin{array}{l}\text { Mean } \\
\text { Square }\end{array}$ & F Ratio & Prob>F \\
\hline Region 4 Flag & 1 & 11.623330 & 11.623330 & 22.4937 & 0.0000 \\
\hline $\log$ (Acres) & 1 & 35.991754 & 35.991754 & 69.6521 & 0.0000 \\
\hline Model & 2 & 52.09404 & 26.0470 & 50.4068 & 0.0000 \\
\hline Error & 394 & 203.59401 & 0.5167 & & \\
\hline C Total & 396 & 255.68806 & & & \\
\hline \multicolumn{6}{|c|}{ Parameter Estimates } \\
\hline & Slope & Std Error & $\begin{array}{l}\text { Least Sq. } \\
\text { Mean }\end{array}$ & Std Error & $\mathbf{N}$ \\
\hline Log(Acres) & -0.339207 & 0.04064 & & & \\
\hline Southeast & & & 4.4332 & 0.03866 & 51 \\
\hline Other & & & 3.9194 & 0.10107 & 345 \\
\hline
\end{tabular}

Note: A non-significant interaction terms was omitted from the model. We chose to exclude project type from this analysis because we had so few restoration and enhancement projects in our data for the southeast. 
Appendix B: Making Sense of Wetland Restoration Costs

\section{Making Sense of Wetland Restoration Costs}

Dennis M. King and Curtis C. Bohlen

University of Maryland

Center for Environmental and Estuarine Studies

P.O. Box 38, Solomons, Maryland 20688

January 1994

Research funded under:

Department of Energy Contract No. DE-AC22-92MT92006,

Project No. 22-92MT 92006.000

with

University of Maryland,

Center for Environmental and Estuarine Studies

Additional funding provided by

U.S. EPA and the Dept. of Transportation 


\section{INTRODUCTION}

\section{The Problem}

Misunderstandings about the cost of wetland restoration projects are widespread and are having an adverse impact on U.S. wetland policy. ${ }^{2}$ Determining the most effective regulatory strategies for controlling the development of wetlands and the best allocation of public funds to restore wetlands and watersheds both require a basic understanding of wetland restoration costs. Making informed private and public investment decisions about projects that may require wetland mitigation also calls for reliable wetland restoration cost data. Unfortunately, the most widely available data on costs of wetland restoration tend to understate the cost of designing and implementing restoration projects that have a reasonable chance of success. This paper explains why misperceptions about restoration costs persist, and provides baseline point and range estimates of restoration costs for various types of wetlands.

\section{The Source of the Problem}

It is no more useful to focus on the average cost of restoring an acre of wetland than to focus on the average cost of restoring a damaged automobile. As a practical matter, costs depend on what is being restored; how badly it is damaged; and how fast, how perfect, and how permanent the repair needs to be. The wetland restoration cost data gathered for the research described here, for example, ranged from $\$ 5$ per acre to $\$ 1.5$ million per acre. Some cost differences result because of the wide range of restoration projects that are undertaken, but site-specific differences can result in significant cost differences even for apparently similar projects.

As with automobiles, however, cost estimating problems can be overcome by grouping wetlands and wetland restoration projects according to structural characteristics that affect restoration cost, and by adjusting the baseline cost estimates for each group using simple indicators of site conditions (e.g., dry or wet, hilly or flat, urban or rural, on-site or off-site disposal of spoil, union or non-union labor).

2. We refer in this paper to wetland restoration. The analysis on which the paper is based, however, dealt with a mix of case studies that included some wetland creation and wetland enhancement projects. For a discussion of technical differences, see Lewis, R. R. 1989. Wetlands Restoration/Creation/Enhance-ment Terminology: Suggestions for Standardization, 1-7 In Wetland Creation and Restoration: The Status of the Science., Volume II: Perspectives (EPA/600/3-89/038), eds. J. A. Kusler and M E. Kentula. Corvalis, OR.: Environmental Protection Agency, Environ-mental Research Laboratory. 
Unfortunately, generally available data on the cost and performance of wetland restoration and creation efforts do not result from analyses that can easily account for these project-specific, site-specific, and wetland-specific differences. The available data come predominately from two sources which for entirely different reasons are both misleading in the sense that they understate the cost of restoring wetlands.

The most reliable and widely circulated sources of restoration cost data are generated by federal agencies involved in programs to restore converted agricultural lands back to wetlands. ${ }^{3}$ These projects usually involve restoring altered hydrology (e.g., breaking drainage tiles or filling ditches) which is inexpensive and usually successful. However, these projects, although important, are not representative of more difficult projects aimed at restoring structurally and biologically more complex wetlands outside the farm belt. Nor do they reflect the problems associated with the restoration and creation of wetlands in urban and suburban landscapes where wetland losses and the associated needs for mitigation are the greatest.

A second potential source of information about the costs of wetland restoration is the nearly 20-year record of wetland creation and restoration projects undertaken as mitigation for wetland impacts regulated under Section 404 of the Clean Water Act. ${ }^{4}$ Relatively little has been reported about the costs or effectiveness of these mitigation projects, but what is available reveals a persistent pattern of low cost and poor success rates. This record, however, reflects more about institutional inadequacies and the failure of mitigation policies than the cost or difficulty of designing and implementing high quality wetland restoration projects. It is the result of perverse incentives in the market for restored and created wetlands that has developed over the last two decades to serve the mitigation needs of Section 404 permit seekers. ${ }^{5}$ This

3. These programs were designed to encourage the conversion of marginal agricultural land to wetland. The USDA Water Bank Program was implemented in 1972 and covers 509,000 acres. A similar Department of the Interior Program, the Small Wetlands Acquisition Program, covers 1.2 million acres. The 1990 Farm Bill established a Wetland Reserve Program with the goal of restoring one million acres of wetland by 1995. The Fish and Wildlife Service also targets wetland creation and restoration through the Private Lands Program and Wildlife Extension Agreements.

4. Under a 1990 agreement between EPA and the Army Corps of Engineers, a process called "sequencing" was established that requires permit seekers to avoid wetland impacts if there is an alternative, minimize impacts where they are unavoidable, and mitigate for residual wetland losses through "compensatory actions such as the restoration of existing wetlands or the creation of man-made wetlands." Current regulations favor on-site and in-kind wetland mitigation.

5. The term "perverse incentive" is used in economics to refer to situations where decision makers are rewarded for exhibiting undesirable behavior, or penalized for exhibiting desirable behavior. In the mitigation market, mitigation suppliers earn high profits by providing low quality restoration and low profits by providing high quality restoration. 
market has, almost from the beginning, provided rewards for low cost, not high quality restoration. For purposes of our analysis, this situation created a problem. The cost data drawn from records of mitigation projects have a significant downward bias and tend not to reflect the costs of completing high quality or even medium quality restoration projects.

\section{Research Objectives}

The research summarized here was designed to overcome the problems with generally available restoration cost data and provide reliable estimates of the costs of designing and implementing wetland restoration projects with a reasonable commitment to both cost and performance.

The preliminary empirical results presented here include point estimates and typical ranges of per-acre costs for nine different categories of wetland restoration projects. ${ }^{6}$ The categories were developed on the basis of wetland characteristics that affect the tasks required to achieve restoration success; not on the basis of wetland functions and values. In this sense they are categories of project types, not categories of wetlands per se. The cost estimates were developed to provide an economic and statistical basis for improving wetland mitigation policy and for assessing how wetland restoration might contribute to the achievement of wetland, floodplain, and watershed goals.

6. The nine categories of wetland projects reflect (1) whether or not the project is a (non-regulatory) agricultural conversion, and (2) the hydrology and vegetation structure of the wetland being restored. The project categories include (1) Aquatic Beds-tidal or nontidal communities of permanently or nearly permanently submerged plants; (2) Complex Projects incorporating three or more wetland types in a single project; (3) Freshwater mixed projects, consisting of nontidal projects in which both forested and emergent vegetation is produced; (4) Freshwater, nontidal projects establishing forested wetlands; (5) Freshwater, nontidal projects establishing emergent wetlands; (6) Projects producing tidal freshwater wetlands; (7) Projects establishing saltmarshes and other marine or estuarine wetlands dominated by emergent vegetation, (8) Projects establishing mangrove communities; and (9) Agricultural Conversions. 


\section{THE RESEARCH APPROACH}

During 1993 we collected wetland restoration cost data for approximately 1,000 separate projects including 90 projects for which we conducted detailed cost analysis (primary data) and 900 projects for which cost data were obtained from other sources (secondary data). We standardized all costs in 1993 dollars; classified and aggregated projects on the basis of location, site characteristics, wetland type, and project objectives; and used the results to develop preliminary cost-per-acre estimates for each of our nine project categories.

\section{Summary of Primary Data}

We developed our primary cost data using detailed engineering and cost accounting profiles. ${ }^{7}$ These were developed in collaboration with leading wetland restoration experts from around the U.S. and were based on the input requirements (e.g., labor, equipment, materials) necessary to complete specific tasks at various project stages (e.g., preconstruction, construction, postconstruction) and the unit costs (e.g., wages, rents, prices) associated with them. Project profiles were developed based on well-designed restoration and creation projects, and costs per task and overall costs were developed by estimating input requirements for each essential task and applying standard unit costs. Hypothetical variations in site and project characteristics were used in some cases to determine how engineering requirements and costs change under differing site conditions (e.g., variations in soil, slope, access, and hydrology, or the presence of an endangered species).

\section{Summary of Secondary Data}

We also collected cost records for individual wetland creation, restoration, and enhancement projects from published and unpublished reports, the general trade literature, and county, state, and federal databases. ${ }^{8}$ These records varied with respect to the degree of detail regarding site and project characteristics, but all included information about the general location of the project, project size, and aggregate project cost. We believe this to be the

7. The approach used to characterize projects in terms of preconstruction, construction, and postconstruction tasks and to estimate input requirements and associated costs was described in King, D., (1992). The economics of ecological restoration. In Natural Resource Damage Assessment: Law and Economics, eds. J. Duffield and K. Ward. New York: Wiley.

8. Our database includes examples of wetland creation, restoration, and enhancement, as well as construction of wetlands for water quality improvement, waterfowl habitat, and for other purposes. Approximately half of all records are for restoration or creation of wetlands on agricultural lands outside of a mitigation context. Over $95 \%$ of the cases in the remaining half of the database are mitigation projects. Three-quarters of them were mitigation of road or highway impacts to wetlands. 
largest and most comprehensive wetland restoration cost database in the world. However, for reasons that will be described later, we believe that it suffers from the same limitations as most other generally available restoration cost data and provides a poor basis for understanding the economics of wetland restoration.

\section{Special Data Limitations}

The secondary data includes cost estimates and cost records for some restoration projects that were undertaken outside of a strictly agricultural or mitigation context. These projects fall under two general categories: (1) wetland construction and restoration projects designed to improve water quality (e.g., treat sewage, storm water, farm runoff, and acid mine drainage), and (2) voluntary projects to create or restore specific wetland functions (e.g., duck habitat). ${ }^{9}$ Costs of constructed wetlands designed to improve water quality were well within the range of costs of wetlands created or restored for mitigation. However, because siting, design, and construction decisions for these projects were directed exclusively at waste treatment, we considered them to be a special case and have not analyzed them further.

The cost records for voluntary projects, even where they might have been useful, were also of limited value. Cost records and descriptions for those projects were often incomplete. In fact, because the cost estimates for projects that use volunteers often exclude the opportunity cost of contributed labor and other "in kind" contributions, they may add to the problem of under-reported costs.

\section{Other Problems}

Our secondary database contained a few records of exceptionally high costs, including one case of restoration costs near $\$ 1.5$ million per acre. However, further investigation revealed that unusually high costs were usually pushed up by extremely small project size (under one-half acre) or by extraordinary conditions at the restoration site (e.g., the need to blast through granite to attain an acceptable elevation). In many cases the selection of extraordinary sites appears to have been the result of regulatory decisions, in particular, the regulatory preference for on-site rather than off-site mitigation. There are many reasons why on-site mitigation might be preferred to off-site mitigation, and we did not compare on-site and off-site alternatives to determine if there were significant cost differences. However, there were clearly

9. For a detailed discussion of constructed wetlands for wastewater treatment, see Hammer, D. A., ed. 1989. Constructed Wetlands For Wastewater Treatment. Chelsea, MI: Lewis. For a discussion of projects designed to achieve broader water quality objectives, see Moshiri, G. A., ed. 1993. Constructed Wetlands for Water Quality Improvement. Boca Raton, FL. 
cases where high levels of spending in restoration would been better invested if siting decisions were based on a search for more favorable locations from the perspective of improving wetland or watershed functions rather than strictly adhering to the regulatory preference for on-site mitigation.

There were two other noteworthy sources of upward bias associated with high cost projects in our secondary database. The providers of cost data for some of these projects were unable to distinguish between restoration costs and the costs of earth moving, landscaping, and other tasks associated with the construction project that resulted in the need for mitigation; this was especially true for highway expansion projects. In other cases, it was impossible for providers of cost data to distinguish between restoration costs and the costs of engaging in the wetland permitting process itself; this was especially true for large complex projects and mitigation banks. Ironically, these sources of upward cost bias contributed to our decision to base our cost estimates primarily on an analysis of our own primary data rather than the larger secondary database.

In the final analysis, we chose to downplay the empirical record associated with historical mitigation projects (the secondary database) and relied primarily on the cost profiles we developed ourselves (the primary database). The reasons why we made this decision may be more important for understanding the economics of wetland restoration than the actual cost estimates that resulted from our research.

\section{Reinterpreting the Dismal Record}

Recent surveys confirm that restoration projects undertaken to meet mitigation requirements under Section 404 of the Clean Water Act have had extraordinarily high failure rates, over $50 \%$ in Florida, California, and the mid Atlantic states. ${ }^{10}$ These high failure rates are often used as evidence that

10. Several reports on the rate of successful wetland mitigation are now available. (1) Bernstein, G. and R. L. Zepp, Jr. 1990. Evaluation of selected wetland creation projects authorized through the Corps of Engineers Section 404 Program. U.S. Fish and Wildlife Service, Annapolis Field Office, Annapolis, MD; (2) Florida Department of Environmental Regulation. 1991. Report on the Effectiveness of Permitted Mitigation. Department of Environmental Regulation, Tallahassee, FL; (3) Erwin, K. L. 1991. An Evaluation of Wetland Mitigation within the South Florida Water Management District. South Florida Water Management District, West Palm Beach, FL; (4) Crewz, D. W. and R. R. Lewis III. 1991. An Evaluation of Historical Attempts to Establish Emergent Vegetation in Marine Wetlands in Florida. Florida Sea Grant Technical Paper TP-60. Florida Sea Grant College, Univ. of Florida, Gainesville, FL; (5) Race, M. S. 1985. Critique of present wetlands mitigation policies in the United States based on an analysis of past restoration projects in San Francisco Bay. Environmental Management 9 (1): 71-82. Some care must be used in interpreting these studies because "success" has been defined in disparate ways (see Harvey, H. T. and M. N. Josselyn. 1986. Wetlands restoration and mitigation policies: comment. 
restoration science is failing. What is rarely reported with the evidence of mitigation failure, however, is the fact that in many cases, the causes of these failures are known-bad plans, poor execution, lack of follow-up, and so on. In fact, in both Florida and the Mid-Atlantic region, many historical mitigation "failures" occurred because planned projects were never undertaken ( $34 \%$ and $16 \%$ of projects examined, respectively). Analyzing the records of projects that were undertaken reveals a similar lack of commitment. For example, at some sites once one excluded the cost of land and the cost of engaging in the 404 permitting process itself, the amount of money devoted to actual restoration activities (e.g., hydrological testing, earth moving, planting) was as low as a few hundred dollars per acre. In general, the records of low costs and high failure rates are two sides of the same coin and reveal less about the state of restoration science than the motivation of those providing restoration.

\section{Underlying Incentives}

The historical record of wetland restoration projects has been influenced to a significant extent by the fact that providing wetland restoration is not only an applied science, but a business. With few exceptions those who design and implement wetland restoration projects earn their livelihoods satisfying the needs of permit seekers involved in the Section 404 wetland permitting program. This mitigation market is driven primarily by demand for low cost permits, not the production of high quality wetlands. There are undoubtedly technical limits to what restoration science can achieve, but high failure rates have more often been the result of underfunded, badly planned, and poorly executed restoration efforts than the result of outright technical failure. These weak efforts are linked directly to the perverse incentive structure that evolved in the mitigation market that served the needs of Section 404 permit seekers.

\section{Institutional or Market Failure}

It would be easy to blame poor incentives and mitigation failure on the wetland mitigation market itself. However, the mitigation market, like most markets, was, in fact, extremely effective at providing what was in demandlow cost mitigation. What was extraordinary about this market was that buyers (permit seekers) and sellers (mitigation suppliers) had strong incentives to be price conscious but hardly any reason to be quality conscious. Apparently, the regulators, who provide the only quality control in the market, did not exercise enough authority to link mitigation results with permit decisions.

Environmental Management 10 (5) 567-9, and Kusler, J. A. and M. E. Kentula. 1989. Wetland Creation and Restoration: The Status of the Science). 
Without such a link, those demanding and supplying mitigation had little incentive to spend what was necessary to provide high quality restoration; thus low costs and high failure rates. This basic problem was exacerbated by (1) the fact that until recently permit approval sometimes depended only on a promise, often unsecured, to provide mitigation, and (2) the fact that enforcement actions to ensure that permitees complied with mitigation agreements were rare.

For purposes of cost analysis the important point is that cost records of past mitigation projects generally reflect the cost of low quality projects and therefore offer a biased perspective. However, as more attention is given to the use of incentive-based and market-based strategies for achieving wetland and other environmental goals, there may be more important lessons to be learned from this example of how and why environmental trading systems can fail to achieve hoped-for results. ${ }^{11}$

11. The hope that mitigation banking will improve the success of wetland mitigation is an important example. The role of regulations in establishing the trading rules and incentives for trade in wetland mitigation banks, and the resulting effects on mitigation decisions are described in Shabman, L., P. Scodari, and D. King. 1994. Expanding Opportunities for Successful Wetland Mitigation: The Private Credit Market Alternative. Report prepared for the U.S. Army Corps of Engineers Water Resources Institute, Fort Belvoir, VA. 


\section{BASELINE COST ESTIMATES}

\section{Typical Costs Per Acre}

Figure 1 displays estimates of wetland restoration costs (excluding land costs) for various project categories ${ }^{12}$. Figure 2 provides a more detailed breakdown of agricultural conversion projects. Table 1 provides numerical cost estimates and shows the allocation of costs by construction stage (preconstruction, construction, and post-construction) and by input category (labor, equipment, material, and other).

\section{Economies of Scale}

There are significant fixed costs associated with all but the most simple kinds of restoration projects. As a result the cost-per-acre for relatively small restoration projects (e.g., plantings to reduce shoreline erosion) can be exceptionally high while the cost-per-acre for large scale projects (e.g., removing water control devices to flood large areas) can be relatively low. However, in many cases the differences in per-acre-costs between large and small projects reflect differences in the types of projects undertaken as well as economies of scale.

Until we further evaluate the relationships between project size and project type, our preliminary indicators of economies of scale should be used with caution. However, Figure 3a illustrates that an inverse relationship does seem to exist between cost per acre and project size for wetland mitigation projects in the primary database, and Figure $3 b$ illustrates that a similar relationship exists in the secondary database. To the extent that the downward bias in project costs in the secondary data is consistent across project sizes, the economies of scale exhibited by the secondary data are still meaningful.

A preliminary analysis of the primary database suggests that for each $10 \%$ increase in project size, costs per acre for non-agricultural projects decline by $3.5 \%$. An analysis of the larger secondary database revealed a remarkably similar decline of $3.1 \%$ in costs per acre for each $10 \%$ increase in project size. Economies of scale for agricultural conversion projects are significantly lower with costs-per-acre declining by only $.6 \%$ for each $10 \%$ increase in project size.

12. Cost estimates for agricultural conversions are based on our secondary data, all other estimates are based on the primary data. 


\section{Cost and Performance}

We developed our cost estimates on the basis of engineering designs and construction specifications with reasonably high likelihoods of meeting restoration targets, and gave adequate attention to pre-construction research and post-construction monitoring and maintenance. For now, however, we make no claim as to the likely success of projects in any category or how project success should be measured. A previous report by the authors develops a framework for evaluating cost-performance relationships and making quality-quantity tradeoffs when evaluating wetland restoration alternatives. ${ }^{13}$ Another report linking cost information with specific restoration design characteristics and weak and strong success criteria for various kinds of wetland restoration is forthcoming in early $1994 .{ }^{14}$

13. See King, D. C., C. Bohlen, and K. J. Adler. 1993. Watershed Management and Wetland Mitigation: A Framework for Determining Compensation Ratios. A report prepared for the EPA, Office of Policy, Planning, and Evaluation. Washington, DC.

14. Weak success criteria may include achieving a wetland designation based on federal delineation criteria, or achieving a given level of vegetative cover after a specified period of time. Strong criteria may include maintaining a population of specific target species, achieving certain sediment trapping or nutrient removal goals, or achieving "functional equivalency" with a natural reference wetland. 


\section{PRELIMINARY CONCLUSIONS}

On the basis of our preliminary analysis of primary and secondary cost data for wetland restoration projects and a review of what is known about the success of these projects and the economic and regulatory conditions under which they were undertaken, we reached the following general conclusions:

- Restoration success depends on the level of spending on restoration and the motivation of the restoration provider, as well the state of restoration science and site-specific conditions.

- Historically low restoration costs and historically low success rates for non-agricultural restoration projects reflect as much about the failure of regulators to demand results as the failure of restoration science to provide results.

- Because conditions in mitigation markets-the rules of exchange and units of exchange-are determined by regulators, they can control the incentives that motivate mitigation suppliers and determine how costquality tradeoffs are made.

- The development of wetland restoration as an applied science and as a policy tool will depend on how well regulators manage the incentives in mitigation markets.

- $\quad$ Site-specific differences can cause the cost of apparently similar projects to differ significantly, sometimes by a factor of five or ten. However, predictability and reliability increases substantially if only a few basic facts are known about the restoration site. So far our analysis suggests that cost adjustment factors based on simple indicators of site conditions can reduce cost estimating error to within acceptable bounds.

- The physical characteristics and geographic scale of agricultural conversion projects and projects undertaken as mitigation for wetland losses differ significantly. Even reliable information about the costs of agricultural conversions is of limited value when assessing the potential of restoration within the broader context of regulatory policy.

- Wetland restoration is an emerging field of applied science with very few engineering or performance standards, and the range of skills and experience among restoration specialists is enormous. This is reflected in a wide range of costs and success rates for most types of restoration projects. 
Figure 1. Estimates of Wetland Restoration Costs by Wetland Category.

\section{Cost Per Acre}

(In 1993 \$; excludes land costs)

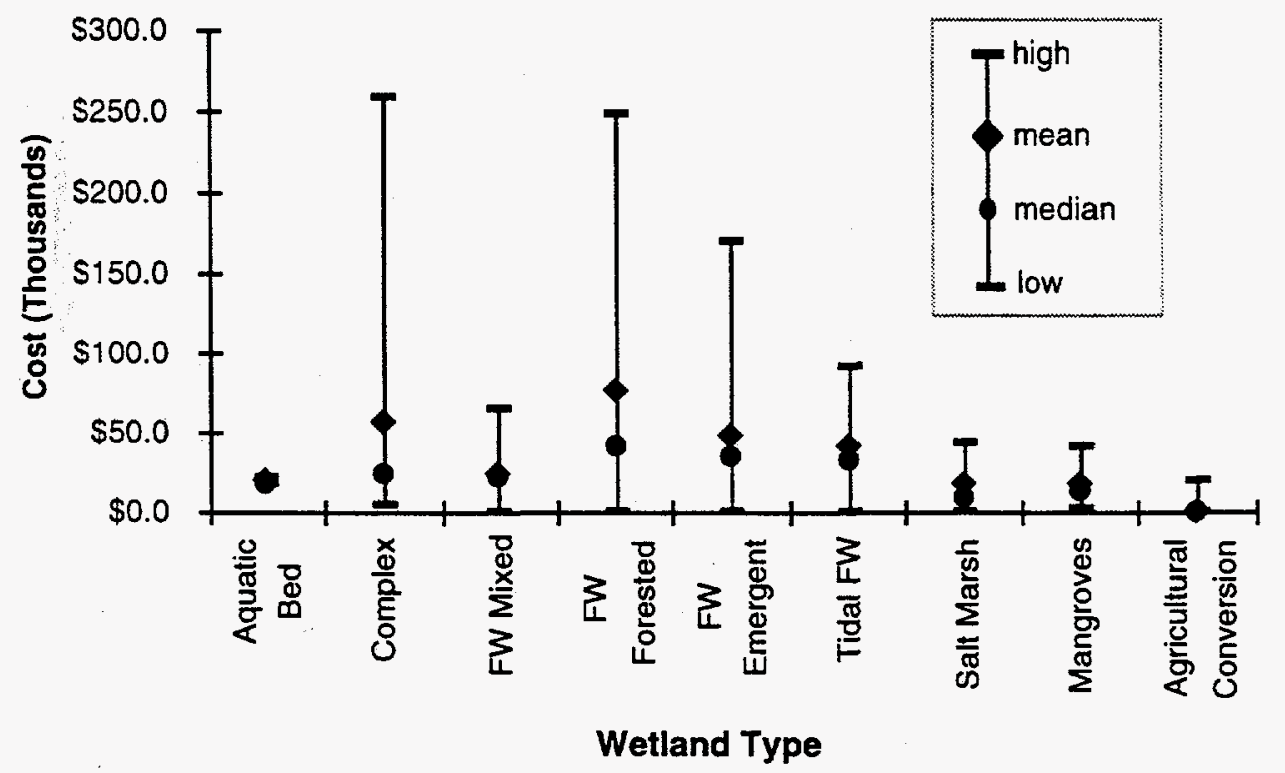

\section{Average Cost Per Acre}

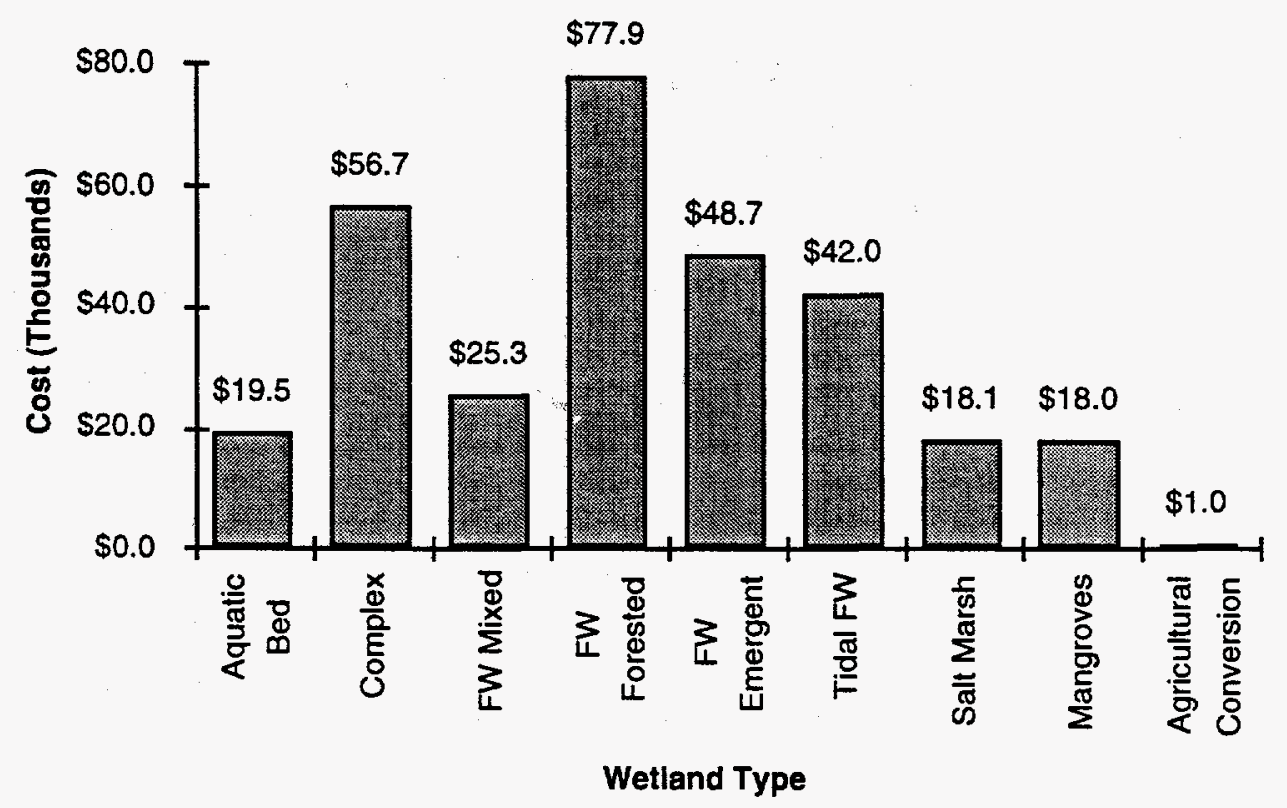


Figure 2. Cost per acre for Agricultural Conversions

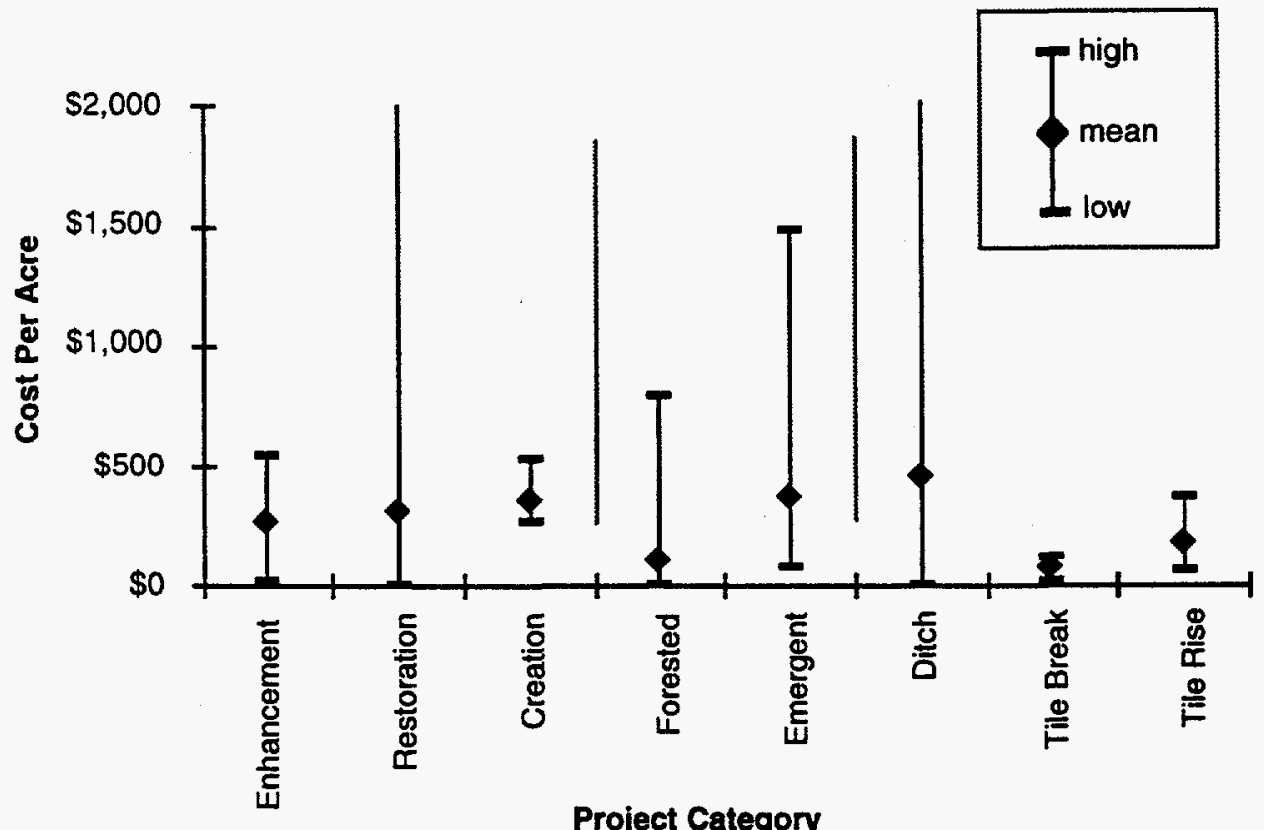

Table 1. Cost Estimates and Cost Allocation by Task and by Input Category (excludes land cost).

\begin{tabular}{|c|c|c|c|c|c|c|c|c|c|}
\hline \multicolumn{10}{|c|}{ Project Type } \\
\hline & Aquatic Bec & Complex & $\begin{array}{l}\text { FW } \\
\text { Mixed }\end{array}$ & $\begin{array}{l}\text { FW } \\
\text { Forest* }\end{array}$ & $\begin{array}{l}\text { FW } \\
\text { Emerg. }\end{array}$ & $\begin{array}{l}\text { Tidal } \\
\text { FW }\end{array}$ & $\begin{array}{l}\text { Salt } \\
\text { Marsh }\end{array}$ & $\begin{array}{l}\text { Man- } \\
\text { grove }\end{array}$ & $\begin{array}{l}\text { Agric. } \\
\text { Conv** }\end{array}$ \\
\hline \multicolumn{10}{|c|}{ Project Costs (Thousands) } \\
\hline $\begin{array}{l}\text { Average } \\
\text { Minimum } \\
\text { Maximum } \\
\text { Median } \\
\text { Sample Size }\end{array}$ & $\begin{array}{l}\$ 19.5 \\
18.3 \\
21.7 \\
18.6 \\
3\end{array}$ & $\begin{array}{l}\$ 56.7 \\
4.3 \\
258.8 \\
24.8 \\
8\end{array}$ & $\begin{array}{l}\$ 25.3 \\
1.4 \\
65.8 \\
23.4 \\
10\end{array}$ & $\begin{array}{l}\$ 77.9 \\
0.9 \\
248.4 \\
42.7 \\
19\end{array}$ & $\begin{array}{l}\$ 48.7 \\
1.7 \\
170.6 \\
35.2 \\
28\end{array}$ & $\begin{array}{l}\$ 42.0 \\
0.6 \\
92.6 \\
32.9 \\
3\end{array}$ & $\begin{array}{l}\$ 18.1 \\
1.0 \\
43.6 \\
10.2 \\
9\end{array}$ & $\begin{array}{l}\$ 18.0 \\
2.1 \\
42.8 \\
13.6 \\
4\end{array}$ & $\begin{array}{l}\$ 1.0 \\
0.005 \\
20.8 \\
0.5 \\
494\end{array}$ \\
\hline \multicolumn{10}{|l|}{ Breakdown by Tasks: } \\
\hline $\begin{array}{l}\text { Preconstruction } \\
\text { Construction } \\
\text { Postconstruction }\end{array}$ & $\begin{array}{l}17 \% \\
63 \\
20\end{array}$ & $\begin{array}{l}10 \% \\
74 \\
16\end{array}$ & $\begin{array}{l}5 \% \\
78 \\
17\end{array}$ & $\begin{array}{l}9 \% \\
74 \\
18\end{array}$ & $\begin{array}{l}13 \% \\
58 \\
28\end{array}$ & $\begin{array}{l}9 \% \\
87 \\
4\end{array}$ & $\begin{array}{l}16 \% \\
73 \\
11\end{array}$ & $\begin{array}{l}13 \% \\
66 \\
21\end{array}$ & $\begin{array}{l}0 \% \\
100 \\
0\end{array}$ \\
\hline \multicolumn{10}{|c|}{ Breakdown by Input Category: } \\
\hline $\begin{array}{l}\text { Labor } \\
\text { Materials } \\
\text { Equipment } \\
\text { Other }\end{array}$ & $\begin{array}{l}58 \% \\
8 \\
34 \\
0\end{array}$ & $\begin{array}{l}50 \% \\
23 \\
14 \\
14\end{array}$ & $\begin{array}{l}74 \% \\
10 \\
16 \\
0\end{array}$ & $\begin{array}{l}51 \% \\
30 \\
18 \\
2\end{array}$ & $\begin{array}{l}63 \% \\
26 \\
9 \\
1\end{array}$ & $\begin{array}{l}31 \% \\
54 \\
14 \\
1\end{array}$ & $\begin{array}{l}52 \% \\
27 \\
20 \\
2\end{array}$ & $\begin{array}{l}51 \% \\
21 \\
28 \\
0\end{array}$ & $\begin{array}{l}45 \% \\
0 \\
55 \\
0\end{array}$ \\
\hline
\end{tabular}

* High end of range involves researching and restoring hydrology and planting; low end involves restoring hydrology only.

Cost breakdowns for agricultural conversions are based on a project consisting of hydrologic modification without planting or formal plan development. 
Figure 3a: Economies of Scale-Primary Data

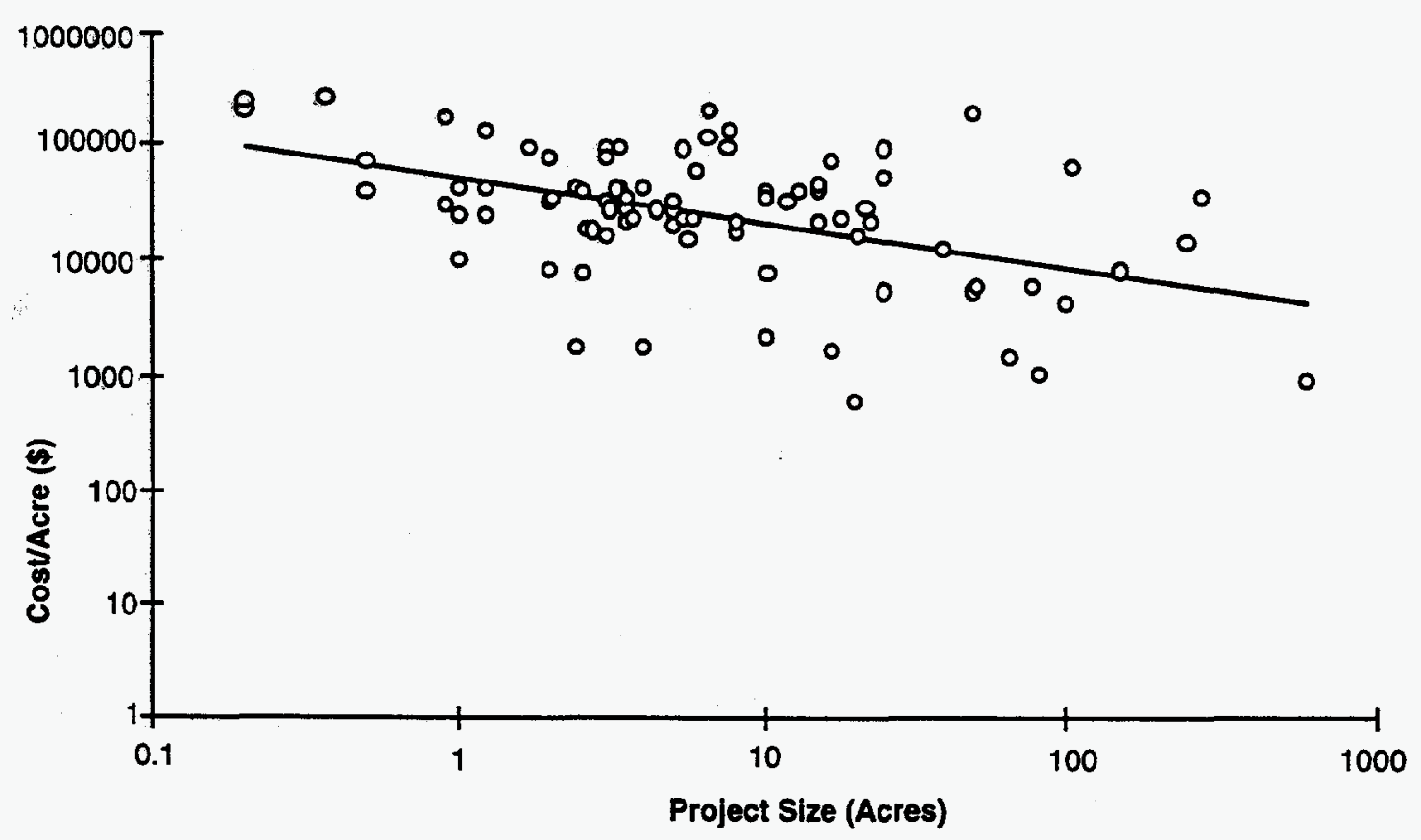

Figure 3b: Economies of Scale-Secondary Data

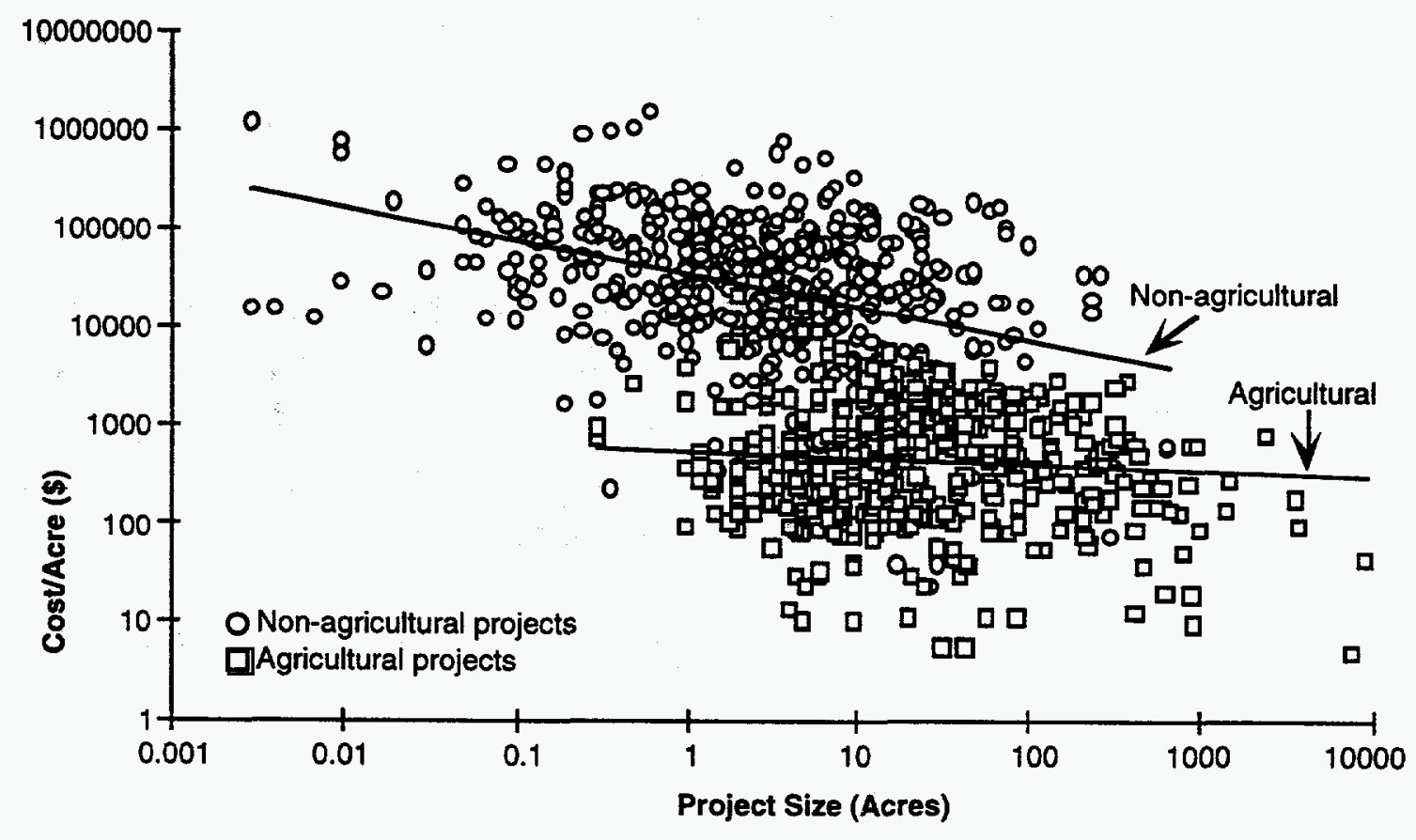


Appendix C: Watershed Management and Compensation Ratios

WATERSHED MANAGEMENT AND WETLAND MITIGATION:

A FRAMEWORK FOR DETERMINING COMPENSATION RATIOS

by

Dennis M. King, ${ }^{1}$ Curtis C. Bohlen, ${ }^{1}$ and Kenneth Adler ${ }^{2}$

1University of Maryland, Center for Environmental and Estuarine Studies, Solomons, Md

2U.S. EPA, Office of Policy, Planning and Evaluation, Washington, DC

This report was prepared under contract No. DE-AC22-92MT92006, Project No. 22-92MT 92006.000. U.S. Dept. of Energy and EPA Cooperative Agreement CR 818-227, with the University of Maryland, Center for Environmental and Estuarine Studies. Chesapeake Biological Laboratory, Solomons, MD.

University of Maryland System Draft Report \#: UMCEES - CBL - 93 - 098 


\section{Overview}

Despite earnest efforts to protect all wetlands, some economically imporant activities that cannot be designed to completely avoid wetlands will be permitted as long as wetland losses are mitigated through wetland creation; restoration, or enhancement. Determining how much mitigation should be required to compensate for lost wetland functions and values is the most contentious issue in wetland mitigation policy.

Wetland mitigation may not be preferred to wetland preservation, but it does provide opportunities to achieve watershed goals by trading up - by gaining wetland functions that are more valuable at a watershed level than those that are lost. One way to take advantage of these opportunities is to establish compensation ratios-acres of compensation wetland required per acre of natural wetland lost-in ways that reflect ecological tradeoffs at a watershed level.

This paper describes a logical, scientifically-based, legally defensible framework for establishing wetland compensation ratios. The framework is based on the idea that compensatory mitigation involves trading one form of environmental capital for another and that full compensation requires increases in environmental functions and values from the compensation wetland that are sufficient to make up for the decline in functions and values resulting from the loss of the existing wetland. Within this framework the "appropriate" compensation ratio is based on the level of functional replacement provided, the speed at which functional replacement is achieved, and the risk that the compensation wetland will not perform as expected.

\section{Statement of the Problem}

\section{Wetland Mitigation}

Many activities that harm wetlands are regulated by federal law under section 404 of the Clean Water Act. State wetland protection laws are also in effect in many states. In general, these laws require that certain activities in wetlands - the depositing of dredged or fill material for $\$ 404$, but other activities in some states - require permits issued by state or federal agencies. These agencies use their permitting authority to minimize the environmental harm caused by these activities, a task accomplished in part by requiring those seeking permits to mitigate environmental impacts.

A Memorandum of Agreement (MOA) between the Army Corps of Engineers (COE) and the Environmental Protection Agency (EPA) outlines the federal policy on wetland mitigation and establishes a preference for the avoidance and minimization of wetland impacts over compensatory mitigation. A similar preference is specified or is being considered in state wetland programs nationwide. However, despite this clear preference on the part of regulators, residual wetland impacts from economic development (i.e., where avoidance is not "practicable") are inevitable. In such cases, compensatory mitigation in the form of wetland creation, restoration, or enhancement will be used to offset the impacts of wetland loss on aquatic ecosystems, wildlife populations, and related social, economic, and aesthetic interests. 


\section{Appropriate Mitigation}

To regulators responsible for the stewardship of wetland resources, determining what constitutes appropriate compensation for unavoidable wetland losses is a central challenge. If compensation requirements are set too low, agencies will fail to protect wetlands and the important functions and values they provide. On the other hand, if compensation requirements are set too high, the high social and economic costs of mitigation will lead to legal challenges to agency decisions, evasion of mitigation requirements, political controversy, and will undermine public support for wetland protection.

\section{Compensation Ratios}

Some regulatory programs address the problem of determining what constitutes appropriate compensation using compensation ratios - the number of created or restored wetland acres required to make up for each acre of wetland damaged. The regulations implementing Maine's Natural Resources Protection Act, for example, establish minimum compensation ratios, from one to one for creation, restoration or enhancement of most wetlands, to 8:1 for preservation of existing wetlands. Florida's regulations establish a general wetland creation ratio of two acres to one. Maryland's non-tidal wetlands regulations recommend different compensation ratios for destruction of different wetland types, with forested wetlands and wetlands of special state concern requiring the highest ratios (up to three acres to one) and most herbaceous communities requiring only one to one replacement.

\section{Functions and Values}

In contrast, the federal program under $\$ 404$ of the Clean Water Act does not rely on standard mitigation ratios. Instead, the mitigation MOA provides guidance on what constitutes appropriate compensation on the basis of wetland functions and values. The MOA specifies that wetland mitigation should "strive to achieve a goal of no overall net loss of wetland values and functions." Moreover, the MOA specifically requires that the assessment of what constitutes appropriate mitigation of wetland impacts should be based "solely on the values and functions of the aquatic resources impacted". In principle, therefore, compensation requirements under the federal program demand a comparison between the wetland functions and values expected from the mitigation project and those lost with the destruction of the original wetland.

Unfortunately, the broad principles outlined in the MOA for assessing compensation requirements on the basis of comparing functions and values provide little practical guidance about how this is to be done. On a case-by-case basis, regulators have been attempting to establish compensation requirements in a manner that is fair, consistent with the MOA, legally defensible, and politically acceptable. Reliance on fixed compensation ratios rather than ad hoc negotiations may seem to impart an element of fairness and predictability to the setting of compensation ratios. However, to be fair and to minimize the ecological and economic costs of mitigation, these ratios need to take at least some account of site-specific conditions and overall watershed goals. To be legally defensible they also need to be based on concepts of functional equivalency and comparative value that are based on accepted science (Want, 1993). 


\section{Current Compensation Criteria}

In practice, compensatory mitigation requirements under federal wetlands programs are determined by a complex process in which many factors are considered (Kruczyncki 1991). Most often they are based on:

- The level of compensation required for similar projects in the past;

- The permit applicant's ability to pay;

- The type of compensation proposed (in kind or out of kind; on site or off site; creation, restoration or enhancement);

- The timing of construction of the compensation project (in advance of, concurrent with, or after destruction of the original wetland); and

- Ad hoc comparisons of wetland functions and values using a wide range of functional analysis tools or simply best professional judgment.

One reason why this hodge podge of mitigation criteria needs to be replaced is the high and rising cost of wetland mitigation, which is encouraging permit seekers to challenge regulators who want them to provide more acres of wetlands than they expect to disturb (King 1991). Most published reports regarding wetland restoration costs are associated with restoring wetlands lost to agricultural uses and typically cite average costs of less than $\$ 1,000$ per acre. However, restoring the types of wetlands most frequently involved in state and federal permitting decisions usually cost tens of thousands of dollars per acre and sometimes range into the hundreds of thousands of dollars per acre. Costs are also rising steadily as more stringent design and construction standards are imposed by regulators in an effort to increase the success of wetland restoration, and as more long-term monitoring and maintenance commitments are required to get a mitigation plan approved. Firms and individuals needing permits, therefore, have a strong financial incentive to create or restore as few acres of wetlands as possible and to challenge even seemingly modest compensation ratios whenever they appear to be unfounded. A clear and logical approach to establishing compensation requirements would minimize such challenges, and would make them easier to answer in courts and before administrative and regulatory appeal boards.

\section{Purpose of the Paper}

The purpose of this paper is to describe alogical, scientifically-based and legally defensible framework for establishing wetlands compensation requirements. The framework rests on the simple idea that full compensation for the losses caused by the destruction of existing wetlands can only occur when the environmental and other values supplied by a restored or created wetland match or exceed those that would have been supplied by the original wetland had it not been disturbed. Appropriate compensation, in other words, must ensure that the increase in environmental functions and values resulting from the compensation is sufficient to make up for the decline in functions and values that result from the damage to existing wetlands.

To be sure, the simple idea of comparing wetland functions and values glosses over considerable complexity. Wetlands, after all, are a form of natural capital and are valuable primarily because of the streams of varied ecological functions and economically valuable products and services that they provide over time. The value of any given wetland is based on its capacity to provide these benefits, which depends in part on it's proximity to other ecological features of the watershed and it's accessibility to humans and other species. 
Assessing the adequacy of compensatory mitigation involves a comparison between the stream of wetland functions and values that would occur over time if the original wetland were not disturbed with the stream of functions provided by compensation wetland. At a basic level such a comparison depends on three critical factors:

(1) The long-term sustained level of wetland function provided by the compensation wetland, as compared to the original;

(2) The speed with which the created or restored wetland reaches a sustained level of function; and

(3) The risk of compensation failure, or more generally, the uncertainty about the level of wetland function that the compensation project will provide.

However, a comparison of existing and proposed compensatory wetland values should also depend on decisions about which wetland functions are most and least important. A logical determination of compensation requirements, in other words, must rest on the selection, perhaps on a case-by-case basis, of which wetland functions are tradable and which trades can help achieve broader goals for the surrounding watershed or eco-region. Where several functions are of regulatory concern, procedures are also necessary that allow simultaneous consideration and weighting of multiple wetland functions ( King and Bohlen 1993, in preparation). However, no matter how weights are assigned and tradeoffs are made between wetland functions and locations, the logical foundation for estimating appropriate compensation ratios is the same. They should be based on a comparative analysis of the streams of functions and values gained and lost.

\section{The Proposed Solution: A Model for Determining Compensation Ratios}

\section{The Basic Model}

For purposes of illustration, the analytic model developed here is used to determine appropriate compensation ratios for "in kind" wetland mitigation-mitigation involving wetlands with similar sets of functions and values. As discussed above, weighting schemes based on watershed goals can be incorporated later to consider "out-of-kind" mitigation alternatives. The model's conceptual basis is shown in Figure 1, which illustrates the streams of wetland values that are gained and lost over time as an existing natural wetland is destroyed and a similar compensatory wetland is created.

Figure 1 illustrates concurrent mitigation. The destruction of the natural wetland takes place at time $T_{0}$ wiping out $100 \%$ of the natural value and at the same time a wetland creation project is started. Gradually, and with some risk of failure, the created wetland is shown to increase in functions and values until year $C$, shown in the illustration as ten years after construction, at which time it reaches the maximum functional level it will achieve, level B. For purposes of this illustration, B is shown to be $80 \%$ of the per acre values of the original wetland and the value of the compensatory wetland is shown to remain constant at that level until $T_{\max }$, the time horizon for regulatory decision making. 


\section{Figure 1: Basic Model of Compensation Ratios}

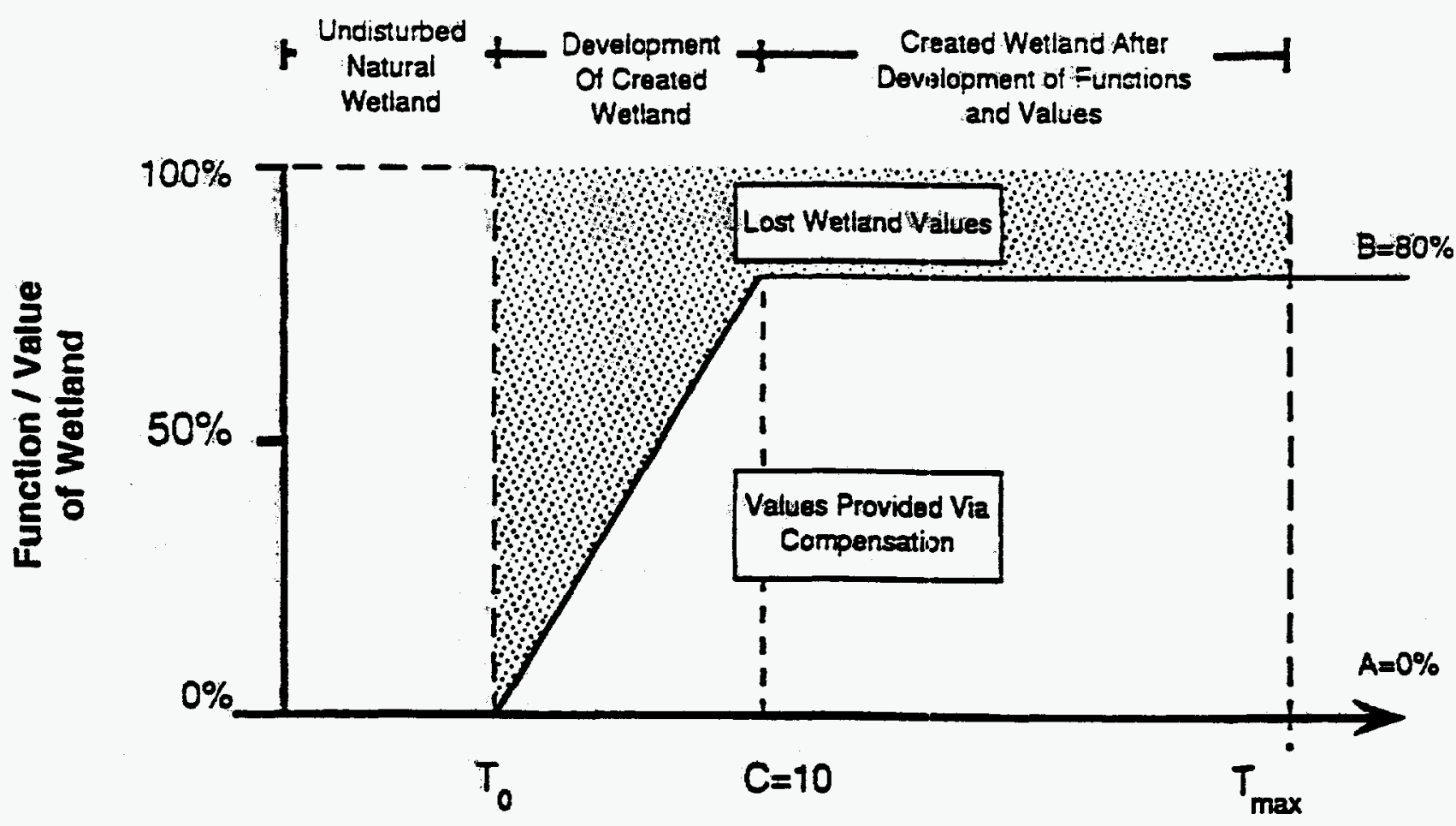

Time

$$
\begin{aligned}
& A=\text { Level of ecological function at compensation site before compensation activity } \\
& B=\text { Level of ecological function after compensation activity } \\
& C=\text { Number of years for functions to reach final level }
\end{aligned}
$$

The straight line increase in function shown in Figure 1 for the created wetland through year $C$ is used for sake of simplicity. The rate of increase is more likely to fall off as the final level of wetland functions is approached or may increase gradually at first and

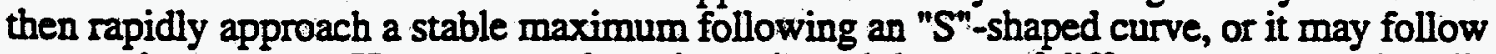
some other pattern. However, we have investigated the use of different curves to describe the increase in wetland functions as the created wetland develops and have determined that for purposes of evaluating compensation ratios it is not very important. Using different functional forms (e.g., quadratic, logarithmic, and so on) to describe the increase in function to level $B$ in year $C$ has very little impact on resulting compensation ratios, on the order of a few percent. So, for the sake of computational convenience and to keep the parameters of the model easy to understand in common sense terms, we employ a straight line (linear) recovery pattern from year $\mathrm{T}_{0}$ to year $\mathrm{C}$.

\section{The Inappropriateness of One-for-One Mitigation}

As can be seen in Figure 1, if only one acre of compensatory wetland is created for every acre of the original wetland destroyed, a net loss of wetland function equivalent to the shaded area occurs. Since the created wetland provides fewer wetland values over time on a per acre basis than did the original wetland, "no net loss" of wetland functions and values requires a compensation ratio greater than one for one. There can be circumstances when this is not the 
case. Figure 1 illustrates the most typical situation where lost wetland values cannot be replaced fully and immediately on an acre-for-acre basis by a created wetland.

The Drawbacks of a Simple Ratio

Initially, consider only long-term wetland functions. The compensation wetland eventually provides $80 \%$ of the functions of the original wetland on a per acre basis. On this basis alone, the appropriate compensation ratio to protect long term wetland values would be $1 / .80$, or 1.25 to one. That is, if functions lost as a result of the trade can be compensated by increased acreage, 1.25 acres of compensation should be required for each natural acre lost.

However, without further adjustment this ratio is too low to prevent a loss of wetland function and values. In the near term, while the compensatory wetland is developing (ten years in the illustration), it provides fewer wetland functions and values than it will once it is fully established. This would result in a near-term loss if the compensation ratio is based solely on long-term performance. In order to ensure full compensation, a somewhat higher compensation ratio is needed. However, this is just one of several adjustments that will need to be made.

\section{Visualizing the Model}

First, consider the total area of Figure 1, the shaded and unshaded areas to the right of time $\mathrm{T}_{0}$. This area represents the stream of wetland values, $100 \%$ per year until $\mathrm{T}_{\max }$ that the original wetland would have provided had it not been destroyed. Similarly, the unshaded polygon represents the replacement wetland values provided by the compensatory wetland. The difference, the shaded area, represents the wetland values that would be lost over time if one to one mitigation were employed.

An appropriate compensation ratio - one that results in "no net loss" of functions and values over time - can be calculated by simply comparing the unshaded area with the total area or, more directly, by analyzing the values of $B$ and $C$. For example, using a time horizon of 70 years ( $T_{\max }=70$ selected for reasons that will be explained later), the shaded area represents $75 \%$ of the total area. Thus in the first 70 years, an acre of compensatory wetland provides $75 \%$ of the value that would have been provided by an acre of the original wetland. The appropriate mitigation ratio is $1 / .75$ or 1.34 to 1 . Similar calculations can be made for the shaded areas associated with other compensation projects represented by different values of $B$ and $C$.

\section{The Need to Compare Present Values}

Calculations to this point have implicitly assumed that wetland values that will be realized as far as 70 years in the future are equal to values lost today. In general, wetlandrelated benefits that accrue in the future, like the benefits from all other natural and manmade assets, are less valuable than those that accrue immediately. The concept of "discounting" cannot be described here, but it is used universally in economics to compare different streams of costs and benefits in "present value" terms and should be applied here to compare different streams of wetland benefits. To determine an appropriate compensation ratio, in other words, one must compare not only the magnitude of the values gained and lost, but when the gains and losses accrue. Since concurrent mitigation means losing the benefits of a natural wetland now and having it replaced later after the compensatory wetland is established, discounting will usually result in higher compensation ratios than not discounting. Discount rates on the order of $3 \%$ to $10 \%$ per 
year are typical for most applications, and the most recent discount rate recommended for evaluating federal programs by the Office of Management and Budget (OMB) in 1992 is 7\%.(Office of Management and Budget 1992)

Using the OMB recommended discount rate of $7 \%$ to adjust the streams of wetland values shown in Figure 1 results in a new shaded area and on the basis of comparing the discounted present values of the gains and losses in wetland function the compensatory wettand provides $(1-.40)$ or $60 \%$ of the value of the original wetland. Thus, if discounting is applied, the appropriate compensation ratio would climb from 1.34 to 1 to 1.67 to 1 .

\section{Accounting for Pre-existing Wetland Values}

So far, we have only considered compensation through the concurrent creation of wetlands that take place, presumably, at sites that have no existing wetland values. Many compensatory mitigation projects, of course, involve the restoration or enhancement of existing wetlands that are already providing wetland values. The compensation ratio for such projects needs to be adjusted to account for these preexisting values. Otherwise compensation projects would be "credited" for providing wetland values that would have existed in their absence.

The framework developed in Figure 1 can be adjusted easily to account for such cases as shown in Figure 2. As in Figure 1, the original wetland is destroyed at time $T_{0}$ and a compensatory mitigation project is undertaken at the same time to generate replacement wetland values. Here, however, the replacement values climb not from zero, but from level $A$ - the preexisting level of wetland value at the mitigation site - and then, as before, reach a maximum level represented by $B$ and stabilize after $C$ years. Visually the unshaded area in Figure 2 represents the amount of wetland values provided by the compensation project which, in effect, is superimposed on the shaded area representing the values lost with the destruction of the initial wetland. The remaining shaded areas above and below the unshaded area, therefore, depict the loss of wetland values with one-for-one mitigation. The size of the unshaded area relative to the shaded area is determined by the values of $A$, $\mathrm{B}$, and $\mathrm{C}$, which provide the basis for establishing an "appropriate" compensation ratio.

Assume for example, that preexisting wetland values at the compensation site were worth $20 \%$ of the per acre value of the original wetland $(A=0.20)$, and, as before, the project is ultimately expected to provide $80 \%$ of those values $(B=0.80)$ after 10 years $(C=$ 10). Applying a discount rate of 7 percent per year, this hypothetical compensation project would supply $45 \%$ of the value of the original wetland on a per acre basis, leading to a compensation ratio of $1 / .45$, or 2.22 to 1 . 


\section{Figure 2: Restoration or Enhancement}

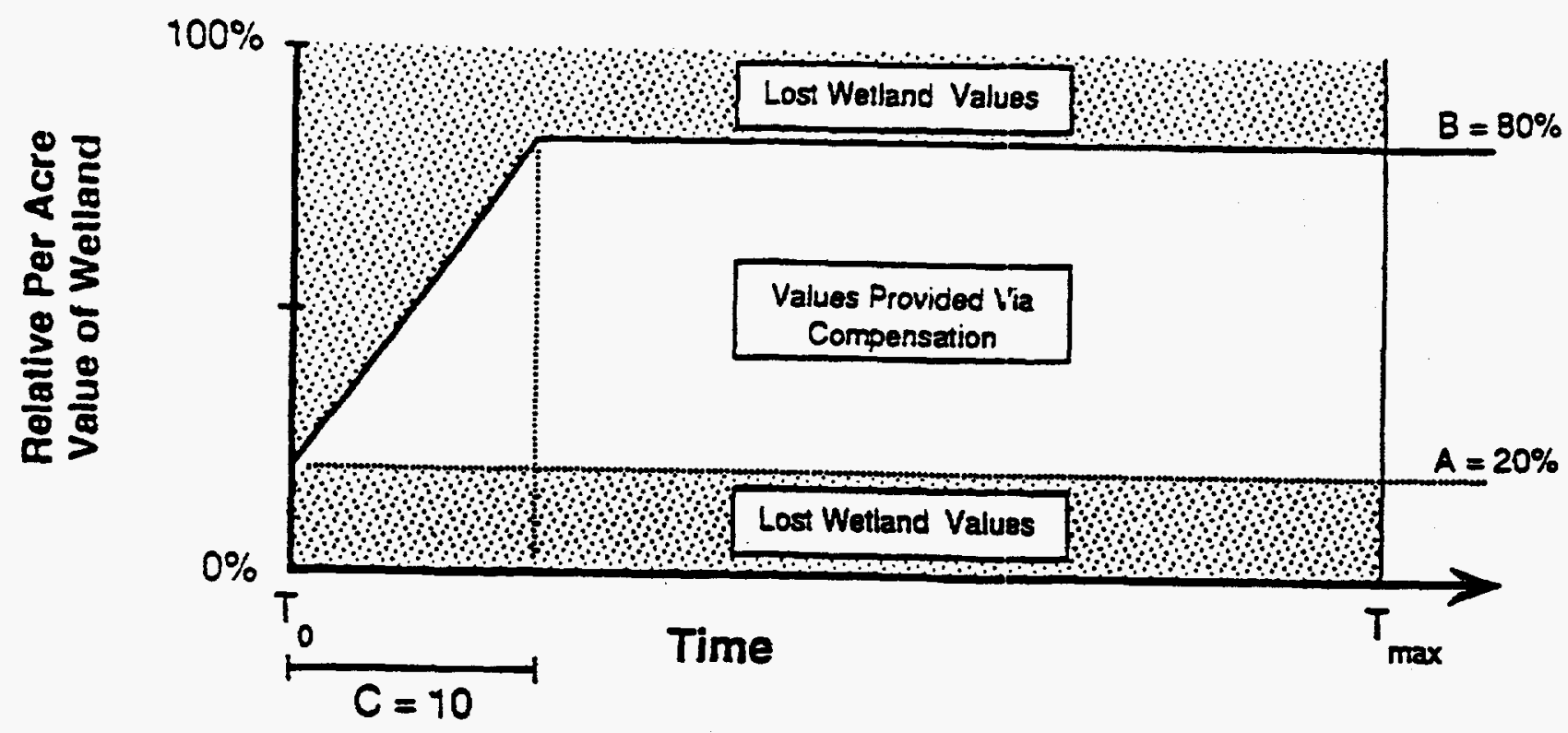

$$
\begin{aligned}
& A=\text { Level of ecological function at compenseation site before compensation activity } \\
& B=\text { Level of ecological function after compensation activity } \\
& C=\text { Number of years for functions to reach final level }
\end{aligned}
$$

\section{Advanced or Delayed Mitigation}

Compensation ratios can also be determined for compensation provided either before or after destruction of the original wetland. Figure 3 illustrates a hypothetical advanced compensation project where the compensatory wetland is created a few years before the original wetland is destroyed and again generates wetland values that climb steadily over a number of years to reach a steady maximum value. The unshaded area which again represents the per acre net increase in wetland values provided by the compensatory wetland now includes the advanced values to the left of $T_{0}$. Graphically, advanced compensation simply shifts the sloping edge of the unshaded area to the left; wetland values are provided sooner and the overall size of the unshaded area is larger. In terms of the compensation ratio formula, the faster delivery of functions lessens the effect of time discounting and increases the present value of the functions provided by the compensation wetland. As one would expect, advanced mitigation requires lower compensation ratios to achieve no net loss than concurrent compensation. In a similar fashion, delayed compensation shifts the sloping edge of the unshaded area to the right and decreases its overall size, resulting in an increase in the compensation ratio. 


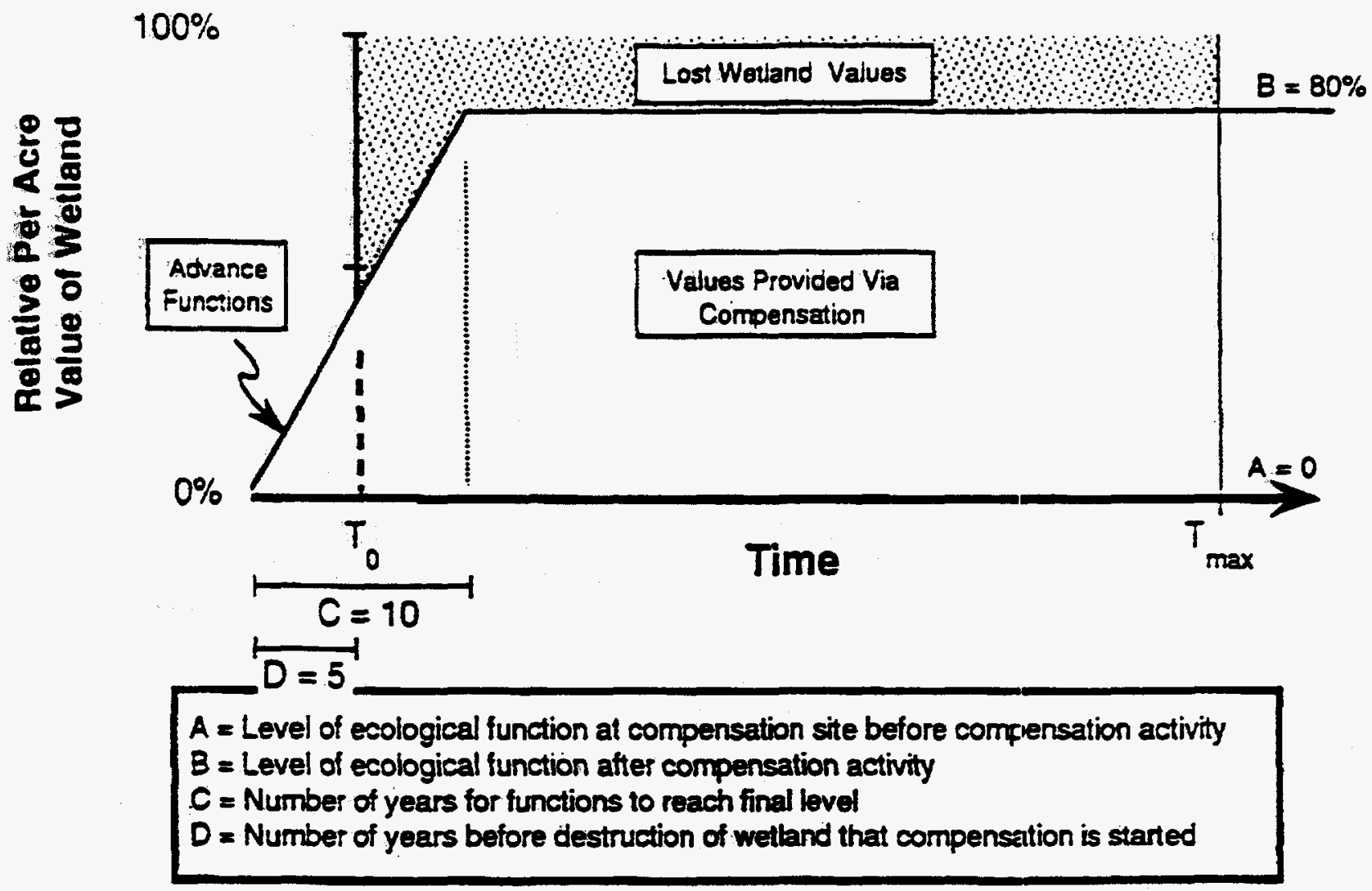

If the mitigation project in Figure 3 were identical to the one shown in Figure 1 (except that it was constructed 5 years in advance of the destruction of the original wetland) the appropriate compensation ratio would be 1.19 to 1 , down from 1.67 to one for concurrent mitigation. Mitigation delayed by 5 years, by contrast, would require a ratio of 2.35 to 1 to fully compensate for the wetland values lost. The higher the social preference for near-term over long-term values (expressed as a higher discount rate), the greater the relative advantage of advance compensation and the greater the disadvantage of delayed compensation.

\section{Uncertainty and the Risk of Failure}

So far the analysis presented here has not addressed one of the strongest justifications for preferring existing wetland functions over those expected through wetland compensation: uncertainty. The evidence shows that a significant proportion of historical wetland mitigation projects have failed to provide intended wetland values. Future projects will also have significant failure rates. However, while expected failure rates should be considered when establishing a compensation ratio it is important to guard against forecasting expected failure rates on the basis of the poor track record for historical mitigation projects. Several recent reviews of historical wetland mitigation, for example, document dismal failure rates (Florida 1991: Bernstein and Zepp 1990). However, the discussion provided about these historical failures tend to reveal more about the inadequacies of wetland management institutions - poor monitoring and enforcement - and the "perverse incentive structure" in historical mitigation markets - rewards for low cost rather than high quality mitigation - rather than any fundamental failure of restoration science(King 1991). 
Wetland creation and restoration will continue to be somewhat experimental for many years to come. Projects that do not perform as intended, therefore, will be frequent enough that the risk of failure needs to be taken into account in determining compensation ratios. There is evidence that improved project siting, design, and construction standards; increased monitoring and enforcement of permit requirements; more long-term site maintenance; and mandatory performance and assurance bonds have already resulted in tremendous improvements in the success rates and have provided incentives for continued improvements. However, unless we are absolutely sure that the compensatory wetland will perform as intended, the estimation of an appropriate compensation ratio should reflect the risk of failure as well as the magnitude and timing of the wetland values gained if the project succeeds.

\section{Adjusting for Uncertainty}

For sake of illustration consider a compensation project that promises $80 \%$ of the values of the original wetland, but is only $80 \%$ likely to succeed. The replacement value of the compensation wetland is not $80 \%$ of the original, but something less. In making such a trade, the regulatory agencies, acting on behalf of current and future citizens, are accepting a gamble where the payoff, if all goes well, is a wetland with $80 \%$ of the per acre values of the original and, if all does not go well, will be less. Quite apart from the concept of "discounting" that is used to adjust certain payoffs expected in the future, is a set of relatively simple techniques for expressing uncertain payoffs from such a gamble in terms of "expected values.'

In general terms, the anticipated wetland value can be used to refer to the value the compensation project was designed to provide. (Up to this point in the paper we have been considering only anticipated values.) The expected wetland value is a slightly more complex term that incorporates the possibility of failure. The expected value, in a statistical sense, represents the average or mean level of wetland functions that would be provided if the wetland compensation project under consideration could be constructed over and over again. It incorporates the intended performance of a created, restored, or enhanced wetland and an assessment of the risk that the intended level of performance will not be achieved. Unless the success of a project is absolutely certain, the "expected value" of B will lie somewhere between the best outcome possible and the worst. Although it is possible that a given project could exceed the expectations of the designer or proposer, it is more important here to consider the likelihood of failure than the likelihood of extraordinary success. In the situation mentioned earlier, for example, where the project had a $80 \%$ chance of achieving $80 \%$ of the natural value and a $20 \%$ chance of being a complete failure, the "expected value" of B would be .64, that is $[(.80 \times .80)+(0 \times .20)]$. On average, we should expect such projects to achieve $64 \%$ of lost wetland values, not $80 \%$.

Wetland regulators attempting to manage ecological risks and maintain the long term value of natural capital should establish compensation requirements based not on anticipated values, but on expected values. Expected values can be incorporated into our model easily by employing a simple "knife-edge" probability function where compensation projects are expected to either "succeed", in which case they generate wetland values represented by B, or "fail", in which case they provide no increase in wetland values over those already available (see Figure 4). 


\section{Figure 4: Expected Values}

$20 \%$ Chance of Failure, $E=0.20$

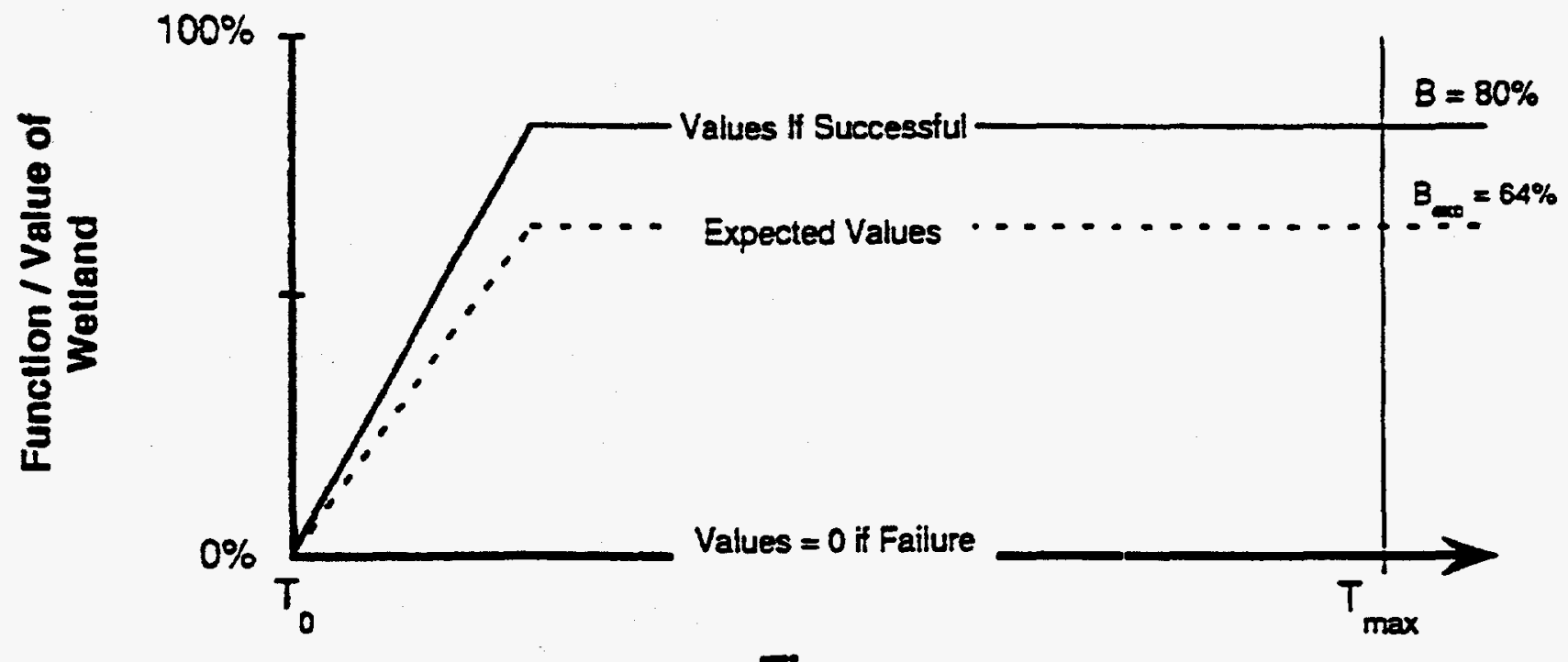

Time

Uncertainty about the "expected value" of the outcome of the wetland compensation project can be introduced to the analysis by incorporating a parameter $E$, the percent likelihood that the project will fail. In the illustration, the compensation project will succeed, reach $B=.80,80 \%$ of the time and the other $20 \%$ of the time, the project will have no value at all $(B=0)$. From earlier discussion we know that if the project is successful, it offers $60 \%$ of the discounted value of the original wetland and requires a compensation ratio of 1.67 . With a $20 \%$ failure rate, the expected value is reduced to $48 \%$ of the original wetland, leading to a compensation ratio of 2.09 to 1 .

The key to incorporating issues of risk into the determination of compensation ratios is estimating the magnitude of the risk of failure - assigning a value to the parameter $E$ for various classes of compensatory mitigation proposals. Projects designed to replace one type of wetland will have a higher success rate than projects to replace other wetland types; wetland restoration projects, in general, are less likely to fail outright than are wetland creation projects (e.g.. Kusler and Kentula 1989); projects designed and built by experienced, previously successful contractors have better chances for success than those created by neophytes; larger wetland restoration projects tend to have a higher success rate than smaller projects, and so on. There is clear justification for adjusting compensation ratios on the basis of factors affecting success which could have far reaching policy implications. The location, size and management plan for a wetland mitigation bank, for example, might justify significantly lower compensation ratios for those who use the bank than for those who attempt individual projects. This could provide an economic incentive for mitigation suppliers and permit seekers to develop and use mitigation banks.

Advanced mitigation may also substantially reduce the effective risks of compensation failure faced by the regulatory agencies. If a mitigation project looks good after two or three years, its chances of failing in the long run may be reduced considerably. A relatively high percentage of compensatory mitigation failures, for example, are the result of problems with hydrology, wave energy, or construction details that become obvious within 
the first few seasons after construction (Florida DER 1991). Many other failures can be prevented or ameliorated through appropriate corrective action during the first few years after construction (e.g. weeding to limit invasion by an invasive plant species). Thus if a compensation project is trending toward success a year or two after it was constructed, and remedial actions have already been taken, the chances may be substantially increased that the project will be successful in the long term. Corresponding adjustments to the compensation ratio could provide strong scientifically-based encouragement for advanced mitigation over concurrent mitigation and at the same time reduce ecological and economic risks.

\section{The Compensation Ratio Formula}

From the previous discussion, the essential characteristics of a compensatory mitigation project can be captured in simple mathematical terms using only five parameters:

A: The level of per acre wetland function at the compensation site prior to the compensation project, expressed as a proportion of the per acre value of the original wetland;

B: The maximum level of per acre wetland function the compensation project will reach, expressed as a proportion of the per acre value of the original wetland;

C: The number of years after construction of the compensation project that it achieves maximum function;

D: The number of years before destruction of the original wetland (at time $t=0$ ) that construction of the compensation project occurs (negative values represent delayed compensation, zero represents concurrent compensation, positive values represent advanced compensation); and

E: The likelihood, ranging from $0 \%$ to $100 \%$, that the mitigation project will fail to achieve any of the anticipated values represented by $B$.

The appropriate compensation ratio expressed using these five parameters can be calculated using the following formula:

$$
\text { C } \sum_{t=1}^{T \max }(1+r)^{-t}
$$

$\mathbf{R}=$

Where:

$$
\overline{(B-A)(1-E)\left[\sum_{t=1-D}^{C-D}(D+t)(1+r)^{-t}+C \sum_{t=1+C-D}^{T \max }(1+r)^{-t}\right]}
$$

Tmax $=$ the time horizon used for planning purposes

(where $\mathrm{r}=7 \%$ the present value is approximately zero after $\operatorname{Tmax}=70$ )

$\mathrm{R}=$ the Compensation Ratio

$\mathrm{t}=$ the year considered

$r=$ the discount rate (the $7 \%$ rate recommended by $\mathrm{OMB}$ or other non-zero value) 


\section{Some Illustrations}

For purposes of illustration, Table 1 displays compensation ratios calculated using the above formula for a variety of hypothetical compensatory mitigation scenarios characterized by different values of A, B, C, D and E. Results are shown for calculations using discount rates of $0 \%, 5 \%, 7 \%$, and $10 \%$.

Table 1. Calculated compensation ratios for a variety of hypothetical compensatory mitigation scenarios.

\begin{tabular}{|c|c|c|c|c|c|c|c|c|c|}
\hline & \multicolumn{5}{|c|}{ PARAMEIERS } & \multicolumn{4}{|c|}{ COMPENSATIONRATIOS } \\
\hline & \multirow[b]{2}{*}{$\overline{\mathbf{A}}$} & \multirow[b]{2}{*}{ B } & \multirow[b]{2}{*}{ C } & \multirow[b]{2}{*}{ D } & \multirow[b]{2}{*}{$E$} & \multicolumn{4}{|c|}{ Discount Rate } \\
\hline & & & & & & $0 \%$ & $3 \%$ & $7 \%$ & $10 \%$ \\
\hline $\begin{array}{l}\text { Concurrent Creation } \\
\text { Advanced Creation } \\
\text { Concurrent Restoration } \\
\text { Creation with Risk }\end{array}$ & $\begin{array}{l}0 \\
0 \\
0.2 \\
0\end{array}$ & $\begin{array}{l}0.8 \\
0.8 \\
0.8 \\
0.8\end{array}$ & $\begin{array}{l}10 \\
10 \\
10 \\
10\end{array}$ & $\begin{array}{l}0 \\
5 \\
0 \\
0\end{array}$ & $\begin{array}{l}0 \\
0 \\
0 \\
0.2\end{array}$ & $\begin{array}{l}1.34 \\
1.24 \\
1.78 \\
1.67\end{array}$ & $\begin{array}{l}1.45 \\
1.22 \\
1.94 \\
1.81\end{array}$ & $\begin{array}{l}1.67 \\
1.19 \\
2.22 \\
2.09\end{array}$ & $\begin{array}{l}1.85 \\
1.15 \\
2.47 \\
2.31\end{array}$ \\
\hline $\begin{array}{l}\text { Delayed Creation } \\
\text { Degraded Wetiand } \\
\text { Concurrent Enhancement } \\
\text { Difficult Creation } \\
\text { Same. Advanced }\end{array}$ & $\begin{array}{l}0 \\
0 \\
0.5 \\
0 \\
0 \\
\end{array}$ & $\begin{array}{l}0.8 \\
1.6 \\
0.8 \\
0.8 \\
0.8\end{array}$ & $\begin{array}{l}10 \\
10 \\
10 \\
10 \\
10\end{array}$ & $\begin{array}{l}-5 \\
0 \\
0 \\
0 \\
5\end{array}$ & $\begin{array}{l}0 \\
0 \\
0.2 \\
0.5 \\
0.1\end{array}$ & $\begin{array}{l}1.45 \\
0.67 \\
4.45 \\
2.67 \\
1.38\end{array}$ & $\begin{array}{l}1.73 \\
0.73 \\
4.84 \\
2.90 \\
1.36\end{array}$ & $\begin{array}{l}2.35 \\
0.83 \\
5.56 \\
3.34 \\
1.32\end{array}$ & $\begin{array}{l}2.98 \\
0.93 \\
6.17 \\
3.70 \\
1.28\end{array}$ \\
\hline
\end{tabular}

*A 7\% Discount Rate is recommended by OMB for evaluating federal projects (OMB 1992)

The first four rows of Table 1 coincide with the scenarios described in previous sections and depicted in Figures 1 through 4. The remainder of the rows vary one or more parameters in order to show the significance of each on the resulting compensation ratios. This exercise suggests the following:

(1) Compensation substantially delayed commands a heavy price in higher compensation ratios, especially if a high discount rate is used.

2) Compensation for destruction of a degraded wetland, where the compensatory wetland is expected to provide higher wetland values than the original, can justify compensation ratios below one to one.

(3) Compensation ratios for projects that rely on enhancement of existing wetlands to replace lost wetland function can be very high indeed.

(4) The probability of success is an important factor in establishing the compensation ratio. Where it is low, the compensation ratio can tend to be very high. 
(5) Advanced mitigation can justify significantly reduced compensation ratios for two reasons: more compensation is provided faster and the probability of success is higher by the time the mitigation is used.

(6) To the extent that mitigation banking involves larger, better designed, more closely monitored compensatory mitigation than individual projects they will have a higher probability of success and should require lower compensation ratios than individual mitigation projects.

\section{A Few Caveats}

The framework developed in the previous sections was kept relatively simple in order to illustrate the important concepts in developing appropriate compensation ratios. The framework is logical, scientifically based and relies on accepted procedures for comparing stream of wetland values and can be applied usefully as it was described in many cases. Like any analytical tool, however, it can be used inappropriately if it's limitations are not recognized. Some noteworthy issues that need to be addressed prior to applying the formula in any given case are considered below. By expanding the simple framework and by accepting a bit more complexity in the way the model is specified, all of the limitations described below could be overcome.

\section{Measures of Wetland Function}

Ideally, compensation ratios would be based on comparisons of particular wetland functions that are of special interest within the context of the watershed of which it is a part or the surrounding eco-region. These wetland functions would be measured and the levels provided by the original wetland and by the proposed compensation wetland would be used to make the comparison; i.e., to estimate the expected value of $B$. In such a situation, balancing losses and gains of significant functions would be straightforward and the appropriate compensation ratio could be established with a high level of accuracy.

Wetland functions, however, are notoriously difficult to quantify and direct measurements of most wetland functions are time consuming and expensive. Existing indirect functional assessment techniques (e.g. HEP and WET) are controversial and were never designed to forecast the functions that an unbuilt compensatory wetland will eventually provide. The time and budget constraints under which regulatory decisions are made, in most cases, will prohibit the use of reliable functional indices so functional comparisons for individual project proposals will fall short of the ideal. Wetland functions will most often need to be estimated using quickly measured surrogates for general wetland quality rather than estimates of specific wetland functions. This limitation is not unique to the approach developed here, but since the recommended approach is based on a statistical formula, it can be misused easily to hide "crackpot rigor."

Regulators must be certain that the measures of wetland function used to set compensation ratios are sufficient to do the iob. 


\title{
Multiple Wetland Functions
}

We have implicitly assumed throughout this paper that wetland functions provided by a compensatory wetland can be expressed using a single number. That assumption allows the value of the compensation site to be unambiguously expressed in the same terms as the value of the original wetland. In some cases, this may be an unacceptable oversimplification. A large non-tidal wetland, for example, may provide water quality protection, habitat for an endangered species, flood amelioration, and shelter for migratory waterfowl. On an acre-foracre basis, a created wetland built to compensate for the loss of such wetland might produce three quarters of the water quality benefits of the original wetland, fail to provide adequate habitat for the endangered species, reduce flooding as well as the original, and provide nesting habitat for twice as many waterfowl. Under such circumstances, arguments could be made for a variety of different compensation ratios. Where multiple wetland functions are of concern, regulators must take care that a compensation ratio calculated on the basis of one or a few wetland functions (or an aggregate index of functions or values) does not lead to a significant loss of unaddressed functions. This could be addressed most directly by employing a checklist of functions, perhaps weighted according to watershed or other goals.

\section{Regulatory personnel must ensure that all functions of regulatory interest are sufficiently protected.}

\section{Quality vs. Quantity Tradeoffs}

Compensation ratios which assign equivalency values in terms of the area of wetland created or restored per acre destroyed may be an inappropriate way to measure the replacement of some wetland functions. Some wetland functions do not scale up or down with the overall size of a given wetland, others do not scale proportionately with the overall number of wetland acres, still others require that certain thresholds be met in the replacement wetland or the surrounding habitat. Waterfowl populations, for example, often scale both with wetland area and with percent of the area in open water, habitat values for mammal and amphibian species that use both wetland and non-wetland areas may scale with length of the wetland-upland boundary, not with area; fish populations may scale with the length of the water-wetland edge, and so on. In fact, habitat complexity and biodiversity may be much more closely related to design of the compensatory wetland than with it's size. Other scaling problems exist if created or restored wetlands simply cannot provide certain functions. If created wetlands provide poor habitat for endangered species, for example, increasing the size of the area may never constitute acceptable mitigation.

\begin{abstract}
Mitigation ratios alone can not protect all wetland values. Regulators must assess whether a compensation plan will protect specific wetland functions and mav need to make tradeoffs to achieve overall watershed goals.
\end{abstract}

\section{No Net Loss of Function or Area}

The framework developed here for assessing wetland compensation is based on preventing loss in the net present value of the expected future stream of wetland functions and values available from the original and the compensatory wetland. This framework can be characterized as "No Net Loss in the Net Present Value of Wetland Functions" and may not, in all cases, be the same thing as attaining the goal of "No Net Loss of Wetlands by 
Acreage and Function," as articulated by the National Wetlands Policy Forum and endorsed by President Bush in 1990.

There are two unusual cases where the present value formulation may not provide for "no net loss" as it is generally perceived. The first is where advanced mitigation takes place so far ahead of the damage being mitigated that below replacement value compensation ( a compensation ratio less than one) could be justified. The second is where a compensation project is expected to provide intermediate or long-term but not permanent wetland functions (e.g., due to anticipated erosion, sedimentation, or altered hydrology). These unusual cases, however, do not detract from the usefulness of the approach since the formula can be adjusted to accommodate them when they occur.

Regulators must check to ensure that protecting the present values of wetland functions will mean sustainine wetlands as natural assets in the long-term

\section{Conclusions}

In this paper we have presented what we believe is a logically consistent, scientifically-based, legally defensible method for determining wetland compensation ratios. The method is based on the principle that wetland compensation should be sufficient at least to replace the time-discounted value of wetland functions lost due to impacts to the original wetland. The method is applicable to wetland creation, restoration, and enhancement projects, and is consistent with the guidance provided in the MOA among U.S. resource agencies which recommends basing compensation requirements on a comparison of wetland functions and values.

The authors believe that the method proposed here strikes a fair balance between what is needed from science and what is necessary for policy. A more sophisticated mathematical treatment would tend to bury the essential conceptual issues in a blizzard of statistical details and would make approach incomprehensible to those who need to use it. A simpler model, (e.g., one that ignored time and risk altogether), although perhaps easier to apply, would not lead to fair results and is unlikely to withstand legal and bureaucratic challenges. The proposed method requires regulatory personnel to estimate just five parameters which correspond to the basic characteristic of wetland compensation projects. It can also be expanded to reflect more complex situations as the need arises.

While no simple formula for setting compensation ratios can address all situations that will arise in practice, the method we have proposed has wide applicability. If it is applied after a careful review of each compensatory mitigation proposal, and if it is used with judgment, it should reduce controversy over what constitutes adequate mitigation and should result in more consistent determinations of compensation ratios than the largely ad hoc methods currently in use. It should also result in more equitable wetland mitigation policy and make it easier to make progress toward the goal of "no net loss" of wetland functions and values. 


\section{Literature Cited}

Bernstein, Giselle, and Robert L. Zepp, Jr. 1990. Evaluation of Selected Wetland Creation Projects Authorized Through the Corps of Engineers Section 404 Program. U.S. Fish and Wildlife Service Annapolis Field Office. Annapolis, MD.

Environmental Protection Agency and Department of the Army. 1989. Memorandum of Agreement between the Environmental Protection Agency and the Department of the Army Concerning the Determination of Mitigation Under the Clean Water Act Section 404 (b)(1) Guidelines.

Florida Department of Environmental Regulation. 1991. Report on the Effectiveness of Permitted Mitigation. Florida Department of Environmental Regulation. Tallahassee, FL.

King, Dennis M. and Curtis C. Bohlen 1993. In Preparation. Comparing The Cost and Performance of Wetland Creation and Restoration, A Report prepared under EPA Cooperative Agreement CR 818-227 between the U.S. EPA and the University of Maryland, Center for Environmental and Estuarine Studies

King, Dennis M. 1992. The Economics of Ecological Restoration in Natural Resource Damages: Law and Economics, edited by Ward and Duffield. John Wiley \& Sons, New York.

King, Dennis M. 1991 Costing Out Restoration in Restoration and Management Notes, Journal of the Society for Ecological Restoration; University of Wisconsin, Summer

Kruczyncki, William L. 1991. Alternative Approaches to Establishing Mitigation Ratios. A Report by EPA Region IV, Atlanta

Kusler, Jon A., and Mary E. Kentula. 1989. Wetland Creation and Restoration: The Status of the Science. EPA 600/3-89/038. U.S. Environmental Protection Agency, Washington D.C.

Office of Management and Budget.Guidelines and Discount Rates for Benefit-Cost Analysis of Federal Programs. OMB Circular A-94 ; Washington, D.C.; 1992

Want, William L. 1993. Law of Wetlands Regulation. Release \#4. Clark Boardman Callaghan. Deerfield IL. 


\section{APPENDIX D}

\section{Wetland Creation/Restoration}

\section{Cost Spreadsheet}

(used to develop cost estimates for cases in the Primary Database) 
Case \#

Wetland Type:

PROJECT TASK

PHASE 1. PRECONSTRUCTION

1.1 Initlal Site Analysis:

1.2 Conceptual Plan

1.3 Plans \& Specifications

TOTAL PRECONSTRUCTION

PHASE 2. CONSTRUCTION

2.1 Site Preparation

2.2 Plant Acquis. \& Install.

TOTAL CONSTAUCTION

PHASE 3. POST CONSTRUCTION

3.1 Malntenance/Modificat.

\subsection{Monitoring}

TOTAL POST CONSTRUCTION

TOTAL COSTS-All tasks

AVERAGE COST PER ACRE

Land Acquisition Cost per Acre

Total Cost Per Acre (Project and Land Acquisition)

\section{N}

\begin{tabular}{|l|l|l|l|l|}
\hline LABOR & MATERIALS & EQUIPMENT & OTHER & TOTAL \\
\hline
\end{tabular}

Size

Size (acres):

Site Location:
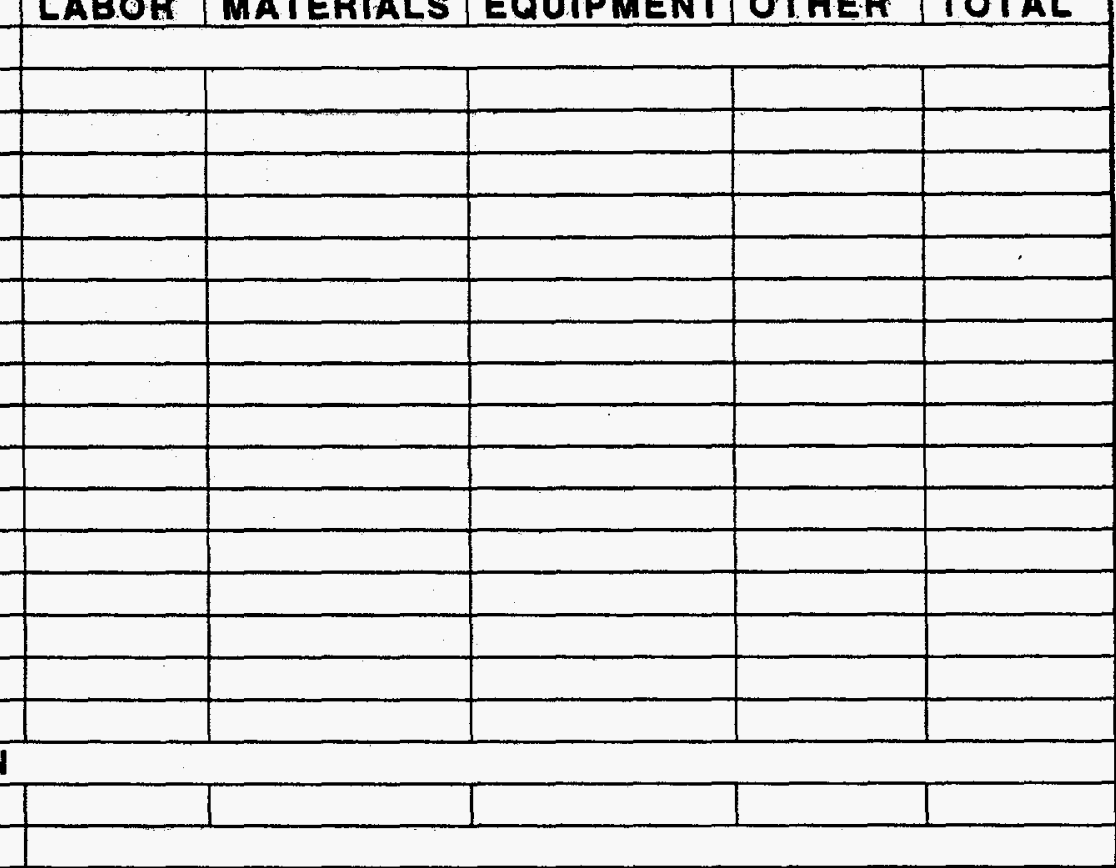
Appendix E: Compensation Ratios for Wetland Mitigation

\title{
Compensation Ratios for Wetland Mitigation
}

Guidelines and Tables for Applying the Methodology described in

"Watershed Management and Wetland Mitigation: A Framework for Determining Compensation Ratios"

\author{
By \\ Dennis M. King, Ph.D. \\ and \\ Curtis C. Bohlen, Ph.D. \\ University of Maryland, \\ Center for Environmental and Estuarine Studies, \\ Chesapeake Biological Laboratory \\ P.O. Box 38, Solomons, Maryland 20688
}

University of Maryland, CEES Report UMCEES-CBL-94-10, March 1994. Prepared under Cooperative Agreement Number CR818-227 with the U.S. EPA, Office of Policy Analysis with support from EPA Region IV (Atlanta) and Region IX (San Francisco). 


\section{BACKGROUND}

A modern industrial society cannot function without causing some harm to wetlands. Thus, despite concerted efforts to conserve remaining wetlands, some development projects that cannot be designed to completely avoid wetlands will occur. In such cases, those seeking permits from federal or state regulatory agencies charged with protecting wetlands will usually be required to mitigate wetland impacts by undertaking or funding wetland creation, restoration, or enhancement projects. To the regulators responsible for implementing wetland permitting programs, determining what constitutes appropriate mitigation for wetland losses is a central challenge. If compensatory mitigation requirements are set too low, they will fail to achieve the "no net loss" goal that the nation has established for wetlands. If compensation requirements are set too high, the associated economic costs and social disruptions will be excessive and will lead to frequent legal and political challenges, poor regulatory compliance, and an undermining of public support for wetland protection.

Some regulatory programs, including those in Maine, Florida, and Maryland, address the problem of determining what constitutes appropriate mitigation by using standard compensation ratios. These ratios establish the number of acres of created or restored wetlands required to offset each acre of damaged wetland (Want 1993). Typically, ratios vary by state and according to the type of wetland harmed and the type of mitigation proposed. The federal wetlands program administered under $\$ 404$ of the Clean Water Act, on the other hand, does not use standard ratios but instead relies on guidance contained in a 1990 U.S. Army Corps of Engineers/U.S. EPA Memorandum of Agreement (MOA) about what constitutes appropriate compensation. That MOA specifically requires that mitigation requirements should be based "solely on the values and functions of the aquatic resources impacted" and not on economic or other considerations. Compensation requirements under the federal program therefore, at least in principle, should be established on the basis of a comparison of the wetland functions and values expected from the compensation wetland and those lost with the destruction of the original wetland.

The relatively simple idea of comparing the wetland functions and values at the lost and replacement wetlands has proven to be complex in practice. Wetlands are important as forms of natural capital because they provide essential life support functions and generate streams of ecological and economic functions, products, and services. However, all wetlands are not equally valuable in ecological or economic terms. The value of each wetland depends on the level and characteristics of the many different biological and geophysical functions it provides, its proximity to other 
features of the watershed, and its accessibility to animal and human populations.

Assessing the adequacy of compensatory mitigation, therefore, involves comparing streams of wetland functions and values that would accrue if the original wetland were not disturbed with streams of functions and values expected from the proposed mitigation. This comparison depends on three key factors:

(1) The sustained levels of wetland function provided by the original and the replacement wetland, which depends only in part on their relative size (the compensation ratio);

(2) The speed with which the created or restored wetland reaches the sustained level of function that it is expected to provide; and

(3) The risk of mitigation failure, or more generally, uncertainty about the level of wetland function that the mitigation project will provide.

\section{EOCUS}

In a previous paper (King , Bohlen, and Adler 1993), the authors described a method for estimating compensation ratios based on these three factors. The method assesses whether trade-offs between wetland quality and wetland area that result from wetland mitigation result in an overall loss of wetland value. The method described in the previous report, does not deal explicitly with multiple sources of wetland value, and therefore is most useful when a single source of wetland value is of overriding management interest. However, as long as mitigation priorities and regional environmental goals have been established (e.g., through watershed planning), it can be applied in situations where multiple wetland values are of concern.

This paper responds to the many requests the authors have received for a set of simple instructions and look-up tables that will allow regulators, permit seekers, and others to estimate "appropriate" compensation ratios based on estimates or negotiated values of a few key parameters.

\section{THE BASIC FRAMEWORK}

The conceptual basis for the compensation ratio formula is depicted in Figure 1. Destruction of the original wetland (at time labeled $T_{0}$ in the figure) leads to a loss of $100 \%$ of it's value. A replacement wetland is created, enhanced, or restored to compensate for the loss of wetland functions. The replacement value of the mitigation site climbs gradually over a period of $C$ years from level $A$-the value provided by the mitigation site in the absence of the mitigation project-to some maximum level-level B. Both A and B 
are expressed as a percent of the per acre value of the original wetland. While $B$, the maximum level of (per acre) wetland value reached at the mitigation site, will typically be less than $100 \%$ of the value of the original wetland, that need not be the case, especially if the original wetland was seriously degraded.

\section{Compensation Model \\ Framework}

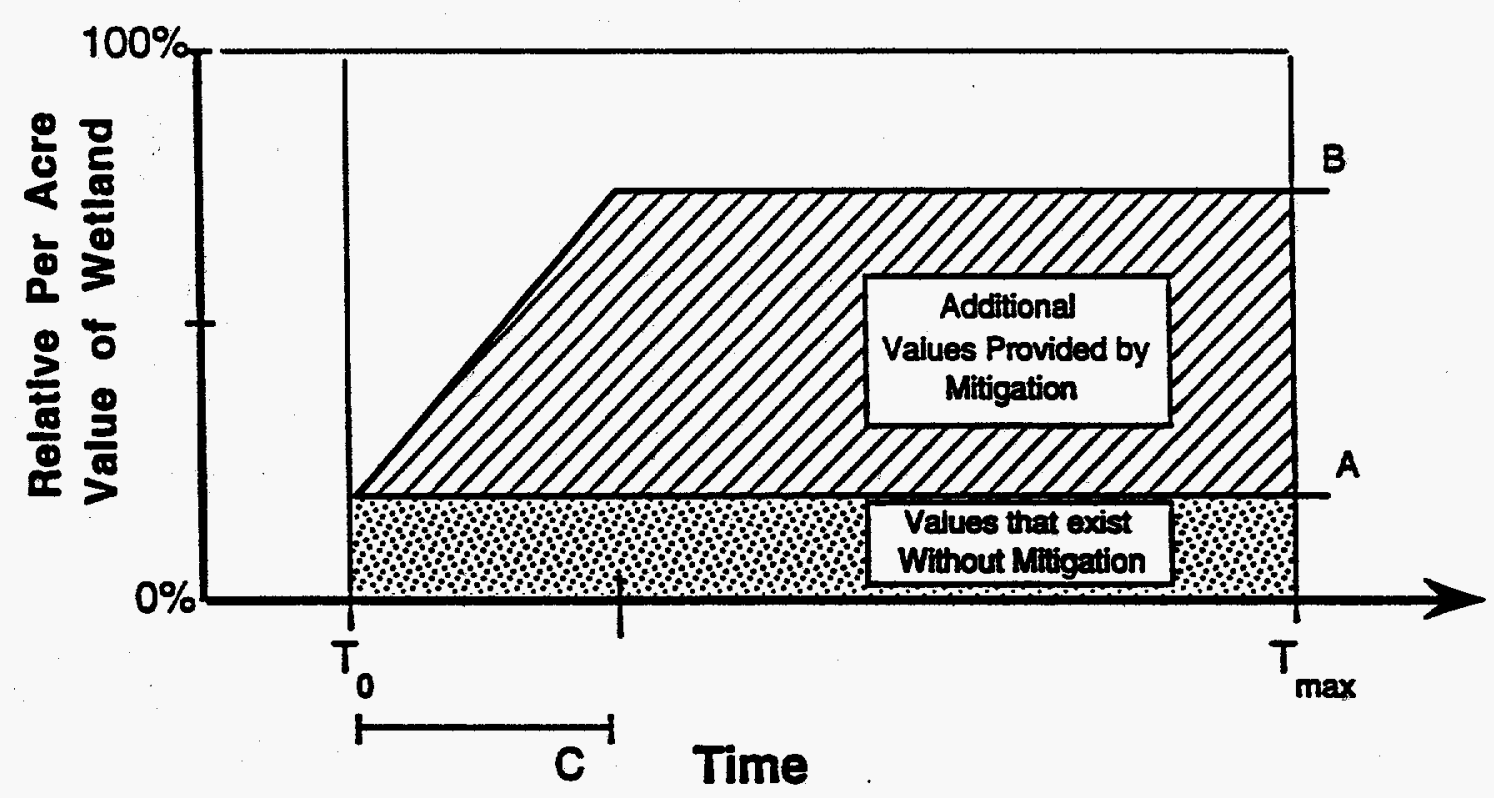

Figure 1: A Simple Wetlands Compensation Model

The total magnitude of the loss of wetland value caused by destruction of the original wetland is represented by the entire area under the $100 \%$ line from $T_{0}$, the time of destruction of the original wetland, to $T_{\max }$, the time horizon selected for the analysis. The maximum possible value of a mitigation project (ignoring for the moment risks of failure and other complications) would require that three conditions be met.

(1) The mitigation site produces wetland value sufficient to replace the value of the lost original wetland ( $B=100 \%$ or more);

(2) The mitigation site generates those maximum wetland values as soon as it is constructed $(\mathrm{C}=0)$; and

(3) Wetland values at the mitigation site in the absence of the mitigation activity are negligible $(A=0)$. Note that the value of $A$ is zero for wetland creation projects, low for restoration projects, and high for enhancement of existing wetlands.)

Such a scenario, however, is unlikely. Generally, wetland projects take years to reach full value $(C>0)$, and often, that full value is not as great as was 
found at the lost wetland $(B<0)$. As a practical matter, therefore, the portion of the original wetland loss that would be offset by mitigation if mitigation is provided on an acre-for-acre basis is depicted by the cross-hatched area and the white area above the cross-hatched area depicts lost values associated with the failure of the mitigation to be fully and immediately successful. The shaded area below the line at $\mathrm{A}$ depicts values already provided by the mitigation site that are not attributable to the mitigation effort. Thus the percentage loss of value with acre-for-acre mitigation depends on the values of $A, B$ and $C$, which are determined by the characteristics of the mitigation project.

\section{THE COMPENSATION FORMULA}

Since the cross-hatched area depicts the value provided by an acre of mitigation and the entire rectangle from $T_{0}$ to $T_{\max }$ depicts the values lost with each acre of the lost wetland, dividing the cross-hatched area by the total area gives the percentage loss of value with one-for-one mitigation. The inverse of this percentage gives a crude estimate of the "appropriate" compensation ratio-the number of acres of mitigation required per acre of lost wetland to achieve no net loss in wetland value.

This simple formula, however, misses a few important considerations. Regulators, acting in the public interest, cannot be indifferent to issues involving the timing and risk of compensatory mitigation. A more thorough version takes account of three additional factors, including

(1) time discounting - to account for the fact that wetland functions replaced in future years do not provide the same in value, measured in present value terms, as wetland functions lost today;

(2) risk-that a wetland creation or restoration project will not perform as well as expected; and

(3) advanced or delayed compensation-the possibility that a mitigation project may be completed and begin providing replacement wetland value either before or after the loss of the original wetland.

These refinements can be made by introducing a few new parameters that characterize when the mitigation is provided and the risk that the mitigation will fail and developing a compensation formula. The formula is not very complicated, but calculating compensation ratios directly from the formula can be time consuming. We have, therefore, developed a set of lookup tables, included as Attachment $A$, which provide the user with estimates of compensation ratios for various combinations of parameter values that characterize the proposed mitigation. To use the tables, the user needs to estimate or somehow settle upon acceptable values of the following parameters: 
A: The level of wetland function provided per acre at the mitigation site prior to the mitigation project, expressed as a percentage of the value of the original wetland;

B: $\quad$ The maximum level of wetland function each acre of successful mitigation is expected to attain, if it is successful, expressed as a percent of the per acre value of the original wetland;

C: The number of years after construction that the mitigation project is expected to achieve maximum function;

$D$ : The number of years before destruction of the original wetland that the mitigation project begins to generate mitigation values (negative values represent delayed compensation);

E: The percent likelihood that the mitigation project will fail and provide none of the anticipated benefits (with mitigation failure, wetland values at the mitigation site return to level $A$ )

$r$ : The discount rate used for comparing values that accrue at different times at their present value (Tables provide estimates based on discount rates of $0 \%, 5 \%$, and $10 \%$ ).

$T_{\text {max: }}$ The time horizon used in the analysis (Using the OMB recommended discount rate of $r=7 \%$ comparisons of value beyond about $t=75$ years are of negligible significance)

\section{V.SOMEILLUSTRATIONS}

Table 1 shows some calculated compensation ratios based on the compensation formula. The first three cases show the effects on the resulting compensation ratio of delaying or advancing the compensatory mitigation project. The next three examples illustrate how pre-existing wetland values or compensation for the loss of a degraded wetland affect compensation requirements. The final set of examples illustrate how the assessment of failure risk can affect estimated compensation ratio.

The characteristics of the mitigation project itself, as reflected in the values of $A, B$, and $C$ are of obvious importance. The last example shown, however, illustrates why advanced mitigation should provide a significant advantage over concurrent mitigation in terms of compensation requirements. Since many mitigation failures can (1) be detected, and (2) be corrected within a year or so of project construction, advanced compensation allows a permittee or a mitigation banker to manage many controllable risk factors and significantly lower the risk of failure. At the same time, advanced mitigation provides replacement wetland values sooner than concurrent 
mitigation so there is less discounting of replacement values and more resulting mitigation credit per acre. Combined, these factors result in a substantial advantage for advanced as compared to concurrent mitigation in terms of the number of mitigation acres required. Lower compensation ratios for advanced mitigation mean lower mitigation costs, which in many cases could more than offset the cost of committing funds for advanced mitigation or investing in a mitigation bank.

Table 1. Calculated compensation ratios for a variety of hypothetical compensation scenarios, based on a time horizon $\left(T_{\max }\right)$ of 100 years.

\begin{tabular}{|c|c|c|c|c|c|c|c|c|c|}
\hline & & & & & & \multicolumn{4}{|c|}{$\begin{array}{c}\text { COMPENSATION } \\
\text { RATIOS }\end{array}$} \\
\hline & \multicolumn{5}{|c|}{ Parameters } & \multicolumn{4}{|c|}{$\begin{array}{c}\text { Discount } \\
\text { Rate }\end{array}$} \\
\hline & A & B & C & D & $\mathbf{E}$ & $0 \%$ & $5 \%$ & $10 \%$ & $20 \%$ \\
\hline Concurrent Creation & $\begin{array}{l}0 \\
0\end{array}$ & 0.7 & 10 & 0 & 0 & 1.5 & 1.9 & 23 & 3.4 \\
\hline Advanced Creation & 0 & 0.7 & 10 & 5 & 0 & 1.4 & 1.5 & 1.4 & 1.4 \\
\hline Delayed Creation & 0 & 0.7 & 10 & -5 & 0 & 1.6 & 2.4 & 3.7 & 8.5 \\
\hline Concurrent Restoration & 0.1 & 0.7 & 10 & 0 & 0 & 1.8 & 2.2 & 2.7 & 4. \\
\hline Original Wetland Degraded & 0 & 1.4 & 10 & 0 & 0 & 0.8 & 0.9 & 1.2 & 1.70 \\
\hline Concurrent Enhancement & 0.5 & 0.7 & 10 & $\mathbf{0}$ & 0.2 & 6.6 & 8.1 & 102 & 15.0 \\
\hline Difficult Creation & 0 & 0.7 & 10 & 0 & 0.5 & 3.0 & 3.7 & 4.7 & 6.8 \\
\hline Very Difficult Creation & 0 & 0.7 & 10 & $\mathbf{0}$ & 0.75 & 6.0 & 7.4 & 9.3 & 13.6 \\
\hline $\begin{array}{l}\text { Same, Advanced and Risk } \\
\text { Adjusted }\end{array}$ & 0 & 0.7 & 10 & 5 & 0.2 & 1.8 & 1.8 & 1.8 & 1.7 \\
\hline
\end{tabular}




\section{WETLAND COMPENSATION RATIOS IN FIVE EASY STEPS}

\section{The Approach}

A report entitled Watershed Planning and Wetland Mitigation: A Framework for Determining Wetland Compensation Ratios by Dennis M. King and Curtis C Bohlen of the University of Maryland, Center for Environmental and Estuarine Studies describes what the authors believe is a technically and legally defensible method for estimating compensation ratios for wetland mitigation (acres of created, restored or enhanced wetland required to compensate for an acre of lost natural wetland).

The method requires that users estimate or at least agree to values of five parameters that characterize the wetland functions and values to be gained and lost over time with acre for acre replacement. The parameters are then used in a modified present value formula to estimate the compensation ratio that would be required to achieve no net loss of wetland value over time. The authors have developed the enclosed look-up tables that contain estimated compensation ratios for a full range of parameter values.

\section{The Key Parameters}

A: The level of per acre wetland function at the compensation site prior to the compensation project, expressed as a proportion of the value of the original wetland;

B: The maximum acre by acre level of wettand function the compensation project will reach, expressed as a proportion of the per acre value of the original wetland;

C. The year after construction of the compensation project that it achieves maximum function;

D. The number of years before destruction of the original wetland (at time $t=0$ ) that construction of the compensation project occurs (negative values represent delayed mitigation, positive values, advanced mitigation);

E: The percent likelihood that the project will fail and wethand values at the mitigation site will remain at $A$

E: The estimated chance that the mitigation project will fail and provide substantially fewer environmental benefits than anticipated

5. The discount rate used to arrive at the present value of wetland values that accue in the future.

\section{The Five Easy Steps}

STEP 1 Estimate or negotiate acceptable values of $A, B, C, D, E$, and r.

STEP 2 Calculate the expected value of $B$, the value of $B$ adjusted to account for the risk of project failure, using the following equation:

$$
B_{\text {ad) }}=B(1-E)+A E
$$

STEP 3: Calculate $V$, the expected increase in wetland values at the mitigation site due to the mitigation project, where:

$$
\text { Increase }=B_{\text {odf }}-A
$$

STEP 4 Go to the Table that corresponds to the selected value of $D$. In the tables provided $D$ can range from +5 (mitigation initiated five years in advance of wetland loss) to -5 (mitigation initiated five years after wettand loss).

STEP 5 Locate the frame that correspond to the calculated value of $V$ and $C$. and pick the Compensation Ratio that corresponds to the selected discount rate of $0 \%$ (top), $5 \%$ (middle) or $10 \%$ (bottom)

For further information contact Dennis King or Curtis Bohlen at :

University of Maryland, Center for Environmental and Estuarine Studies, P.O. Box 38, Solomons, Maryland 20688 (410-326-7212) 


\section{Concurrent Compensation}

\section{Using Compensation Ratio Tables}

There are eloven separalo tables, one for concurrent mitigation.

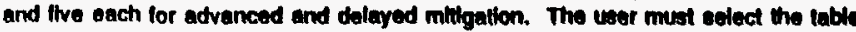

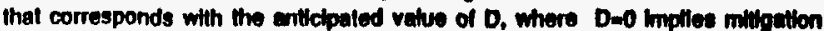

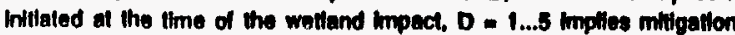

between one and the years $t h$ advance of the welland hmpact. and $D=-1$ to -5 indicates milligallon begun from one to 5 yeare anter the wettend trpact. All lables are based on $T$ max $=100$ years.

STEP I Estlmaic or negotlate nceeptable valuee of A, B, C, D, E, and r.

STEP 2 Adfus the value of $B$ to accoum tor the rlok of propect lathure

$$
B_{\omega}=\text { E(I-E)+AE }
$$

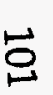

STEP 3 Celcutale $V$, the expected merease in wetland vatue div to the compeneallon profort.

STEP 4 Bo to the Table that corresponds to the selectod vahue of D.

Values rango from -5 (delayed milugallon) to +S(advenced mitigallon).

STEP 5 Locate the freme that correspond to the valuse of $V$ and $C$.

and read the compensallon ratto lor discoumt ritee of $0 \%$, s\% or tox.

To calculate compensation ratios not provided in these tables, wee the general formute, witich be

$$
\left.R=\frac{C \sum_{r=0}^{+\infty}(1+r)^{-1}}{(1-E)(B-A)\left[\sum_{1=-0}^{c-D}\left[(t+D)(1+r)^{-1}\right]+C \sum_{(c-D)+1}^{r}(1+r)^{-1}\right.}\right]
$$

Valve D:_ 0

\begin{tabular}{|c|c|c|c|c|c|c|c|c|c|c|}
\hline & 1 & 2 & 4 & 6 & 1 & 10 & 11 & 20 & 23 & 30 \\
\hline \multirow{3}{*}{$120 x$} & 0.70 & 0.70 & 0.79 & 0.00 & 0.01 & 0.01 & 0.84 & 0.00 & 0.60 & 1.03 \\
\hline & 0.011 & 0.03 & 0.07 & 0.01 & 0.85 & 1.00 & 1.12 & 124 & 1.37 & 2.13 \\
\hline & 0.05 & 0.00 & 0.07 & 1.00 & 1.19 & 1.25 & 1.52 & 1.01 & 2.12 & 3.60 \\
\hline \multirow[t]{3}{*}{$1200 x$} & 0.24 & 0.85 & 0.05 & 0.08 & 0.87 & 0.80 & 0.01 & 0.09 & 0.00 & 1.11 \\
\hline & 0.00 & 0.00 & 0.04 & 0.00 & 1.03 & 1.00 & 121 & 1.34 & 1.49 & 2.91 \\
\hline & 0.02 & 0.0 & 1.05 & 1.18 & 125 & 1.28 & 1.4 & 1.00 & 2,30 & 4.20 \\
\hline \multirow[t]{3}{*}{$110 x$} & 0.02 & 0.12 & 0.90 & 0.04 & 0.8 & 0.90 & 0.96 & 1.01 & 1.00 & 1.22 \\
\hline & 0.9 & 0.00 & 1.08 & 1.00 & 1.19 & 1.18 & 1.32 & 1.47 & 1.62 & 2.52 \\
\hline & 1000 & 1.00 & 1.18 & 125 & 130 & 1.40 & 1.70 & 2.14 & 2.50 & 4.59 \\
\hline \multirow[t]{3}{*}{$100 x$} & 1.01 & 1.02 & 1.00 & 1.04 & 1.08 & 1.00 & 1.00 & 1.18 & 1.15 & 1.34 \\
\hline & 1.08 & 1.00 & 1.19 & 8.10 & 124 & 1.30 & 1.45 & 1.01 & 1.70 & 2.77 \\
\hline & 1,10 & 1.18] & 128 & 1.30 & 150 & 1.09 & 1.9? & 2.35 & 2.75 & 5.00 \\
\hline \multirow{3}{*}{$\infty x$} & 1.18 & 1.19 & 1.14 & 9.16 & 1.10 & 1.10 & 121 & 1.24 & 180 & 1.49 \\
\hline & 0.17 & 1.20 & 125 & 1.52 & 1.50 & 1.44 & 1.64 & 1.70 & 1.90 & 3.00 \\
\hline & 122 & 120 & 1.40 & 1.50 & 1.07 & 1.01 & 2.18 & 2.01 & 3.00 & 5.60 \\
\hline \multirow[t]{3}{*}{$6 x$} & 120 & 181 & 120 & 1.00 & 1.91 & 1.32 & 1.36 & 1.40 & 1.43 & 1.67 \\
\hline & 1.91 & 1.90 & 0.41 & 1.00 & 1.65 & 1.02 & 1.01 & 2.01 & 223 & 0.47 \\
\hline & 123 & 1.4. & 1.80 & 1.22 & 102 & 2.09 & 247 & 2.04 & 3.4 & e.34 \\
\hline \multirow{3}{*}{$\pi x$} & 1.44 & 1.45 & 1.40 & 1.40 & 1.80 & 1.81 & 1.35 & 1.80 & 1.04 & 1.11 \\
\hline & 180 & 184 & 1.01 & 1.09 &.$n$ & 1.05 & 2.07 & 8.30 & 2.55 & 3.98 \\
\hline & 137 & 1.69 & 1100 & 1.02 & 2.14 & 2.20 & 202 & 0.30 & 3.04 & 121 \\
\hline \multirow[t]{3}{*}{ 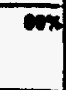 } & 1.00 & 1.0 & 1.71 & 8.75 & 1.74 & 1.70 & 1.01 & 1.06 & 1.01 & 2.23 \\
\hline & 1.78 & 1.70 & 1.600 & 1.07 & 2.07 & 2.10 & 2.42 & 2.69 & 2.91 & 4.62 \\
\hline & 1.00 & 1.02 & 2.10 & 200 & 2.80 & 2.71 & 320 & 0.02 & 4.59 & 0.41 \\
\hline \multirow[t]{3}{*}{$\mathbf{c o x}$} & 2.00 & 2.00 & 2.05 & 2.07 & 2.00 & 2.12 & 2.17 & 2.23 & 830 & 204 \\
\hline & 2.10 & 2.10 & 2.20 & e.97! & 2.40 & 2.00 & 2.00 & 0.22 & 9.51 & 3.58 \\
\hline & 20 & 230 & 200 & 2.70 & 9.00 & 920 & $\mathbf{0 . 0 4}$ & 4.70 & 8.51 & 10.09 \\
\hline \multirow[t]{3}{*}{$\sqrt{m x}$} & 8.60 & 2.04 & 2.50 & 280 & 2.62 & 2.64 & $2 . n$ & 2.7 & 2.07 & $\mathbf{5 . 3 4}$ \\
\hline & 2.09 & 2.06 & 8.02 & $2 . \infty$ & 9.10 & 0.24 & 3.02 & 4.09 & 404 & 8001 \\
\hline & 2.78 & 20 & .3.13 & 3.46 & 0.78 & s.07 & 4.93 & 807 & 0.09 & 12.61 \\
\hline \multirow{3}{*}{$\sin$} & 9.97 & 2.00 & 0.92 & 9.48 & 0.40 & 3.59 & 3.62 & 9.72 & 9.03 & 9.40 \\
\hline & 9.00 & 9.60 & 9.70 & sest & 4.19] & 1.53 & 4.003 & 5.37 & 5.05 & 0.25 \\
\hline & 2.00 & 9.200| & 121 & 4.50 & 8.00 & 8.43 & 0.81 & 7.09 & 8.10 & 18.01 \\
\hline \multirow[t]{3}{*}{$\sin$} & 8.03 & 8.00 & 5.19 & 8.10 & 8.80 & 820 & 8.49 & 8.50 & 5.74 & 6.69 \\
\hline & 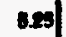 & 6.00 & 8.05 & 8.02 & 020 & 0.49 & 128 & 0.00 & 0.02 & 13.07 \\
\hline & ceo & $8 . x$ & 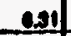 & end & 200 & 0.14 & 200 & $11.7 \mathrm{~s}$ & $19 . m$ & 25.22 \\
\hline \multirow[t]{3}{*}{$\sin$} & 90.10 & 10.10 & 10.85 & 10.50 & 10.41 & 10.80 & 10.06 & 11.10 & 11,40 & 13.30 \\
\hline & 10.00 & $10 . \pi$ & 1120 & 11.04 & 12.00 & 12.20 & 1400? & 16.12 & 17.00 & 25.74 \\
\hline & $1 \mathrm{~d}$ & $x=0$ & 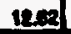 & $12 \pi$ & 1800 & 1020 & 10.7 & 20.40 & 21.55 & 50,44 \\
\hline
\end{tabular}

Value of C 


\section{Delayed Compensation}

Yaluo of D: $\quad-1$

Volue of $\mathrm{C}$

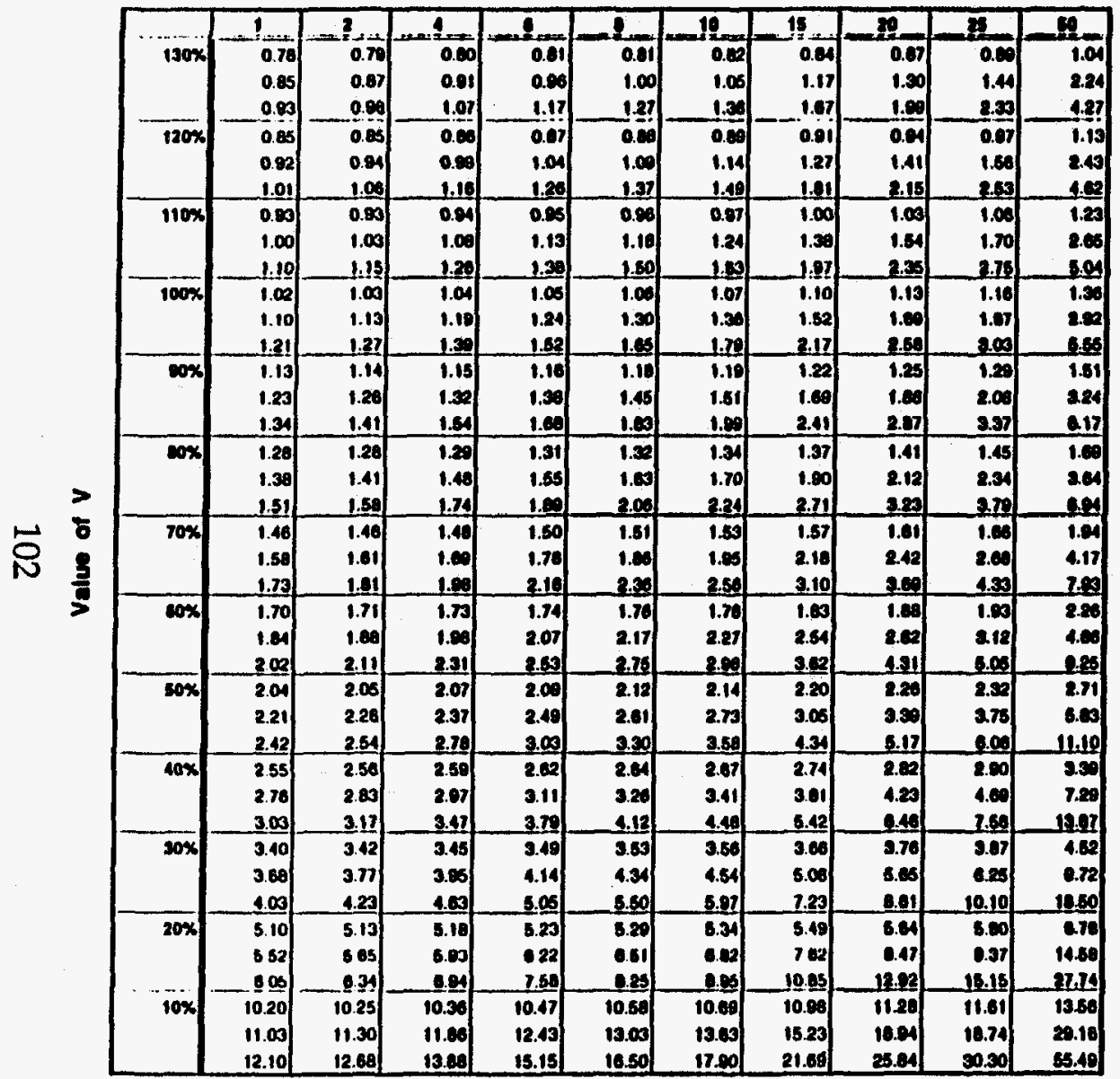

VDlwor

Value of C

Value of $r$

\begin{tabular}{|c|c|c|c|c|c|c|c|c|c|c|c|}
\hline & 1 & 8 & 4 & e. & 8 & 10 & 15 & 20 & 23 & 50 & \\
\hline $130 x$ & $\begin{array}{l}0.70 \\
0.00 \\
1.00\end{array}$ & $\begin{array}{l}0.00 \\
0.01 \\
1.07\end{array}$ & $\begin{array}{l}0.01 \\
0.86 \\
1.17\end{array}$ & $\begin{array}{l}0.01 \\
1.00 \\
1.29\end{array}$ & $\begin{array}{l}0.82 \\
1.05 \\
1.40\end{array}$ & $\begin{array}{l}0.60 \\
1.10 \\
1.61\end{array}$ & $\begin{array}{l}0.85 \\
1.23 \\
1.94\end{array}$ & $\begin{array}{l}0.00 \\
1.37 \\
2.10\end{array}$ & $\begin{array}{l}0.80 \\
1.51 \\
2.56\end{array}$ & $\begin{array}{l}1.06 \\
2.36 \\
1.70\end{array}$ & $\begin{array}{l}0 \% \\
5 \% \\
10 \%\end{array}$ \\
\hline $120 x$ & $\overrightarrow{0.60}$ & 0.06 & 0.07 & 0.80 & 0.89 & 0.80 & 0.92 & 0.85 & 0.90 & 1.15 & \\
\hline & 0.07 & 0.00 & 1.04 & 1.00 & 1.14 & 1.10 & 1.33 & 1.48 & 1.64 & 2.55 & \\
\hline & 1.11 & 1.10 & 1.27 & 1.39 & 1.61 & 1.64 & 1.02 & 2.37 & 2.78 & 5.09 & \\
\hline $\operatorname{tiox}$ & 0.04 & 0.04 & 0.85 & 0.80 & 0.97 & 0.89 & 1.01 & 1.04 & 1.07 & 1.25 & \\
\hline & 1.06 & 1.00 & 1.13 & 8.10 & 1.24 & 1.30 & 1.45 & 1.62 & 1.79 & 2.79 & \\
\hline & 121 & 183 & 139 & 1.62 & 1.65 & 1.79 & 2.12 & 2.50 & 3.03 & 5.55 & \\
\hline $\sin x$ & 1.00 & 1.04 & 1.05 & 1.08 & 1.07 & 1.00 & 1.11 & 1.14 & 1.17 & 1.37 & \\
\hline & 1.16 & 1.10 & 1.25 & 1.31 & 1.37 & 1.43 & 1.00 & 1.78 & 1.87 & 3.06 & \\
\hline & 1.30 & 1.20 & 1.83 & 1.67 & 1.01 & 1.07 & 2.39 & 2.04 & .3.33) & 6.10 & \\
\hline $\cos$ & 1.15 & 1.15 & 8.18 & 1.10 & 1.10 & 1.20 & 1.23 & 1.27 & 1.30 & 1.53 & \\
\hline & 1.20 & 1.32 & 1.30 & 1.45 & 1.32 & 1.69 & 1.78 & 1.98 & 2.18 & 3.41 & \\
\hline & 1.40 & 1.65 & 1.70 & 1.05 & 2.02 & 2.10 & 2.65 & 3.16 & 3.70 & 8.78 & \\
\hline$\omega x$ & 1.20 & 1.20 & 1.31 & 1.32 & 1.34 & 1.35 & 1.39 & 1.43 & 1.47 & 1.72 & \\
\hline & 1.46 & 1.40 & 1.50 & 1.03 & 1.71 & 1.79 & 2.00 & 2.22 & 2.46 & 3.83 & \\
\hline & 1.0 & 1.14 & 1.91 & 2.00 & 2.27 & 2.40 & 2.08 & 3.65 & 1.117 & 7.63 & \\
\hline $20 x$ & 1.47 & 1.40 & 1.60 & 1.31 & 1.63 & 1.54 & 1.58 & 1.60 & 1.68 & 1.86 & \\
\hline & 1.06 & 1.70 & 1.70 & 1.87 & 1.86 & 2.05 & 2.20 & 2.64 & 2.01 & 4.30 & \\
\hline & 1.00 & 10 & 2.10 & 2.30 & 2.60 & 2.01 & 3.41 & 1.00 & 4.76 & 8.72 & \\
\hline $\cos x$ & 1.72 & 1.79 & 1.74 & 1.76 & 1.78 & 1.00 & 1.25 & 1.00 & 1.96 & 2.29 & \\
\hline & 1.08 & 1.ce) & 800 & 2.10 & 2.20 & 2.30 & 2.07 & 2.97 & 328 & 5.11 & \\
\hline & 29 & 832 & 2.64 & 2.70 & 2.02 & 3.28 & 3.08 & 4.74 & 5.56 & 10.17 & \\
\hline $\cos$ & 2.00 & 2.07 & 2.00 & 2.12 & 2.14 & 2.10 & 2.22 & 2.28 & 2.35 & 2.75 & \\
\hline & 2.20 & 2.37 & 2.40 & 2.61 & 2.74 & 2.80 & 3.20 & 3.58 & 3.94 & 6.13 & \\
\hline & 200 & 2.20 & 2.05 & 3.30 & 3.09 & 3.0.9 & 4.77 & 5.69 & 6.67 & $12.2 !$ & \\
\hline $40 \%$ & 8.60 & 2.50 & 2.62 & 2.04 & 2.87 & 2.70 & 2.71 & 2.05 & 2.94 & 344 & \\
\hline & 8.00 & 2.07 & 3.11 & 3.27 & 3.42 & 3.50 & 4.00 & 4.45 & 4.92 & 7.66 & \\
\hline & $2 \times 2$ & 9.48 & 3.01 & 4.17 & 4.89 & 1.02 & 6.2? & 2.11 & 0.33 & 15.26 & \\
\hline 200 & 3.41 & 3.45 & 9.40 & 3.53 & 3.56 & 3.80 & 3.70 & 3.00 & 3.91 & 4.58 & \\
\hline & 3.06 & 3.00 & 1.18] & 4.35 & 4.58 & $4 . m$ & 5.330 & 6.93 & 6.56 & 10.22] & \\
\hline & 4.44 & 4.05 & 8.00 & 3.50 & 6.05 & 6.56 & 7.95 & 0.48 & $11 ! 4 !$ & 2035 & \\
\hline $20 x$ & 6.16 & 6.10 & 6.23 & 6.28 & 5.34 & 5.40 & B.55 & 5.71 & 5.87 & 607 & \\
\hline & B.78 & 6.001 & 0.23 & 0.63 & 0.84 & 7.16 & $-\infty$ & - $(x)$ & 1005 & is $\mathrm{d}:$ & \\
\hline & ...6. & 0.92 & 1.63 & 0.34 & 2.07 & 0.85 & 11.03 & $14.2 !$ & 16.67 & 3052 & \\
\hline $100 x$ & 10.31 & 10.36 & $\mid 10.47$ & 10.50 & 10.69 & 10.80 & 11.10 & 11.41 & 11.74 & 13.74 & \\
\hline & 11.59 & 11.07 & 12.46 & 13.06 & 13.68 & 14.32 & 18.00 & 17.79 & 19.69 & 30.65 & \\
\hline & |3.31 & 13.24 & 18,27 & 10.07 & 18.13 & 10.69 & 20.00 & 28.43 & 33..33| & 61.04 & \\
\hline
\end{tabular}




\section{Delayed Compensation}

Velue of D: $-3$

Value of C

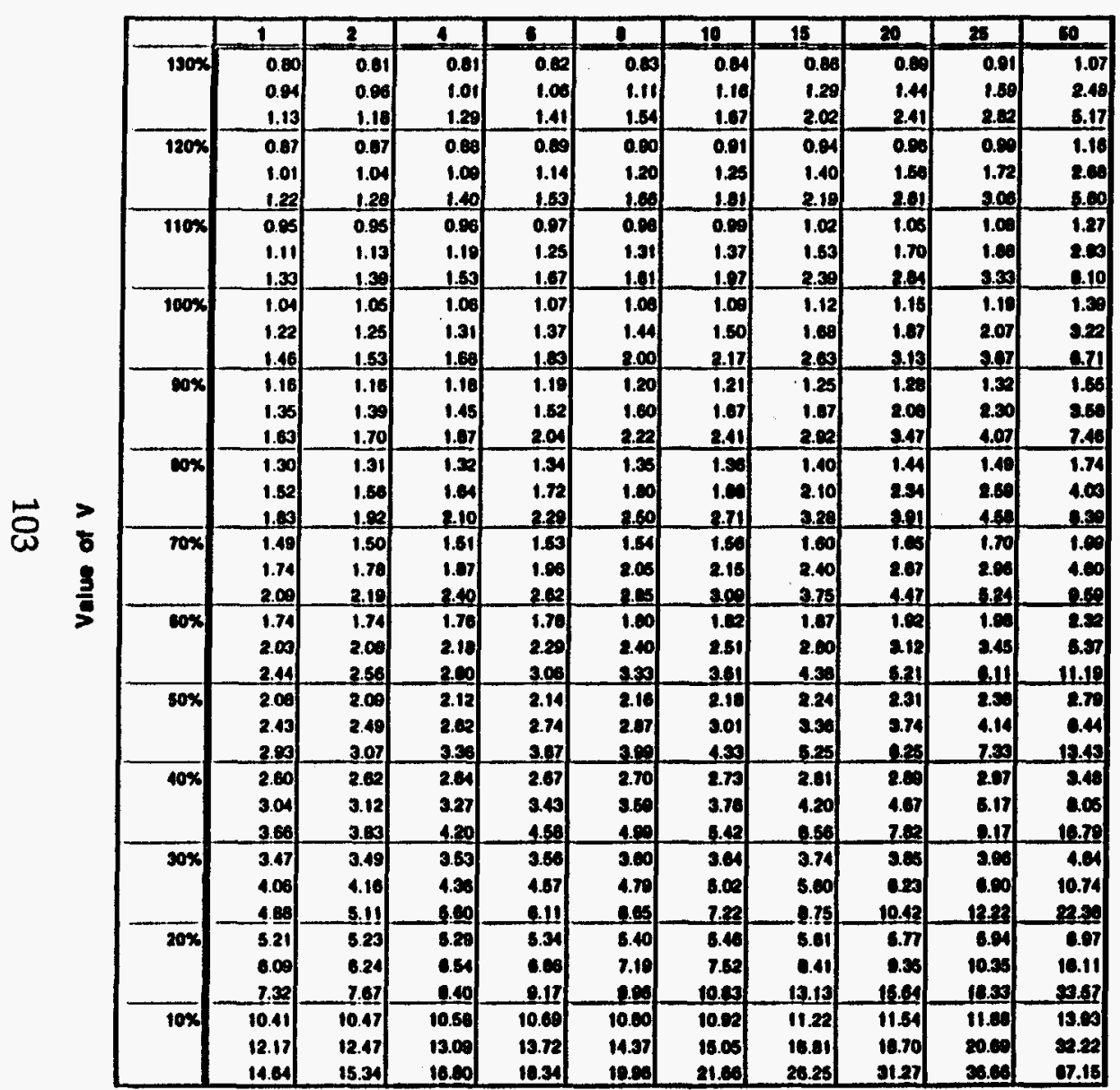

Value of $\mathrm{C}$

Value of $r$

\begin{tabular}{|c|c|c|c|c|c|c|c|c|c|c|c|}
\hline & 1 & 2 & 1 & 6 & 1 & 10 & 48 & 20 & 25 & 50 & \\
\hline $120 x$ & $\begin{array}{l}0.01 \\
0.09 \\
1.24\end{array}$ & $\begin{array}{l}0.81 \\
1.01 \\
1.30\end{array}$ & $\begin{array}{l}0.02 \\
1.06 \\
1.42 \\
\end{array}$ & $\begin{array}{l}0.03 \\
1.11 \\
1.55 \\
\end{array}$ & $\begin{array}{l}0.84 \\
1.16 \\
1.69\end{array}$ & $\begin{array}{l}0.05 \\
1.22 \\
1.03\end{array}$ & $\begin{array}{l}0.07 \\
1.30 \\
2.22 \\
\end{array}$ & $\begin{array}{l}0.80 \\
1.51 \\
2.65 \\
\end{array}$ & $\begin{array}{l}0.92 \\
1.67 \\
3.10\end{array}$ & $\begin{array}{l}1.09 \\
2.61 \\
5.68 \\
\end{array}$ & $\begin{array}{c}0 \% \\
5 \% \\
10 \%\end{array}$ \\
\hline $1200 \%$ & $\begin{array}{l}0.60 \\
1.08 \\
.3 .30\end{array}$ & $\begin{array}{l}0.68 \\
1.00 \\
.04\end{array}$ & $\begin{array}{l}0.60 \\
1.18 \\
1.54\end{array}$ & $\begin{array}{l}0.80 \\
1.20 \\
1.80\end{array}$ & $\begin{array}{l}0.01 \\
1.26 \\
1.83\end{array}$ & $\begin{array}{l}0.82 \\
1.32 \\
1.99\end{array}$ & $\begin{array}{l}0.05 \\
1.47 \\
2.41\end{array}$ & $\begin{array}{l}0.97 \\
1.64 \\
2.87\end{array}$ & $\begin{array}{l}1.00 \\
1.01 \\
3.36\end{array}$ & $\begin{array}{l}1.16 \\
2.82 \\
6.16\end{array}$ & \\
\hline 1100 & $\begin{array}{l}0.10 \\
1.10 \\
1.40\end{array}$ & $\begin{array}{l}0.00 \\
1.10 \\
1.69 \\
\end{array}$ & $\begin{array}{l}0.07 \\
1.25 \\
1.69\end{array}$ & $\begin{array}{l}0.00 \\
1.31 \\
1.83 \\
\end{array}$ & $\begin{array}{l}0.09 \\
1.37 \\
2.00 \\
\end{array}$ & $\begin{array}{l}1.00 \\
1.44 \\
2.12\end{array}$ & $\begin{array}{l}1.03 \\
1.61 \\
2.63 \\
\end{array}$ & $\begin{array}{l}1.06 \\
1.79 \\
3.13 \\
\end{array}$ & $\begin{array}{l}1.09 \\
1.08 \\
3.67 \\
\end{array}$ & $\begin{array}{l}1.20 \\
3.00 \\
6.72\end{array}$ & \\
\hline $100 \%$ & $\begin{array}{l}1.08 \\
1.28 \\
1.01\end{array}$ & $\begin{array}{l}1.06 \\
1.31 \\
1.00\end{array}$ & $\begin{array}{l}1.07 \\
1.37 \\
1.08\end{array}$ & $\begin{array}{l}1.00 \\
1.44\end{array}$ & $\begin{array}{l}1.00 \\
1.51 \\
2.20\end{array}$ & $\begin{array}{l}1.10 \\
1.50 \\
2.30\end{array}$ & $\begin{array}{l}1.13 \\
1.77 \\
2.69\end{array}$ & $\begin{array}{l}1.17 \\
1.96 \\
3.44\end{array}$ & $\begin{array}{l}1.20 \\
2.17 \\
4.03\end{array}$ & $\begin{array}{l}1.41 \\
3.39 \\
7.39\end{array}$ & \\
\hline $\cos$ & $\begin{array}{l}1.17 \\
1.12 \\
1.20 \\
\end{array}$ & $\begin{array}{l}1.16 \\
1.40 \\
1.07 \\
\end{array}$ & $\begin{array}{l}1.10 \\
1.63 \\
2.05 \\
\end{array}$ & $\begin{array}{l}1.20 \\
1.60 \\
2.24 \\
\end{array}$ & $\begin{array}{l}1.21 \\
1.60 \\
2.44\end{array}$ & $\begin{array}{l}1.23 \\
1.76 \\
2.05 \\
\end{array}$ & $\begin{array}{l}1.26 \\
1.96 \\
3.21\end{array}$ & $\begin{array}{l}1.30 \\
2.10 \\
3.02 \\
\end{array}$ & $\begin{array}{l}.34 \\
2.42 \\
1.49\end{array}$ & $\begin{array}{l}1.57 \\
3.76 \\
0.21\end{array}$ & \\
\hline $\mathbf{c o x}$ & $\begin{array}{l}1.32 \\
1.00 \\
2.01\end{array}$ & $\begin{array}{l}1.32 \\
1.44 \\
.11\end{array}$ & $\begin{array}{l}1.34 \\
1.72 \\
2.34\end{array}$ & $\begin{array}{l}1.36 \\
1.00 \\
260\end{array}$ & $\begin{array}{l}1.36 \\
1.00 \\
2.74\end{array}$ & $\begin{array}{l}1.36 \\
1.00 \\
2.80\end{array}$ & $\begin{array}{l}1.12 \\
2.21 \\
3.21\end{array}$ & $\begin{array}{l}1.46 \\
2.46 \\
4.30\end{array}$ & $\begin{array}{l}1.50 \\
2.72 \\
5.04\end{array}$ & $\begin{array}{l}1.77 \\
4.23 \\
0.23\end{array}$ & \\
\hline $700 x$ & $\begin{array}{r}1.80 \\
1.60 \\
820\end{array}$ & $\begin{array}{l}1.81 \\
1.07 \\
2.41 \\
\end{array}$ & $\begin{array}{l}1.83 \\
1.00 \\
2.40\end{array}$ & $\begin{array}{l}1.64 \\
2.00 \\
2.06 \\
\end{array}$ & $\begin{array}{r}1.50 \\
2.16 \\
3.14 \\
\end{array}$ & $\begin{array}{l}1.30 \\
2.28 \\
3.40 \\
\end{array}$ & $\begin{array}{l}1.62 \\
2.52 \\
4.13 \\
\end{array}$ & $\begin{array}{l}1.67 \\
2.01 \\
4.91 \\
\end{array}$ & $\begin{array}{l}1.72 \\
3.11 \\
8.76 \\
\end{array}$ & $\begin{array}{r}2.02 \\
1.64 \\
10.55 \\
\end{array}$ & \\
\hline $\cos$ & $\begin{array}{l}1.78 \\
2.10 \\
2.0\end{array}$ & $\begin{array}{l}1.70 \\
2.10 \\
2.41\end{array}$ & $\begin{array}{l}1.70 \\
2.20 \\
2.00\end{array}$ & $\begin{array}{l}1.00 \\
2.40 \\
3.30 \\
\end{array}$ & $\begin{array}{l}1.02 \\
2.52 \\
3.66\end{array}$ & $\begin{array}{l}1.04 \\
2.63 \\
3.97 \\
\end{array}$ & $\begin{array}{l}1.60 \\
2.04 \\
4.01\end{array}$ & $\begin{array}{l}1.05 \\
3.27 \\
5.72 \\
\end{array}$ & $\begin{array}{l}2.00 \\
3.62 \\
6.22\end{array}$ & $\begin{array}{r}2.35 \\
5.64 \\
12.3 !\end{array}$ & \\
\hline $100 x$ & $\begin{array}{l}2.10 \\
2.60 \\
2.28\end{array}$ & $\begin{array}{l}2.12 \\
2.62 \\
.327\end{array}$ & $\begin{array}{l}2.14 \\
2.76 \\
3.70\end{array}$ & $\begin{array}{l}2.10 \\
2.00 \\
4.08\end{array}$ & $\begin{array}{l}2.16 \\
3.02 \\
4.39\end{array}$ & $\begin{array}{l}2.21 \\
3.16 \\
4.72\end{array}$ & $\begin{array}{l}2.27 \\
3.53 \\
5.79\end{array}$ & $\begin{array}{l}2.34 \\
3.903 \\
6.60\end{array}$ & $\begin{array}{l}2.40 \\
4.35 \\
8.07\end{array}$ & $\begin{array}{r}2.03 \\
0.17 \\
14.77\end{array}$ & \\
\hline $\operatorname{cox}$ & $\begin{array}{l}2.00 \\
3.20 \\
4.00 \\
\end{array}$ & $\begin{array}{l}2.04 \\
3.20 \\
1.22 \\
\end{array}$ & $\begin{array}{l}.67 \\
3.44 \\
4.62\end{array}$ & $\begin{array}{l}2.70 \\
3.00 \\
5.00\end{array}$ & $\begin{array}{l}2.73 \\
3.78 \\
5.49 \\
\end{array}$ & $\begin{array}{l}2.70 \\
3.05 \\
5.06\end{array}$ & $\begin{array}{l}.84 \\
4.42 \\
7.22 \\
\end{array}$ & $\begin{array}{l}2.02 \\
4.91 \\
0.60 \\
\end{array}$ & $\begin{array}{r}3.01 \\
5.44 \\
10.00\end{array}$ & $\begin{array}{r}3.53 \\
8.47 \\
18.47\end{array}$ & \\
\hline $\operatorname{sex}$ & $\begin{array}{l}3.61 \\
4.28 \\
6.32\end{array}$ & $\begin{array}{l}3.69 \\
4.97 \\
5.62\end{array}$ & $\begin{array}{l}3.68 \\
4.68 \\
0.10\end{array}$ & $\begin{array}{l}3.00 \\
4.00 \\
0.72\end{array}$ & $\begin{array}{l}.04 \\
8.03 \\
7.32\end{array}$ & $\begin{array}{l}3.60 \\
5.27 \\
7.04\end{array}$ & $\begin{array}{l}3.70 \\
5.69 \\
0.69\end{array}$ & $\begin{array}{r}3.69 \\
6.55 \\
11.47\end{array}$ & $\begin{array}{r}4.01 \\
7.25 \\
13.44\end{array}$ & $\begin{array}{r}4.71 \\
11.29 \\
24.62\end{array}$ & \\
\hline $20 x$ & $\begin{array}{l}6.20 \\
6.30 \\
1.06\end{array}$ & $\begin{array}{l}8.20 \\
0.58 \\
0.44\end{array}$ & $\begin{array}{l}6.34 \\
6.07 \\
2.24\end{array}$ & $\begin{array}{r}8.40 \\
7.21 \\
10.00\end{array}$ & $\begin{array}{r}8.46 \\
7.55 \\
10.90\end{array}$ & $\begin{array}{r}3.52 \\
7.80 \\
11.01 \\
\end{array}$ & $\begin{array}{r}5.67 \\
14.00 \\
14.49\end{array}$ & $\begin{array}{r}5.04 \\
0.02 \\
11.20\end{array}$ & $\begin{array}{r}6.01 \\
10.87 \\
20.17\end{array}$ & $\begin{array}{r}7.06 \\
16.93 \\
35.93\end{array}$ & \\
\hline $10 x$ & $\begin{array}{l}10.62 \\
12.70 \\
10.11\end{array}$ & $\begin{array}{l}10.60 \\
19.10 \\
16.07\end{array}$ & $\begin{array}{l}10.60 \\
19.75 \\
18.46\end{array}$ & $\begin{array}{l}10.00 \\
14.41 \\
20.17\end{array}$ & $\begin{array}{l}10.82 \\
18.10 \\
21.80\end{array}$ & $\begin{array}{l}11.04 \\
15.01 \\
23.09\end{array}$ & $\begin{array}{c}11.35 \\
17.66 \\
28.60\end{array}$ & $\begin{array}{l}11.68 \\
10.64 \\
34.40\end{array}$ & $\begin{array}{l}12.02 \\
21.74 \\
40.33\end{array}$ & $\begin{array}{l}11.13 \\
33.87 \\
73.87\end{array}$ & \\
\hline
\end{tabular}




\section{Advanced Compensation}

Value of D: $-5$

Velue of $\mathrm{C}$

Value of

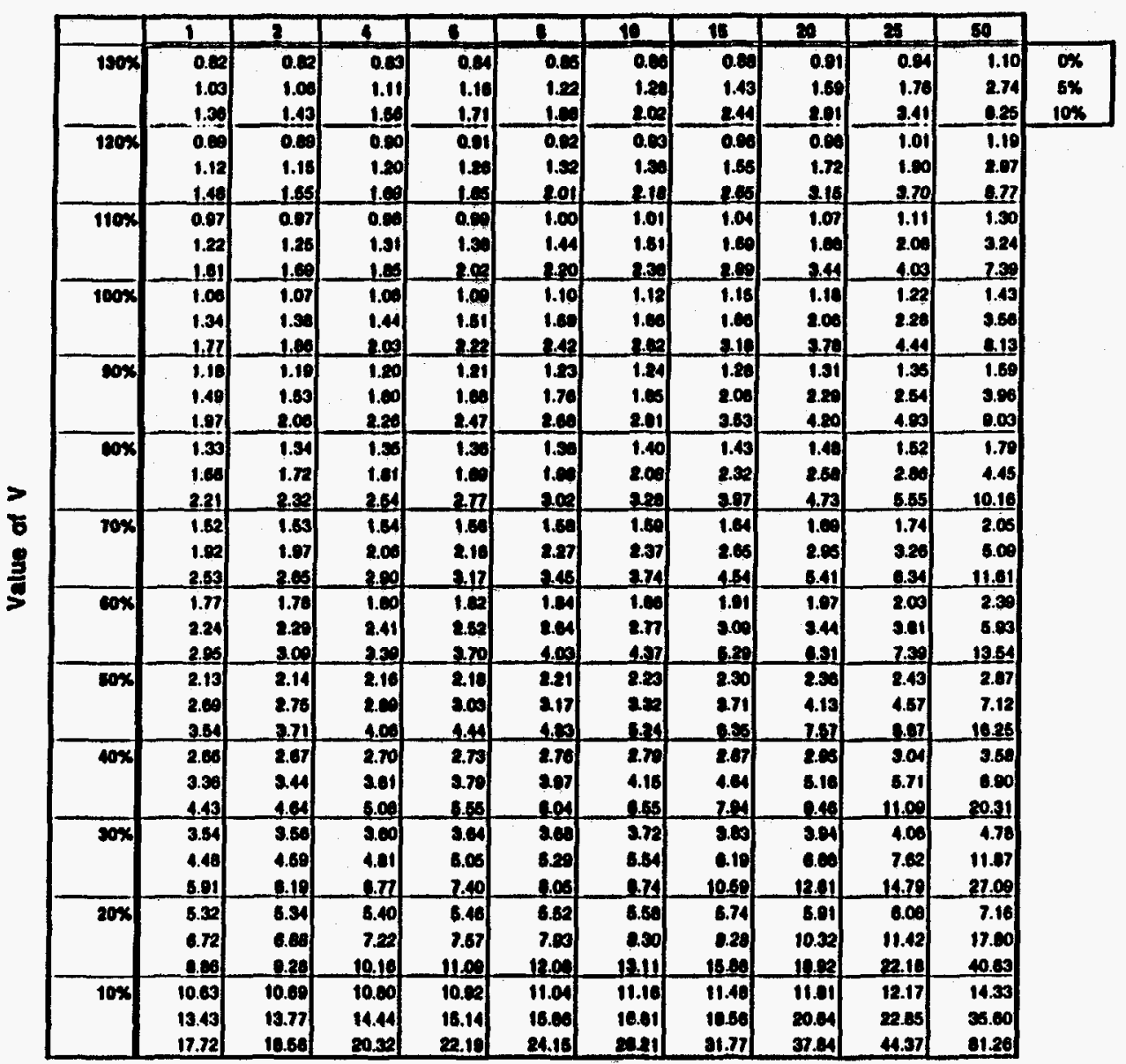




\section{Advanced Compensation}

Volue of Q:

Value of $\mathrm{C}$

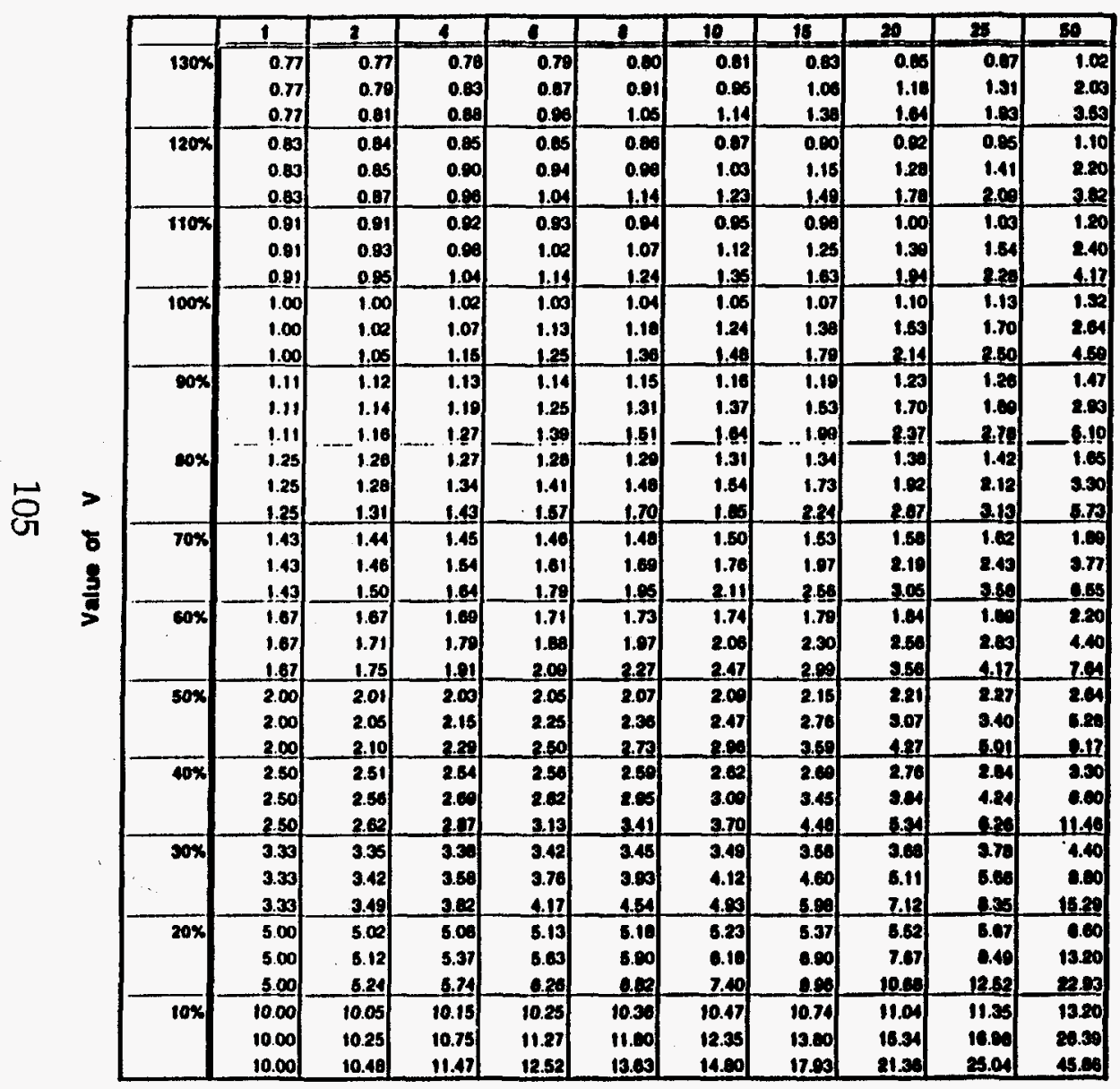

VDlue of D: 2

Value of C

Value of $r$

\begin{tabular}{|c|c|c|c|c|c|c|c|c|c|c|c|}
\hline & 1 & 2 & 4 & 6 & $e$ & 10 & 15 & 20 & 25 & 50 & \\
\hline $1 \operatorname{sen}$ & $\begin{array}{l}0.76 \\
0.78 \\
0.70 \\
\end{array}$ & $\begin{array}{l}0.77 \\
0.75 \\
0.73\end{array}$ & $\begin{array}{l}0.77 \\
0.70 \\
0.00\end{array}$ & $\begin{array}{l}0.78 \\
0.63 \\
0.60\end{array}$ & $\begin{array}{l}0.79 \\
0.80 \\
0.85\end{array}$ & $\begin{array}{l}0.80 \\
0.80 \\
1.08 \\
\end{array}$ & $\begin{array}{l}0.02 \\
1.01 \\
1.25 \\
\end{array}$ & $\begin{array}{l}0.04 \\
1.12 \\
1.49 \\
\end{array}$ & $\begin{array}{l}0.86 \\
1.24 \\
1.76\end{array}$ & $\begin{array}{l}1.00 \\
1.93 \\
3.21 \\
\end{array}$ & $\begin{array}{l}0 \% \\
5 \% \\
10 \% \\
\end{array}$ \\
\hline $120 \%$ & $\begin{array}{l}0.00 \\
0.70 \\
0.70\end{array}$ & $\begin{array}{l}0.03 \\
0.01 \\
0.70\end{array}$ & $\begin{array}{l}0.84 \\
0.05 \\
0.67\end{array}$ & $\begin{array}{l}0.05 \\
0.06 \\
0.05\end{array}$ & $\begin{array}{l}0.05 \\
0.04 \\
1.03\end{array}$ & $\begin{array}{l}0.68 \\
0.08 \\
1.12\end{array}$ & $\begin{array}{l}0.69 \\
1.00 \\
1.38\end{array}$ & $\begin{array}{l}0.91 \\
1.22 \\
1.62\end{array}$ & $\begin{array}{l}0.84 \\
1.35 \\
1.90\end{array}$ & $\begin{array}{l}1.09 \\
2.00 \\
3.47\end{array}$ & \\
\hline $110 \times$ & $\begin{array}{l}0.80 \\
0.97 \\
0.98\end{array}$ & $\begin{array}{l}0.00 \\
0.00 \\
0.07\end{array}$ & $\begin{array}{l}0.91 \\
0.08 \\
0.05\end{array}$ & $\begin{array}{l}0.82 \\
0.80 \\
1.04\end{array}$ & $\begin{array}{l}0.83 \\
1.06 \\
1.13\end{array}$ & $\begin{array}{l}0.04 \\
1.07 \\
1.22\end{array}$ & $\begin{array}{l}0.87 \\
1.19 \\
1.49\end{array}$ & $\begin{array}{l}0.89 \\
1.33 \\
1.77\end{array}$ & $\begin{array}{l}1.02 \\
1.47 \\
2.07 \\
\end{array}$ & $\begin{array}{r}1.10 \\
2.28 \\
3.79 \\
\end{array}$ & \\
\hline $160 x$ & $\begin{array}{l}0.00 \\
0.85 \\
0.91\end{array}$ & $\begin{array}{l}1.00 \\
0.06 \\
0.09\end{array}$ & $\begin{array}{l}1.00 \\
1.02 \\
1.00\end{array}$ & $\begin{array}{l}1.08 \\
1.07 \\
1.14\end{array}$ & $\begin{array}{l}1.08 \\
1.12 \\
1.24\end{array}$ & $\begin{array}{l}1.04 \\
1.10 \\
1.35\end{array}$ & $\begin{array}{l}1.06 \\
1.31 \\
1.03\end{array}$ & $\begin{array}{l}1.08 \\
1.46 \\
1.94\end{array}$ & $\begin{array}{l}1.12 \\
1.62 \\
2.28\end{array}$ & $\begin{array}{l}1.30 \\
2.51 \\
4.17\end{array}$ & \\
\hline $\cos$ & $\begin{array}{r}1.10 \\
1.006 \\
1.99 !\end{array}$ & $\begin{array}{l}1.11 \\
1.00 \\
1.00\end{array}$ & $\begin{array}{l}1.12 \\
1.14 \\
j .19\end{array}$ & $\begin{array}{r}1.13 \\
1.19 \\
-1.2 ?\end{array}$ & $\begin{array}{r}1.14 \\
1.25 \\
1.39\end{array}$ & $\begin{array}{r}1.15 \\
1.31 \\
-1.40\end{array}$ & $\begin{array}{r}1.10 \\
1.46 \\
-1.89\end{array}$ & $\begin{array}{r}1.21 \\
1.62 \\
-8.16\end{array}$ & $\begin{array}{l}1.25 \\
1.60 \\
2.53\end{array}$ & $\begin{array}{r}1.45 \\
2.79 \\
163\end{array}$ & \\
\hline $\cos$ & $\begin{array}{l}1.24 \\
1.10 \\
1.14\end{array}$ & $\begin{array}{l}1.24 \\
1.22 \\
1.10\end{array}$ & $\begin{array}{l}1.28 \\
1.20 \\
1.30\end{array}$ & $\begin{array}{l}1.27 \\
1.34 \\
1.42\end{array}$ & $\begin{array}{l}1.28 \\
1.40 \\
1.55\end{array}$ & $\begin{array}{l}1.29 \\
1.47 \\
1.60\end{array}$ & $\begin{array}{l}1.30 \\
1.64 \\
2.04\end{array}$ & $\begin{array}{l}1.36 \\
1.63 \\
2.43\end{array}$ & $\begin{array}{l}1.40 \\
2.02 \\
2.05\end{array}$ & $\begin{array}{l}1.63 \\
3.14 \\
5.21\end{array}$ & \\
\hline $200 x$ & $\begin{array}{l}1.41 \\
1.35 \\
1,30\end{array}$ & $\begin{array}{l}1.40 \\
1.30 \\
1.30 \\
\end{array}$ & $\begin{array}{l}1.44 \\
1.48 \\
1.49\end{array}$ & $\begin{array}{l}1.45 \\
1.63 \\
1.63 \\
\end{array}$ & $\begin{array}{l}1.46 \\
1.01 \\
1.27 \\
\end{array}$ & $\begin{array}{l}1.40 \\
1.60 \\
1.02 \\
\end{array}$ & $\begin{array}{l}1.52 \\
1.68 \\
2.33 \\
\end{array}$ & $\begin{array}{l}1.50 \\
2.00 \\
2.71 \\
\end{array}$ & $\begin{array}{l}1.60 \\
2.31 \\
3.25 \\
\end{array}$ & $\begin{array}{l}1.86 \\
3.59 \\
5.86 \\
\end{array}$ & \\
\hline $\cos x$ & $\begin{array}{l}1.65 \\
1.60 \\
1.60\end{array}$ & $\begin{array}{l}1.68 \\
1.63 \\
1.50\end{array}$ & $\begin{array}{l}1.67 \\
1.71 \\
1.74\end{array}$ & $\begin{array}{l}1.00 \\
1.70 \\
1.00\end{array}$ & $\begin{array}{l}1.71 \\
1.07 \\
2.07\end{array}$ & $\begin{array}{l}1.73 \\
1.86 \\
2.24\end{array}$ & $\begin{array}{l}1.77 \\
2.19 \\
2.72\end{array}$ & $\begin{array}{l}1.22 \\
2.43 \\
3.24\end{array}$ & $\begin{array}{l}1.87 \\
2.69 \\
3.79\end{array}$ & $\begin{array}{l}2.17 \\
4.19 \\
0.95\end{array}$ & \\
\hline $\cos$ & $\begin{array}{l}1.00 \\
1.00 \\
1.00\end{array}$ & $\begin{array}{l}1.00 \\
1.06 \\
1.00\end{array}$ & $\begin{array}{l}2.01 \\
2.05 \\
2.00\end{array}$ & $\begin{array}{l}2.00 \\
2.16 \\
2.20\end{array}$ & $\begin{array}{l}2.06 \\
2.25 \\
2.40\end{array}$ & $\begin{array}{l}2.07 \\
2.35 \\
2.60\end{array}$ & $\begin{array}{l}2.13 \\
2.63 \\
3.26\end{array}$ & $\begin{array}{l}2.10 \\
2.02 \\
3.00\end{array}$ & $\begin{array}{l}2.24 \\
3.23 \\
4.55\end{array}$ & $\begin{array}{l}2.61 \\
6.02 \\
.34\end{array}$ & \\
\hline $\operatorname{sax}$ & $\begin{array}{l}2.40 \\
2.00 \\
2.29 \\
\end{array}$ & $\begin{array}{l}2.40 \\
2.44 \\
2.39\end{array}$ & $\begin{array}{l}2.81 \\
2.60 \\
2.01 \\
\end{array}$ & $\begin{array}{l}2.64 \\
2.60 \\
2.05\end{array}$ & $\begin{array}{l}2.60 \\
2.41 \\
3.10\end{array}$ & $\begin{array}{l}2.60 \\
2.04 \\
2.30 \\
\end{array}$ & $\begin{array}{l}2.66 \\
3.20 \\
1.02 \\
\end{array}$ & $\begin{array}{l}2.73 \\
3.65 \\
4.05 \\
\end{array}$ & $\begin{array}{l}2.81 \\
4.01 \\
5.69 \\
\end{array}$ & $\begin{array}{r}3.26 \\
\quad .26 \\
10.42 \\
\end{array}$ & \\
\hline 800 & $\begin{array}{l}9.30 \\
3.17 \\
3.00\end{array}$ & $\begin{array}{l}3.22 \\
3.25 \\
3.17\end{array}$ & $\begin{array}{l}3.38 \\
3.41 \\
3.49\end{array}$ & $\begin{array}{l}3.39 \\
3.50 \\
3.80\end{array}$ & $\begin{array}{l}3.42 \\
3.75 \\
4.13\end{array}$ & $\begin{array}{l}3.45 \\
3.02 \\
4.48\end{array}$ & $\begin{array}{l}3.54 \\
4.39 \\
5.43\end{array}$ & $\begin{array}{l}3.64 \\
4.67 \\
0.48\end{array}$ & $\begin{array}{l}3.14 \\
5.39 \\
7.58\end{array}$ & $\begin{array}{r}4.31 \\
0.37 \\
13.90\end{array}$ & \\
\hline $200 x$ & $\begin{array}{l}4.85 \\
4.78 \\
4.55\end{array}$ & $\begin{array}{l}4.90 \\
4.80 \\
4.70\end{array}$ & $\begin{array}{l}8.02 \\
6.12 \\
6.21\end{array}$ & $\begin{array}{l}5.00 \\
6.30 \\
5.00\end{array}$ & $\begin{array}{l}.13 \\
8.62 \\
8.20 \\
\end{array}$ & $\begin{array}{r}5.10 \\
5.60 \\
6.72 \\
\end{array}$ & $\begin{array}{r}5.32 \\
6.57 \\
0.15 \\
\end{array}$ & $\begin{array}{l}.46 \\
7.30 \\
0.71\end{array}$ & $\begin{array}{r}5.61 \\
8.00 \\
11.39\end{array}$ & $\begin{array}{r}8.52 \\
12.56 \\
20.84\end{array}$ & \\
\hline $10 x$ & $\begin{array}{l}2.80 \\
2.60 \\
2.00\end{array}$ & $\begin{array}{l}0.98 \\
0.78 \\
0.82\end{array}$ & $\begin{array}{l}10.05 \\
10.23 \\
10.49\end{array}$ & $\begin{array}{l}10.16 \\
10.73 \\
11.39 \\
\end{array}$ & $\begin{array}{l}10.25 \\
11.24 \\
12.39\end{array}$ & $\begin{array}{l}10.30 \\
11.70 \\
13.45 \\
\end{array}$ & $\begin{array}{l}10.63 \\
13.14 \\
18.30\end{array}$ & $\begin{array}{l}10.92 \\
14.61 \\
10.42\end{array}$ & $\begin{array}{l}11.22 \\
18.16 \\
22.76\end{array}$ & $\begin{array}{l}13.03 \\
25.11 \\
41.69\end{array}$ & \\
\hline
\end{tabular}




\section{Advanced Compensation}

Vִalue o! D: 3

Value of $\mathrm{C}$

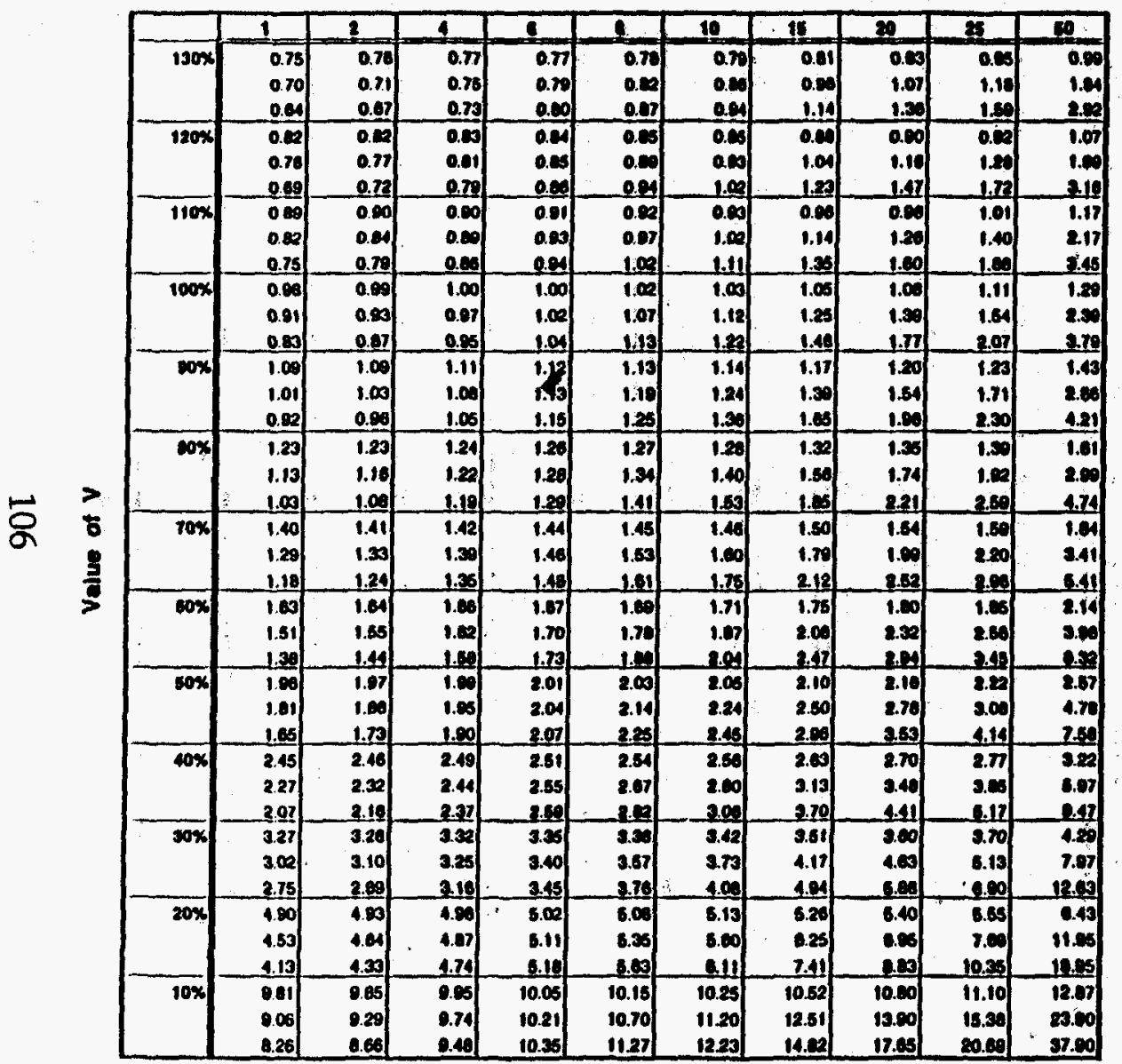

VlworD: 4

Valus of $\mathbf{C}$

Value of $\mathrm{r}$

\begin{tabular}{|c|c|c|c|c|c|c|c|c|c|c|c|}
\hline & 1 & 2 & 4 & a. & 2 & 10. & 15. & 20. & 25 & 50 & \\
\hline $\operatorname{sen}$ & $\begin{array}{l}0.76 \\
0.60 \\
0.50\end{array}$ & $\begin{array}{l}0.76 \\
0.60 \\
0.41\end{array}$ & $\begin{array}{l}0.76 \\
0.71 \\
0.8 \\
\end{array}$ & $\begin{array}{l}0.77 \\
0.78 \\
0.72\end{array}$ & $\begin{array}{l}0.77 \\
0.70 \\
0.70 \\
\end{array}$ & $\begin{array}{l}0.72 \\
0.02 \\
0.00 \\
\end{array}$ & $\begin{array}{l}0.00 \\
0.02 \\
1.04\end{array}$ & $\begin{array}{l}0.82 \\
1.02 \\
1.23 \\
\end{array}$ & $\begin{array}{l}0.81 \\
1.13 \\
1.45 \\
\end{array}$ & $\begin{array}{l}0.98 \\
1.75 \\
2.05 \\
\end{array}$ & $\begin{array}{c}0 \% \\
5 \% \\
10 \% \\
\end{array}$ \\
\hline $180 x$ & $\begin{array}{l}0.01 \\
0.72\end{array}$ & $\begin{array}{l}0.01 \\
0.74\end{array}$ & 0.01 & $\begin{array}{l}0.23 \\
0.01\end{array}$ & $\begin{array}{l}0.44 \\
0.06\end{array}$ & $\begin{array}{l}0.45 \\
0.50\end{array}$ & $\begin{array}{l}0.07 \\
0.00\end{array}$ & $\begin{array}{l}0.60 \\
1.10\end{array}$ & $\begin{array}{l}0.81 \\
1.22\end{array}$ & $\begin{array}{l}1.00 \\
1.00\end{array}$ & \\
\hline & 0.08 & 0.60 & 0.72 & 0.7 & 0.05 & Q.99 & 1:12] & 1.31 & 1.5? & -207? & \\
\hline $116 x$ & 0.00 & 0.60 & 0.00 & 0.00 & 0.01 & 0.02 & 0.05 & 0.07 & 1.00 & 1.15 & \\
\hline & 0.70 & 0.60 & 0.4 & 0.60 & 0.03 & 0.07 & 1.00 & $1.20 \mid$ & 1.33 & 2.07 & \\
\hline & 209 & 0.72 & 0.79 & 0.0 & 0.03 & 1.01 & 1:22 & 1.46 & 1.71! & 3.13 & \\
\hline $100 x$ & 0.07 & 0.00 & 0.00 & $1 . \infty$ & 1.00 & 1.02 & 1.04 & 1.07| & 110 & 1.27| & \\
\hline & 0.00 & 0.6 & 0.03 & 0.07 & 0.02 & 1.07 & 1.10 & 1.32 & 1.46 & 2.27 & \\
\hline & Q.75 & $2 \pi$ & 0.0 & 0.04 & 1.02 & 1.11 & 1,35 & 1.60 & 1.86 & 3.44 & \\
\hline $\cos x$ & 1.00 & 1.00 & 1.00 & 1.11 & (.12) & 8.13 & t.16 & 1.10 & 1.22 & 1.41 & \\
\hline & 0.00 & 0.60 & 1.03 & 1.00 & (.13 & 1.18 & 1.32 & (1.47) & 1.63 & 2.53 & \\
\hline & 0.0 & 0.07 & 0.00 & 1.06 & 1.14 & 1.24 & 1.50 & 1.78 & 2.09 & 3.83 & \\
\hline $\cos x$ & 121 & 1.22 & 123 & 1.24] & 1.28 & 1.27 & 1.80 & 1.34 & 1.37 & 1.58 & \\
\hline & 1.00 & 1.11 & 1.18 & 1.22] & 1.27] & 1.39] & 1.49 & 1.85 & 1.89 & 2.81 & \\
\hline & oes & 0.0 & 1.00 & 1.110 & 1.28 & 1,39 & 1.68) & 2.01 & 2.35 & 4.31 & \\
\hline $\operatorname{rax}$ & 1.50 & 1.30 & 1.41 & 1.42 & 1.44 & 1.45 & 1.49 & 1.53 & 1.57 & 1.81 & \\
\hline & 1.29 & 1.20 & 1.20 & 1.00 & 1.45 & 1.52 & 1.79) & 1.08 & 2.00 & 3.25 & \\
\hline & 107 & 1.18 & 123 & 1,34 & 1.86 & 1.59 & 1.02 & 2.29 & 2.69 & 4.92 & \\
\hline $\cos$ & 1.62 & 1.00 & 1.4. & 1.60 & 1.67] & 1.09 & 1.74 & 1.76 & 1.03 & 2.12 & \\
\hline & 1.4 & 1.47 & 1.65 & 1.02 & 1.70 & 1.78 & 1.00 & 2.21 & 2.44 & 3.79 & \\
\hline & 19 & 14 & 1.44 & 1.67 & 1.71 & 1.03 & 3.28 & 2.07 & 3.14 & 6.24 & \\
\hline $\cos x$ & 1.04 & 1.06 & 1.07 & 1.00 & 2.01 & 2.003 & 2.00 & 2.14 & 2.20 & 254 & \\
\hline & 1.70 & $1 . n$ & 1.80 & 1.04 & 2.04 & 2.13 & 2.30 & 2.65 & 2.93 & 4.55 & \\
\hline & 1.50 & 1.57 & 1.72 & 1.09 & 2.05 & 2.22 & 2.60 & 3.21 & 3.76 & 8.09 & \\
\hline 40x] & 2.43 & 2.44 & 2.40 & 2.48 & 2.31 & 2.54 & 2.60 & 2.67 & 2.74 & 3.18 & \\
\hline & 2.10 & 2.21 & 2.32 & 2.43 & 2.65 & 2.60 & 2.00 & 3.31 & 366 & 5.69 & \\
\hline & 1.24 & 1.27 & 218 & 8.2.35| & 2.504 & 2.70 & 3.37 & 1.01 & 4.70 & (0.61) & \\
\hline $\operatorname{cox}$ & 9.24 & 3.26 & 9.20) & 3.32 & 3.35 & 3.39) & 3.47] & 3.50 & 3.66 & 4.23] & \\
\hline & 2.60 & 2.08 & 3.00 & 3.24 & 3.30 & 3.55 & 3.97| & 4.41 & 4.88 & 7.50 & \\
\hline & 2.80 & 2.98 & 2.07 & 3.14 & 3.11 & 3.71 & 49 & 5.35 & 6.2? & 11.48 & \\
\hline $20 x$ & 4.60 & 4.60 & 4.09 & 1.00 & 5.02 & 8.00 & 5.21 & 6.34 & 5.49 & 6.35 & \\
\hline & 4.34 & 4.42 & 1.64 & 4.60 & 6.00 & 5.33 & 6.05 & 0.62 & 7.32 & 11.37 & \\
\hline & 378 & 34 & 4.31 & 4.70 & 5.12 & 8.56 & 0.24 & 0.02 & 0.41 & 17.22 & \\
\hline 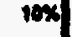 & D.71 & 0.70 & 2.85 & 0.85 & 10.05 & 10.15 & 10.41 & 10.69 & 10.98 & 12.70 & \\
\hline & 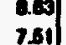 & $\begin{array}{l}104 \\
7.97\end{array}$ & $\begin{array}{l}-.20 \\
8.02\end{array}$ & 0.72 & 10.10 & 10.66 & 11.01 & 13.23 & 14.64 & $\begin{array}{r}22.19 \\
\end{array}$ & \\
\hline & & ond & 8.0.4 & Q.41I & 10.24 & 11.12 & 13.47] & 18.05] & $18.81]$ & 34.45 & \\
\hline
\end{tabular}




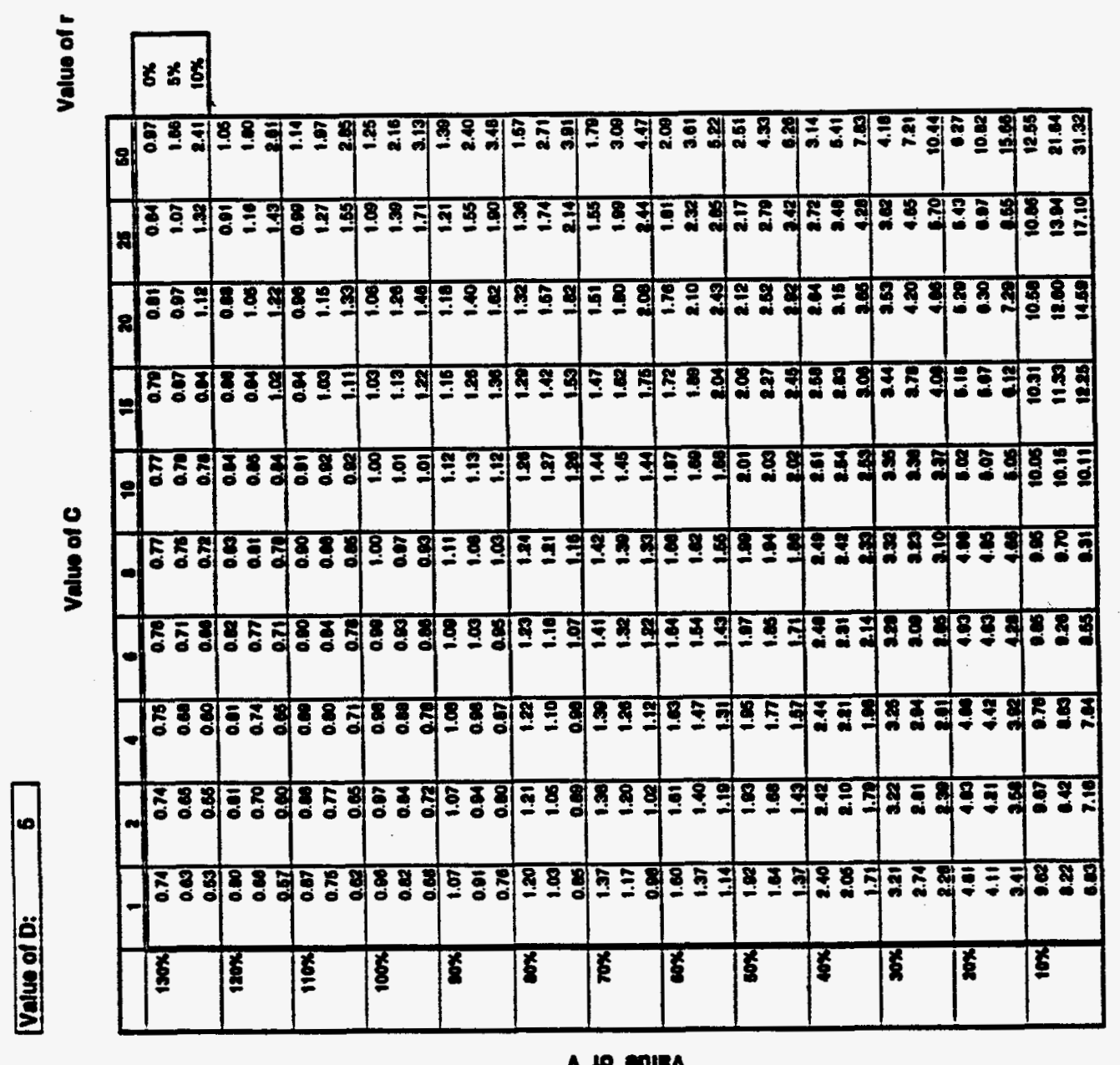

